\author{
Universidade de SÃo Paulo \\ Instituto de Física de SÃo Carlos \\ Departamento de FísICA E InformáticA \\ Grupo de Física TeÓricA
}

Nelson Mesquita Fernandes

\title{
Acuidade visual e codificação neural da mosca Chrysomya megacephala
}

São Carlos, SP

2010 

Nelson Mesquita Fernandes

\section{Acuidade visual e codificação neural da mosca Chrysomya megacephala}

Tese de Doutorado apresentada ao Programa de Pós-Graduação em Física do Instituto de Física de São Carlos da Universidade de São Paulo, para obtenção do título de Doutor em Ciências.

Área de Concentração: Física Básica. Orientador: Prof. Dr. Roland Köberle

São Carlos, SP 
AUTORIZO A REPRODUÇÃO E DIVULGAÇÃO TOTAL OU PARCIAL DESTE TRABALHO, POR QUALQUER MEIO CONVENCIONAL OU ELETRÔNICO, PARA FINS DE ESTUDO E PESQUISA, DESDE QUE CITADA A FONTE.

Fernandes, Nelson Mesquita

Acuidade visual e codificação neural da mosca Chrysomya megacephala./Nelson Mesquita Fernandes; orientador Roland Köberle - São Carlos, 2010.

$102 \mathrm{p}$.

Tese (Doutorado - Programa de Pós-Graduação em Física Área de concentração: Física Básica) - Instituto de Física de São Carlos da Universidade de São Paulo.

1. Neurobiofísica. 2. Sistema visual. 3. Neurônios H1. 4. Reconstrução da segunda ordem de estímulo. 5. Redução dimensional do estímulo. I. Título. 


\section{FOLHA DE APROVAÇÃO}

Nelson Mesquita Fernandes

Tese apresentada ao Instituto de Fisica de São Carlos da Universidade de São Paulo para obtençäo do título de Doutor em Ciências. Área de Concentração: Fisica Básica.

Aprovado em: 12/03/2010

\section{Comissão Julgadora}

Prof. Dr. Mauro Copelli Lopes da Silva

Instituição: UFPE

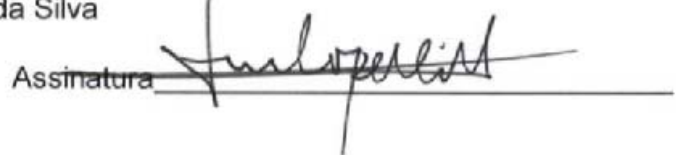

Prof. Dr. Nestor Felipe Caticha Alfonso

Instituiçăo: IF/USP

Assinatura
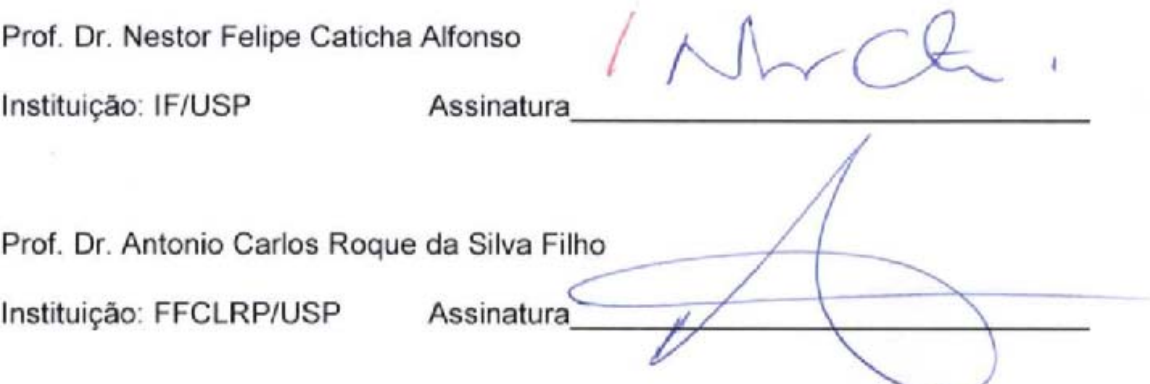

Prof. Dr. Leonardo Paulo Maia

Instituição: IFSC/USP

Assinatura

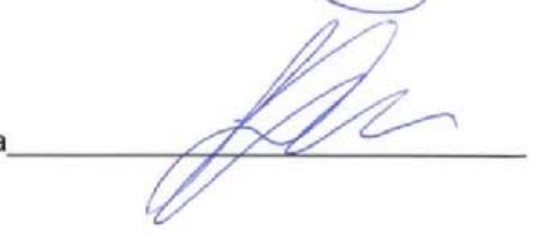

Prof. Dr. Roland Koberle

Instituição: IFSC/USP

Assinatura

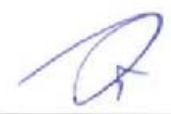



Aos meus pais,

pela intensa dedicação

aos filhos. 



\section{Agradecimentos}

Agradeço ao meu orientador Roland Köberle pela oportunidade de realizar este trabalho.

À Fundação de Amparo à Pesquisa do Estado de São Paulo - FAPESP - pelo suporte financeiro deste projeto (04/11730-0).

À secretária Maria Cristina Vieira Ligo da Silva pelo eficiente e essencial apoio administrativo.

Ao Prof. Tito José Bonagamba e ao Instituto de Física de São Carlos pelo excelente programa de pós-graduação ao qual fiz parte.

Aos técnicos Lírio de Almeida e Ivanilda Zucolotto pelo apoio técnico e pela amizade.

A todos os colegas de pesquisa com quem tive oportunidade de compartilhar sala, idéias e discussões: Deusdedit Spavieri, Damian Oliva, Bruna Dayana, Carlos Alessandro, Ingrid Esteves, Mario Gazziro, Nataly Horner, Rafael Viegas e Paulo Matias, entre outros.

A todos meus colegas de graduação pelos longos anos de convívio e intensas discussões científicas. Em especial aos amigos Caio (Flash), Angelo (Pinóquio) e Arthur pelos memoráveis momentos de descontração nestes últimos meses.

Ao meu tio Miro e a minha tia Dedê por acreditarem em mim e me apoiarem durante tantos anos.

Aos meus pais, a quem também dedico esta tese, aos meus avós e a minha irmã pelo apoio incondicional dado a mim.

Agradeço à Monique, minha noiva retada, pelo incentivo e paciência em todos os momentos. 

"To a good approximation, all the species are insects." Robert May, Baron May of Oxford 



\section{Resumo}

FERNANDES, N. M. Acuidade visual e codificação neural da mosca Chrysomya megacephala. 2010. 102p. Tese (Doutorado) - Instituto de Física de São Carlos Universidade de São Paulo, São Carlos, 2010.

Descrevemos os processos de captura, criação e micromanipulação cirúrgica das moscas Chrysomya megacephala. Apresentamos os processos de geração de estímulo e registro da atividade dos dois neurônios $H 1$ localizados na placa lobular de seu cérebro. Um primeiro resultado apresentado refere-se a acuidade de seu sistema visual. Desenvolvemos um procedimento para comparar sua taxa de disparos espontâneos com as respostas do neurônio $H 1$ quando sujeito a estímulos de excitação e inibição. Mostramos que o sistema visual da mosca não está apenas adaptado a detectar grandes fluxos ópticos mas também, é capaz de detectar pequenas velocidades de aproximadamente $1,5^{\circ} . s^{-1}$ e de apenas $0,25^{\circ}$ de amplitude. Estes valores mostram que a mosca é capaz de detectar deslocamentos angulares muito menores do que sua abertura omatidial, $\Delta \phi=1-2^{o}$. Outro resultado apresentado é obtido ao estudarmos o processo de codificação-decodificação neural. Alguns sistemas sensoriais agem como um conversor analógico-digital, recebendo um estímulo $S(t)$ e codificando-o em uma seqüencia de pulsos, spikes. O processo de decodificação da resposta neural consiste em receber este conjunto pulsos e gerar uma estimativa $S_{e}(t)$ do estímulo. Este processo requer a computação e subseqüente inversão de funções de correlação de alta ordem. A dimensão das matrizes que representam estas funções pode se tornar proibitivamente grande. Apresentamos um eficiente método para reduzir estas funções de correlação. Esta aproximação tem baixo custo computacional, evita a inversão de grandes matrizes e nos dá um excelente resultado para a reconstrução do estímulo. Testamos a qualidade de nossa reconstrução sobre estímulos de rotação e translação. A contribuição dos núcleos de segunda ordem para a reconstrução do estímulo é de apenas $8 \%$ da contribuição dos núcleos de primeira ordem. Entretanto, em instantes específicos, a adição destes núcleos pode representar uma contribuição de até 100\%. Finalmente, investigamos quais atributos do estímulo são codificados pelos neurônios $H 1$. Nosso espaço de estímulos possui um conjunto da ordem de $2 \times 10^{96}$ elementos. É impossível imaginar que o sistema formado pelos dois neurônios $H 1$ seja capaz de codificar eficientemente esta enorme quantidade de elementos. É razoável considerar que este sistema seja ao menos capaz de codificar um atributo essencial do movimento, seu sentido - rotações horizontais para direita ou para esquerda. Desta forma, apresentamos dois estímulos distintos para a mosca, um no qual suas velocidades são retiradas de uma distribuição Gaussiana e outro que contém apenas o sentido deste movimento. Obtemos uma correlação da ordem de $80-90 \%$ entre as estimativas de ambos os estímulos, estimativas obtidas através do processo de reconstrução linear. Obtemos aproximadamente $85 \%$ de eficiência na predição do sentido deste movimento. Ao utilizarmos a Teoria da Informação, encontramos uma 
diferença de apenas $10 \%$ entre as taxas de informação transmitida sobre os estímulos Gaussiano e sua versão reduzida. Concluímos que a propriedade comum a estes dois estímulos, o sentido do movimento, é o atributo relevante a ser codificado pelos neurônios $H 1$.

Palavras-chave: Neurobiofísica. Sistema visual. Neurônios H1. Reconstrução de segunda ordem do estímulo. Redução dimensional do estímulo. 


\section{Abstract}

FERNANDES, N. M. Visual acuity and neural encoding of the fly Chrysomya megacephala. 2010. 102p. Tese (Doutorado) - Instituto de Física de São Carlos Universidade de São Paulo, São Carlos, 2010.

We describe the practices of capturing, creation, and microsurgery of the flies Chrysomya megacephala. We present the procedures of stimulus generation and recording of the activity of the two H1 neurons in the lobula plate of its brain. One first result presented is related to its visual system acuity. We developed a method to compare its spontaneous firing rate with the $H 1^{\prime} s$ responses to excitatory and inhibitory stimuli. We show that the fly's visual system is not only adapted to detect large optic flows but is also capable to detect small velocities about $1,5^{\circ} . \mathrm{s}^{-1}$ with just $0,25^{\circ}$ of amplitude. These values show that the fly is capable to detect angular displacements much smallers than its ommatidial aperture, $\Delta \phi=1-2^{\circ}$. Another relevant result is attained studying the processes of neural encode-decode. Some sensorial systems act as an analog-to-digital conversor, these systems encode the input stimulus $S(t)$ in a sequence of action potential, spikes. The decoding process of the neural response consists of capturing this set of spikes and to generate an estimate $S_{e}(t)$ of the stimulus. This process requires the computation and subsequent inversion of high order correlations functions. The dimension of the matrixes that represent these functions can become prohibitively large. We present an efficient method to reduce these correlation functions. This approximation has low computational cost, avoids large matrixes inversion and give to us an excellent result to the stimulus reconstruction. We tested the reconstruction quality of rotational and translational stimuli. The contribution of second order stimulus reconstruction kernels is just $8 \%$ of first order kernels contribution. However, in specific times, the addition of these kernels may represent a $100 \%$ contribution. Finally, we investigate which stimulus features are codified by the $H 1$ neurons. The stimulus space has a set of about $2 \times 10^{96}$ elements. It is impossible to imagine that the system formed by the two $H 1$ neurons could be able to encode efficiently this amount of elements. It is reasonable to consider that this system is at least able to encode an essencial characteristic of movement, its direction - horizontal rotations to the right or to the left. Therefore, we presente two different stimuli to the fly, one which have velocities taken from a Gaussian distribution and another which contains just the direction of this movement. We obtain about $80-90 \%$ correlation between the estimates of both stimuli, estimates obtained through linear reconstruction methods. We obtain about $85 \%$ of efficiency in the prediction of stimulus direction. We find just a $10 \%$ difference between the information rate transmitted about the Gaussian stimulus and its reduced version using Information Theory. We conclude that the common attribute of these stimuli, the direction of movement, is the relevant attribute to be codified by the $H 1$ neurons. 
Keywords: Neurobiophysics. Visual system. H1 neurons. Second order stimulus reconstruction. Dimensional reduction of stimulus. 


\section{Lista de Figuras}

Figura 2.1 - Ciclo de vida da Chrysomya megacephala . . . . . . . . . . . . 24

Figura 2.2 - Dinâmica de vôo da mosca . . . . . . . . . . . . . . . . . 26

Figura 2.3 - Sistema visual da mosca . . . . . . . . . . . . . . . . 27

Figura $2.4-$ Omatídeo . . . . . . . . . . . . . . . . 27

Figura 2.5 - Neurônio H1 . . . . . . . . . . . . . . . . . . . . . . . . . . . . . . 29

Figura 2.6 - Codificação neural . . . . . . . . . . . . . . . . . . . . . . 30

Figura 2.7 - Estímulo visual . . . . . . . . . . . . . . . 31

Figura 2.8 - Imobilização e microcirurgia da mosca . . . . . . . . . . . . . . . . 34

Figura 2.9 - Montagem final do experimento . . . . . . . . . . . . . . . 34

Figura 2.10 - Etapas de aquisição do sinal neural . . . . . . . . . . . . . . . 37

Figura $3.1-$ Olhos compostos . . . . . . . . . . . . . . . 39

Figura 3.2 - Variação da amplitude do estímulo . . . . . . . . . . . . . . 41

Figura 3.3 - Seqüencia de estímulos . . . . . . . . . . . . . . . . . . 42

Figura 3.4 - Degradação da resposta neural . . . . . . . . . . . . . . . . . . 43

Figura 3.5 - Comparação entre taxas de disparo . . . . . . . . . . . . . . . 43

Figura 4.1 - Sensibilidade de movimento dos dois neurônios H1 . . . . . . . . . 46

Figura $4.2-R^{11}, R^{22}$ e $R^{12} \ldots \ldots \ldots \ldots \ldots$

Figura 4.3 - Núcleos de segunda ordem . . . . . . . . . . . . . . . 56

Figura 4.4 - Parâmetros $A_{1111}$ e $B_{1111} \ldots \ldots$. . . . . . . . . . 57

Figura 4.5 - Função de 4-pontos e sua aproximação Gaussiana parametrizada 57

Figura 4.6 - Reconstrução do estímulo rotacional . . . . . . . . . . . . . . . 59

Figura 4.7 - Contribuição de $K_{11}$ e $K_{22}$. . . . . . . . . . . . . . . . . . 61 
Figura 4.8 - Reconstrução do estímulo de translação . . . . . . . . . . . . . 61

Figura 5.1 - Correlação do estímulo . . . . . . . . . . . . . . . 65

Figura 5.2 - Posição do estímulo . . . . . . . . . . . . . . . . . . . 65

Figura 5.3 - "Digitalização" do estímulo . . . . . . . . . . . . . . 66

Figura 5.4 - Resposta ao estímulo "Digital" . . . . . . . . . . . . 67

Figura 5.5 - Reconstrução do estímulo "Digital" . . . . . . . . . . . . . . 69

Figura 5.6 - Diagrama de Venn . . . . . . . . . . . . . . . 71

Figura 5.7 - Taxa de Entropia Total e do Ruído de $S(t)$ e $S_{D}(t) \ldots . .$. . . 73

Figura 5.8 - Taxa de Informação de $S(t)$ e $S_{D}(t), \tau=12 b i n s \ldots \ldots . . . . .73$

Figura B.1-Raster-plot . . . . . . . . . . . . . . . . . . . 94

Figura B.2 - Histograma de "palavras" . . . . . . . . . . . . . . . . 95

Figura B.3 - Entropia total e do ruído por unidade de tempo . . . . . . . . . 96

Figura B.4 - Entropia total e do ruído . . . . . . . . . . . . . . . 96

Figura B.5 - Eficiência do neurônio H1 . . . . . . . . . . . . . . . . . . . . 99

Figura B.6 - Ruído e Eficiência do H1 . . . . . . . . . . . . . . . . . 100

Figura B.7 - Codificação por 2 H1s . . . . . . . . . . . . . . . . . . . 100

Figura B.8 - Entropia total e do ruído, $H 1^{ \pm} \ldots \ldots$. . . . . . . . . 101

Figura B.9 - Eficiência de $H 1^{ \pm} \ldots \ldots \ldots$. . . . . . . . . . . . 101

Figura B.10 - Atividade complementar de $H 1^{ \pm} \ldots \ldots$. . . . . . . . . . . . 102

Figura B.11 - Eficiência do detector de rotação . . . . . . . . . . . . . . . . . . . 102 


\section{Sumário}

1 Introdução 19

2 Materiais e Métodos 23

2.1 Chrysomya megacephala . . . . . . . . . . . . . . 23

2.1.1 Captura, controle e criação . . . . . . . . . . . . . . . . . 23

2.1.2 Sistema visual - Neurônio H1 . . . . . . . . . . . . . . . . . . 25

2.2 Geração de estímulos . . . . . . . . . . . . . . . . . . . . 30

2.3 Aquisição de dados . . . . . . . . . . . . . . . . . . . . . . . 33

2.3.1 Micromanipulação da mosca . . . . . . . . . . . . . . . . . . 33

2.3.2 Tratamento do sinal neural . . . . . . . . . . . . . . . . . 35

3 Acuidade do Sistema Visual da Mosca 39

4 Reconstrução do Estímulo a partir do Trem de Pulsos 45

4.1 Uma estimativa do estímulo . . . . . . . . . . . . . . . . . . . 46

4.2 Escolhendo um conjunto adequado de funções . . . . . . . . . . . . . . . 51

4.3 Aproximação "Gaussiana" para um $\mathrm{H} 1$. . . . . . . . . . . . . . . . . . . . 52

4.4 Aproximação "Gaussiana" para dois H1 . . . . . . . . . . . . . . . . . 54

4.5 Reconstruindo o estímulo da mosca e medindo sua qualidade . . . . . . . . 58

5 Redução Dimensional no Espaço de Estímulos 63

5.1 Geração do estímulo "Digital" . . . . . . . . . . . . . . . . 64

5.2 Resposta neural ao estímulo "Digital" . . . . . . . . . . . . . 67 
5.2 .1 Reconstrução linear de $S(t)$ e $S_{D}(t) \ldots \ldots \ldots$. . . . . . 68

5.2 .2 Codificação de $S(t)$ e $S_{D}(t) \ldots \ldots \ldots$. . . . . . . . 70

6 Conclusões $\quad 75$

$\begin{array}{ll}\text { Referências } & 79\end{array}$

Apêndice A - Processo de Ornstein-Uhlenbeck $\quad 87$

$\begin{array}{ll}\text { Apêndice B - Medida Direta da Informação } & 91\end{array}$

B.1 Um neurônio H1 . . . . . . . . . . . . . . . . . . . . . . . . . 91

B.2 Sistema de 2 neurônios H1 . . . . . . . . . . . . . . . . . . . . . 98 


\section{Introdução}

Estudar o funcionamento do cérebro humano é uma das tarefas mais intrigantes da ciência de nossos dias. Este órgão é uma densa e complexa rede de células constituída por aproximadamente cem bilhões de neurônios classificados em pelo menos mil diferentes tipos (1). Estes neurônios se interconectam e têm a capacidade de enviar e receber sinais por meio de até $10^{5}$ sinapses (2). Apesar de haver uma grande variedade de neurônios, a maior parte deles possui a mesma estrutura morfológica, composta por uma rede dendrítica, um corpo celular, um axônio, e terminais pré-sinápticos. O cérebro humano é responsável pela percepção do mundo exterior, pelo controle de nossas ações, pelo processo de aprendizagem, por nossa memória, nossa consciência, criatividade, emoções, linguagem e muitas outras atividades que permitem nossa interação com o meio ambiente. Ou seja, nosso cérebro consiste na mais poderosa e compacta rede de processamento de que temos conhecimento.

Um dos caminhos possíveis para entender o funcionamento cerebral é estudar como seus neurônios representam e transmitem informações sensoriais, como por exemplo, no sistema visual. Entretanto, estudar um sistema de tamanha complexidade como o sistema visual humano pode ser uma tarefa bastante difícil. Uma alternativa seria estudar sistemas sensoriais mais simples e acessíveis, como o sistema visual de invertebrados, que possuem certas semelhanças com o sistema sensorial humano e que poderiam ajudar a compreendêlo.

Desta forma, estudamos parte do duto óptico do sistema visual da mosca Chrysomya megacephala. Medimos a atividade de seu neurônio sensível a movimentos horizontais, neurônio $H 1$, como resposta a um estímulo dependente do tempo. A mosca é um animal de fácil criação em laboratório e sua robustez e relativa facilidade de manuseio nos permite a realização de horas de aquisições eletrofisiológicas in vivo. Além disso, a escolha deste animal deve-se a certos estágios do sistema visual da mosca já serem bastante conhecidos e alguns de seus neurônios serem identificados e exaustivamente estudados há décadas (3-11). Apesar do extenso conhecimento de sua morfologia, a performance coletiva de seus neurônios, capazes de processar informação sensorial e reagir em alguns milésimos 
de segundos, ainda é algo não completamente entendido (12-18). Quando um animal necessita se locomover, desviar de obstáculos, localizar um predador ou uma presa, ele utiliza - inter alia - a informação visual que chega na forma de padrões do fluxo óptico e que permitem ao animal estimar seu próprio movimento e o movimento de outros objetos em seu campo visual. A mosca utiliza esta informação visual e seus mecanismos de vôo extremamente eficientes para ajustar sua velocidade e realizar impressionantes acrobacias aéreas. Ou seja, o cérebro da mosca é capaz de codificar e utilizar uma grande quantidade de informação visual em uma curta escala temporal mesmo sendo extremamente simples comparado ao cérebro humano, possui aproximadamente apenas um milhão de neurônios.

Recentemente, foi anunciada a construção do computador mais poderoso do mundo - Sequoia/IBM - que ocupará uma área de $320 m^{2}$ e será capaz de realizar da ordem de $2 \times 10^{16}$ operações por segundo com uma potência de aproximadamente $6 M W$. O cérebro de uma mosca doméstica, apenas em repouso, já realiza da ordem de $10^{11}$ operações por segundo a uma potência de aproximadamente $0,1 m W(19)$. Tentamos entender quais são suas limitações e quais propriedades trazem a este sistema tamanha eficiência, eficiência trazida por milhões de anos de evolução e ainda não atingida por sistemas construídos pelo homem até os dias de hoje (20-27). Desta forma, poderemos trazer imensos avanços tecnológicos baseados em estratégias de processamento altamente eficientes, similares ao que encontramos no cérebro.

Para estudar esse sistema biológico, devemos dispor de ferramentas de instrumentação eletrônica capazes de realizar a captação de dados de forma confiável, precisa e pouco invasiva. Além disso, devemos considerar as particularidades deste organismo e seu sistema visual, e.g. sua resolução espacial e tempos característico de vôo, para gerarmos estímulos adequados para a tarefa para a qual este sistema foi criado (28-32). Temos a nossa disposição diversas ferramentas desenvolvidas por nossa equipe de instrumentação eletrônica (33) e as descrevemos no capítulo 2, juntamente com uma breve descrição sobre o sistema visual da mosca, desde seus fotoreceptores até o neurônio $H 1$. Nos capítulos posteriores apresentamos importantes resultados a respeito do sistema visual da mosca e sua codificação neural.

No capítulo 3 investigamos a precisão com que o sistema visual da mosca é capaz de realizar a tarefa de detecção de movimento. Uma mosca pode efetuar de forma eficiente movimentos numa velocidade de aproximadamente $3000^{\circ} \cdot s^{-1}$ durante um vôo de perseguição $(5,27,34-37)$. Mostramos que o sistema visual da mosca não só está adaptado a detectar grandes fluxos ópticos, mas também, é capaz de detectar movimentos 
de pequenas velocidades e amplitudes. Os valores encontrados mostram que a mosca é capaz de detectar deslocamentos angulares muito menores do que sua abertura interomatidial estimada, abertura muitas vezes considerada como sua mínima percepção visual. Esta medida estabelece um limite, sob nossas condições experimentais, para a precisão do sistema visual da espécie estudada.

Toda informação visual relevante aos neurônios $H 1$ da mosca é codificada em sua seqüência de potenciais de ação, trem de pulsos (38-45). No capítulo 4 construímos uma estimativa do estímulo apresentado para a mosca a partir dos trens de pulsos registrados simultaneamente de ambos neurônios $H 1$, processo de decodificação neural. A construção desta estimativa requer a manipulação de funções de correlação de quatro pontos, representadas por matrizes contendo um grande número de elementos. Apresentamos um método que evita o cálculo e posterior inversão destas matrizes, tarefa computacionalmente árdua. Com este procedimento, construímos com grande eficiência computacional uma excelente estimativa do estímulo apresentado para a mosca.

Por fim, capítulo 5, analisamos quais atributos do estímulo são relevantes para o sistema formado pelos dois neurônios $H 1$, ou seja, quais características do estímulo são codificadas em sua resposta neural. Nosso espaço de estímulos possui um conjunto da ordem de $2 \times 10^{96}$ elementos. É impossível imaginar que os dois neurônios $H 1$ possam codificar eficientemente esta quantidade astronômica de elementos. Efetuamos uma brusca redução sobre o espaço de estímulos e verificamos por dois métodos distintos, Reconstrução Linear do Estímulo (46) e Teoria da Informação (42, 47, 48), que o sentido de movimento é o atributo realmente relevante a ser codificado pelos neurônios $H 1$. Ou seja, apesar da riqueza presente originalmente no espaço de estímulos, apenas sua propriedade mantida durante a redução do espaço é codificada. Este resultado nos remete a um novo panorama para confecção de modelos de codificação do estímulo. 


\section{$2 \quad$ Materiais e Métodos}

\subsection{Chrysomya megacephala}

Na próxima seção ilustraremos como é feita a captura, controle e criação das moscas utilizadas em nossos experimentos. Em seguida fazemos uma descrição de seu sistema visual, abrangendo desde seu primeiro estágio de processamento, os omatídeos, até o neurônio H1.

\subsubsection{Captura, controle e criação}

Para confrontarmos resultados obtidos em diferentes experimentos, temos que garantir que as repetidas realizações deste estejam sob mesmas condições. Para tal, devemos manter o controle do ambiente que o cerca afim de eliminarmos a interferência de variáveis indesejadas em nossos resultados. Em sistemas biológicos, como a mosca, o isolamento destas varáveis é extremamente complexo devido ao grande número de parâmetros a ser controlado. Além das condições ambientais controladas durante um experimento, como temperatura, umidade do ar e luminosidade, necessitamos controlar uma série de parâmetros antes mesmo do nascimento das moscas.

Após atraídas por matéria orgânica animal em decomposição e capturadas no meio ambiente, as moscas são colocadas em um balde fechado e alimentadas com açúcar, água e fígado bovino, sendo este último destinado para o fornecimento protéico necessário para o desenvolvimento ovariano das fêmeas adultas (49). Não utilizamos estas moscas selvagens para aquisição de dados por não termos informação sobre sua origem. Fazemos com que estas moscas depositem ovos em um recipiente que contém uma ração*. Logo após a

\footnotetext{
*Ração à base de leite em pó, ágar, levedura de cerveja, nipagin e caseína, preparado de acordo com
} $(50,51)$. 
oviposição, retiramos as moscas adultas e esperamos até que estes ovos ecludam em larvas. Neste estágio, fechamos o recipiente com um pano permitindo a entrada de ar e impedindo a saída destas larvas. Com este procedimento, forçamos sua permanência junto à ração por aproximadamente 5 dias, fazendo com que estas se alimentem e atinjam uma massa corporal crítica. Após alcançarem esta massa, liberamos as larvas do recipiente fazendo com que estas migrem para uma serragem seca e empupem. A fase de pupa dura cerca de 7 dias até eclodirem e se tornarem adultas. Esta é a última fase da vida da mosca (Figura 2.1).

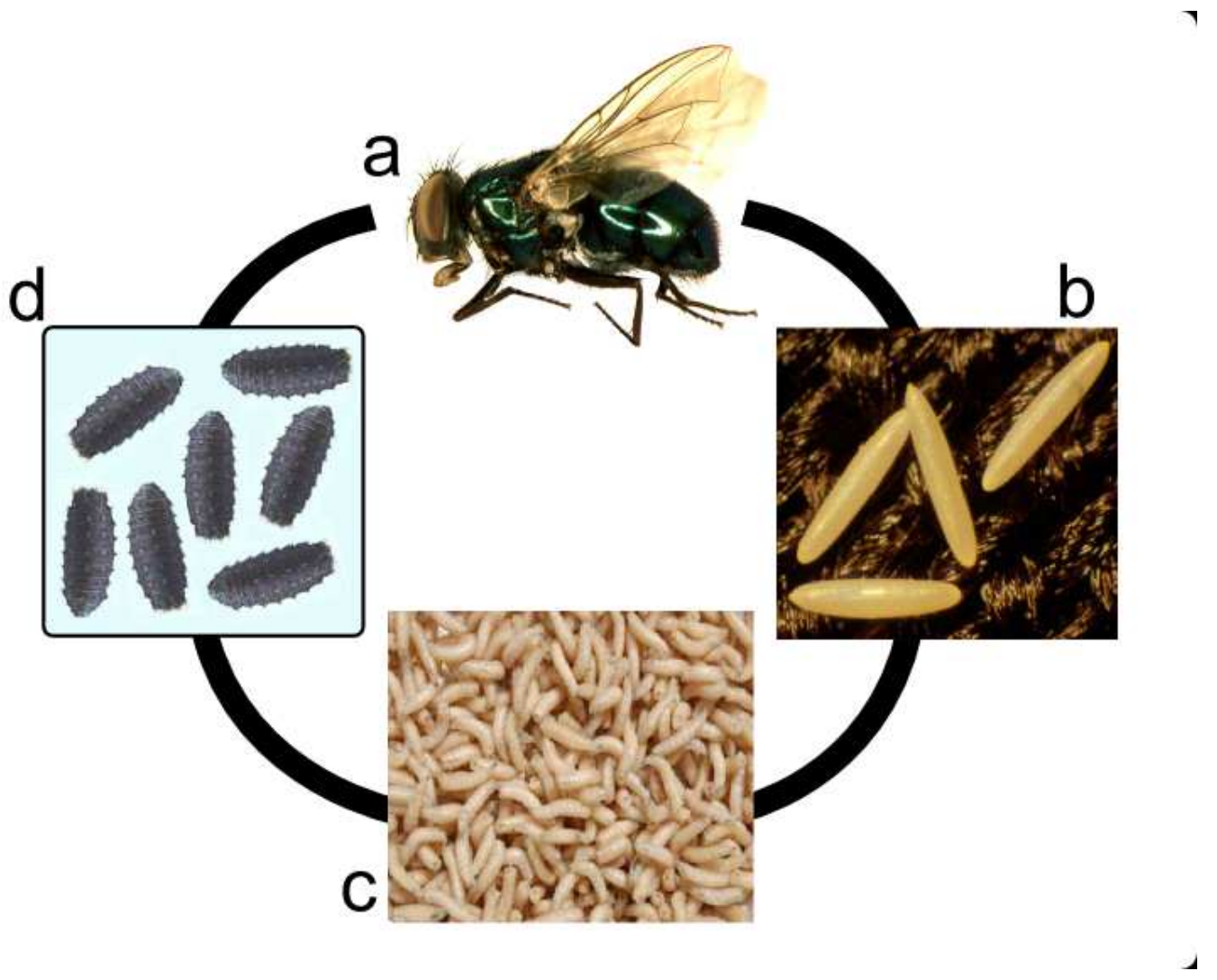

Figura 2.1 - Ciclo de vida da Chrysomya megacephala. (a) Mosca adulta. A mosca adulta e selvagem é capturada e mantida em um balde fechado. Esta mosca é alimentada com açúcar e carne bovina. (b) Ovos. Por terem alimentação à base de proteína, as moscas desenvolvem ovários, tornando possível a deposição de ovos. (c) Larvas. Após a eclosão dos ovos em larvas, mantém-se estas alimentando-se de ração cerca de 5 dias. (d) Pupa. Após o desenvolvimento completo das larvas estas empupam por cerca de 7 dias até eclodirem e chegarem à fase adulta.

Com base em estudos prévios (52) e a experiência em criação adquirida por nosso grupo, estabeleceu-se que as condições ideais a serem mantidas ao longo da criação das moscas são:

- Temperatura: $25 \pm 5^{\circ} \mathrm{C}$; 
- Umidade Relativa: $60 \pm 10 \%$;

- Fotoperíodo: 12 horas;

Estas condições interferem ao longo de todas as fases do desenvolvimento do animal. Manter tais condições durante todo o ano e durante um experimento é de extrema importância para garantirmos que os resultados obtidos em experimentos distintos possam ser posteriormente confrontados.

\subsubsection{Sistema visual - Neurônio H1}

Conhecer o sistema visual da mosca e a participação de determinados neurônios no processo de codificação da informação visual é de fundamental importância para a compreensão do nosso trabalho $(33,53-56)$.

Animais utilizam informação visual para se locomover, desviar de obstáculos, localizar um predador ou presa, ou seja, para todas as funções necessárias a sua sobrevivência no meio-ambiente. Dentre os animais, os insetos formam o grupo com maior diversidade do planeta: há cerca de 800 mil espécies descritas. Entre estas espécies, aproximadamente 120 mil são moscas, ordem "Diptera". Elas surgiram há cerca de 300 milhões de anos e são um dos animais mais bem sucedidos da Terra em termos evolutivos (4). Um dos motivos deste sucesso são seus mecanismos de controle de vôo extremamente eficientes, tornandoas capazes de realizar correções de curso em menos de $30 \mathrm{~ms}$ atingindo velocidades de até $3000^{\circ} . s^{-1}(34-37)$, característica importante tanto para sobrevivência quanto para a perseguição de parceiras para acasalamento, garantindo a perpetuação de sua espécie (Figura 2.2). Estas propriedades impressionantes de vôo fizeram com que as moscas fossem estudadas exaustivamente nas últimas décadas, tanto em relação aos seus aspectos aerodinâmicos $(5,27,34-37)$ quanto neurofisiológicos $(4,8)$.

Este sistema visual altamente adaptado da mosca pode ser dividido em cinco estruturas principais: "Olho Composto", "Lâmina", "Medula", "Lóbula" e "Placa Lobular". Ilustramos na Figura 2.3 o caminho percorrido pela informação visual captada nos olhos compostos que tem como destino, assim como as saídas dos demais sistemas sensoriais, o centro neuromotor da mosca. Este conjunto de informações induzirá uma resposta motora adequada ao cenário sensorial detectado (57). 


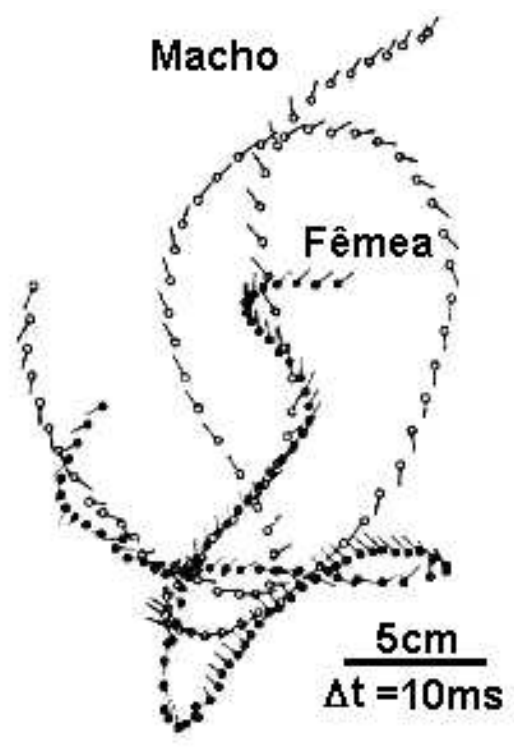

Figura 2.2 - Dinâmica de vôo da mosca. Registro uma mosca macho na tentativa de capturar uma fêmea utilizando fotografia de alta velocidade. Devido à rápida ocorrência desse movimento, toda a perseguição mostrada levou apenas um segundo, não é possível a observação do mesmo à olho nú. Os símbolos (branco para a mosca macho e preto para a fêmea) mostram a cabeça da mosca e o ângulo de seu corpo em intervalos de 10 milissegundos. Imagem adaptada de (34)

O processamento da informação visual começa no "Olho Composto". Nas moscas, esta estrutura é formada por uma rede hexagonal de aproximadamente 5 mil omatídeos. Cada omatídeo possui uma lente de aproximadamente $30 \mu m$ de diâmetro $(62,63)$ e oito células fotoreceptoras (R1-R8) sensíveis a comprimentos de onda na região do ultravioleta, azul e verde (Figura 2.4) (8, 60). Os processos de transdução da luz em sinal elétrico ocorre através da absorção de fótons por organelas pigmentadas presentes nas células fotoreceptoras $(30,64-66)$. Os 6 fotoreceptores R1-R6 de omatídeos vizinhos têm eixos ópticos paralelos fazendo com que os sinais destes fotoreceptores sejam combinados na lâmina. Os dois outros fotoreceptores, R7 e R8, não têm conexão com a lâmina e seus sinais vão direto para o próximo nível, a medula.

Na "Lâmina" o sinal dos fotoreceptores é pré-processado para que apenas a variação da intensidade luminosa em relação a sua média seja codificada $(67,68)$. Este processo é importante devido a típica variação de $7-8$ ordens de grandeza da intensidade luminosa ao longo de um dia (Tabela 1). Na lâmina observamos um mapeamento retinotópico do estímulo visual, sinais de entrada próximos são processados em regiões adjacentes do cérebro. Os axônios dos neurônios da lâmina projetam-se juntamente com os axônios dos fotorreceptores R7-R8 configurando o sinal de entrada da medula. 


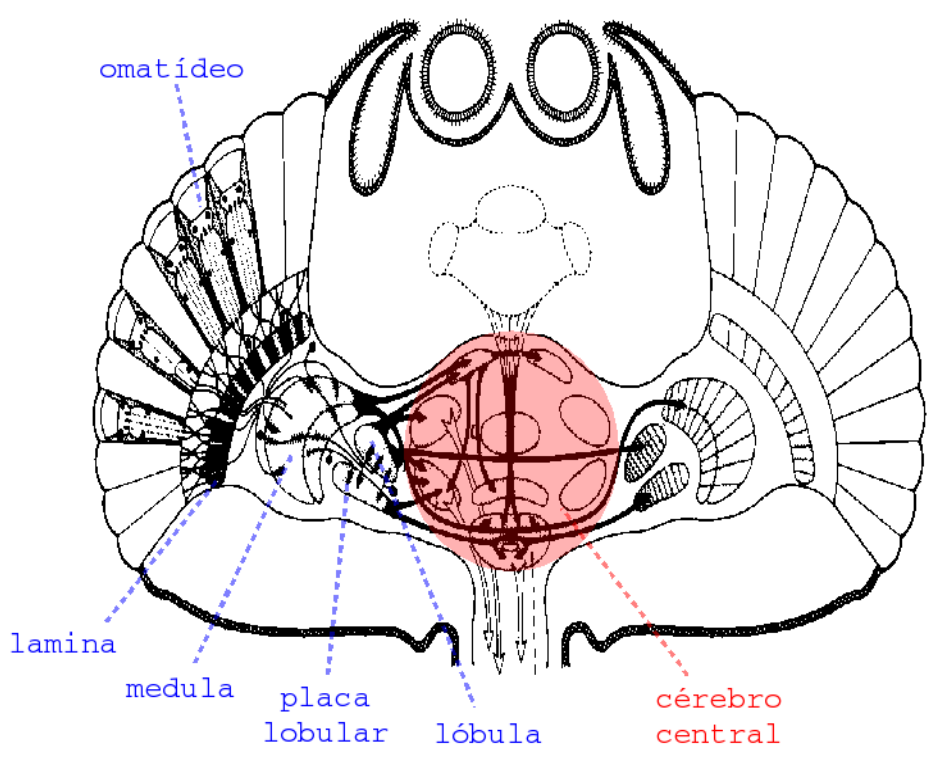

Figura 2.3 - Sistema visual da mosca. Corte horizontal da cabeça da mosca indicando os vários estágios de processamento do sistema visual: Omatídeo, Lâmina, Medula, Placa Lobular e Lóbula. A informação do cenário sensorial percorre este caminho até o centro neuromotor da mosca. Imagem adaptada de (58).
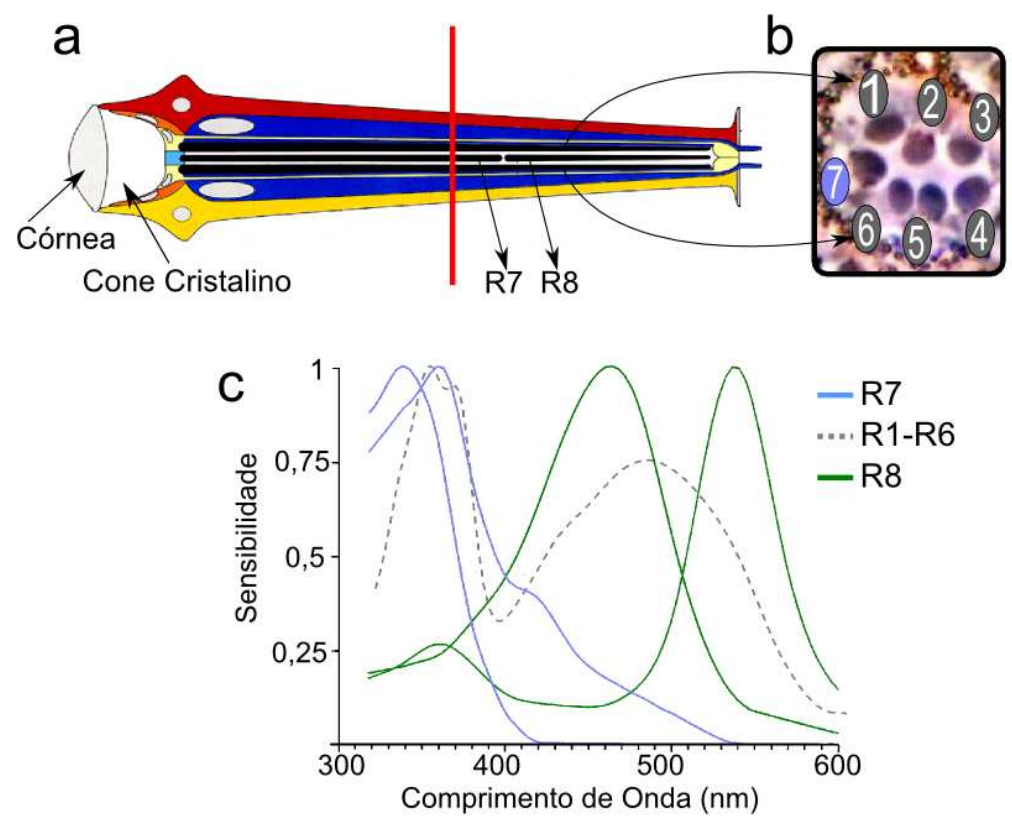

Figura 2.4 - Omatídeo. (a) Representação do omatídeo e suas partes. Linha vermelha representa corte mostrado em (b). (c) Sensibilidade aos diferentes comprimentos de onda dos receptores R1-R6, R7 e R8. Adaptado de (59-61) 
Tabela 1 - Intensidades luminosas. Variação da intensidade luminosa ao longo de um dia. $1 l u x=4 \pi c d . m^{-2}$.

\begin{tabular}{|l|c|}
\hline Exemplo & Luminância (lux) \\
\hline \hline Luz de Sirius, estrela mais brilhante no céu noturno & $1 \times 10^{-5}$ \\
\hline Noite limpa sem lua & $2 \times 10^{-3}$ \\
\hline Exigência mínima para luzes de emergência & $1 \times 10^{-2}$ \\
\hline Lua cheia & 1 \\
\hline Sala de estar & 50 \\
\hline Recomendado para iluminação de escritórios & 320 \\
\hline Luz do dia & $(10-25) \times 10^{3}$ \\
\hline Luz do sol direta & $(32-130) \times 10^{3}$ \\
\hline
\end{tabular}

A "Medula" foi pouco estudada devido ao tamanho reduzido de suas células, o que dificulta aquisições eletrofisiológicas. Entretanto, há evidências que sugerem que esta esteja ligada à computação e extração de parâmetros visuais tais como velocidade, direção, orientação e contraste do estímulo fornecido (39, 68-70). A saída da medula se bifurca para a lóbula e para a placa lobular.

A "Lóbula" recebe informação de uma grande quantidade de células da medula e pouco se sabe sobre sua função no sistema visual. Alguns neurônios da lóbula só estão presentes em moscas machos $(39,69,70)$ evidenciando que estes neurônios estejam associados à detecção de pequenos objetos no campo visual, já que esta característica é relacionada com comportamentos de fuga ou perseguição - função que os machos desempenham melhor do que as fêmeas (37).

Na "Placa Lobular" existem cerca de 60 neurônios gigantes (diâmetro do corpo celular de aproximadamente $10 \mu \mathrm{m}$ ) que estão relacionados à detecção de movimento em campos receptivos amplos. Estes neurônios são conhecidos como Células Tangenciais da Placa Lobular e são agrupados em classes de acordo com sua anatomia e características de suas respostas, como a direção e sentidos preferências de integração do estímulo, entre outras características envolvidas com a estabilização do vôo (8).

Entre dezenas de neurônios da placa lobular, nós estudamos o "Neurônio H1". Este neurônio é sensível à movimentos horizontais de trás para frente em relação à cabeça da mosca. Não há outro tipo de neurônio na placa lobular que possua esta mesma característica, tornando possível identificá-lo de forma inequívoca. O sistema visual da mosca possui um neurônio H1 em cada hemisfério. Sua rede dendrítica cobre quase toda a placa lobular, fazendo com que estes respondam a estímulos em praticamente todo campo visual, com maior intensidade na região fronto-equatorial (11). A projeção de seu axônio na 
placa lobular do hemisfério contralateral excita as células HS e CH que possuem sinapses inibitórias espalhadas em sua arborização, que por sua vez, inibem o H1 contralateral. Estas conexões estão envolvidas com a diferenciação de movimentos de translação e rotação. Portanto, o H1 faz parte de um mecanismo binocular de detecção de velocidades para medir o "auto-movimento" da mosca (Figura 2.5) $(3,4)$.

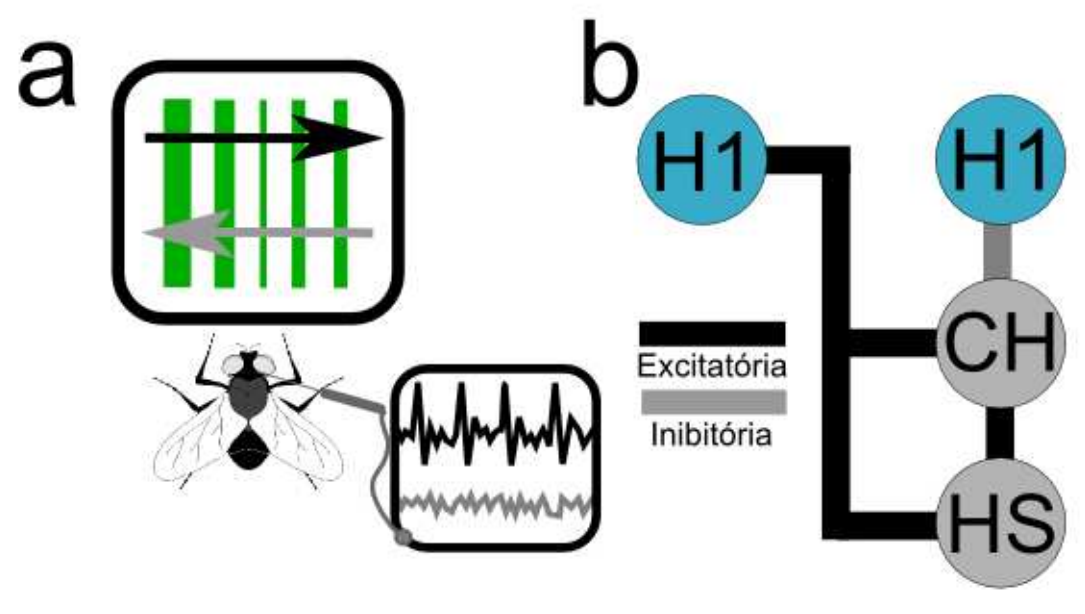

Figura 2.5 - Neurônio H1. (a) Estímulo apresentado à mosca em ambos os sentidos, excitatório (preto) e inibitório (cinza). Ao excitarmos a mosca no sentido de trás para frente observamos a atividade do neurônio $\mathrm{H} 1$ contralateral. $\mathrm{O}$ mesmo não acontece quando invertemos o sentido do estímulo. (b) Esquema representando as conexões entre alguns neurônios da placa lobular. Ao disparar, o neurônio H1 ipsilateral excita os neurônios $\mathrm{CH}$ e $\mathrm{HS}$ contralaterais. Estes neurônios possuem conexões que inibem a atividade do $\mathrm{H} 1$ contralateral. $\mathrm{O}$ mesmo acontece nos dois hemisférios do cérebro da mosca. Adaptado de $(3,4)$

A resposta do neurônio H1 se dá na forma de seqüencias de pulsos elétricos, ou potenciais de ação (spikes), detectáveis extracelularmente. Os potenciais de ação transmitem informação apenas através de seus tempos de ocorrência, ou seja, uma seqüencia de spikes é caracterizada simplesmente por uma lista de tempos em que estes ocorreram. Esta seqüencia é conhecida como trem de pulsos e toda informação que cada H1 transmite sobre o estímulo - e portanto o mundo exterior - reside no trem de pulsos emitido pelo neurônio (Figura 2.6) (71, 72).

Vemos que já em cérebros menos sofisticados como o da mosca $\left(\sim 10^{6}\right.$ neurônios) é possível o estudo dos mecanismos de codificação neural também presentes em sistemas biológicos mais complexos, como por exemplo, o cérebro humano. 


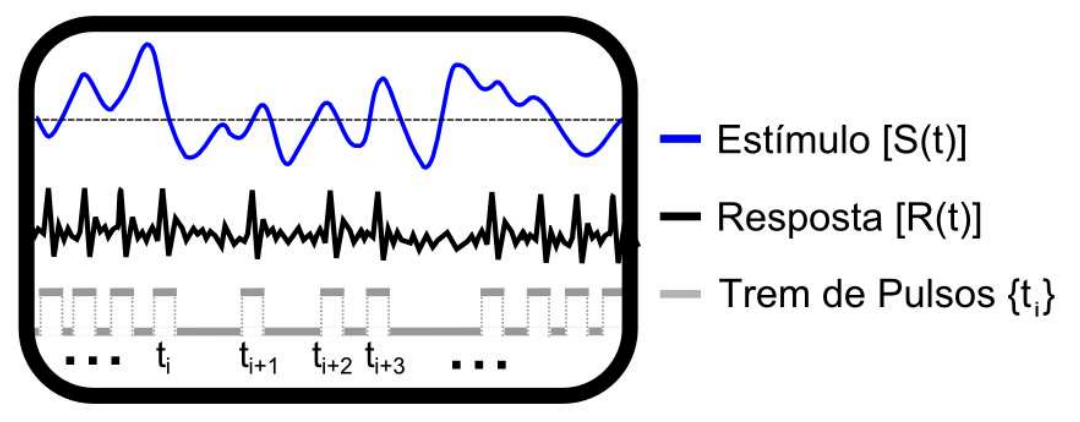

Figura 2.6 - Codificação neural. Ao apresentarmos um estímulo em função do tempo $S(t)$ (azul) e registrarmos a atividade $R(t)$ do neurônio $\mathrm{H} 1$ (preto), observamos uma seqüencia de pulsos praticamente idênticos (spikes). Devido a esta semelhança entre os pulsos, podemos caracterizar $R(t)$ apenas pelos tempos $\left\{t_{i}\right\}$ de ocorrência dos disparos.

\subsection{Geração de estímulos}

Para investigar a codificação neural, devemos gerar estímulos apropriados às características já conhecidas do neurônio H1 e do sistema visual da mosca.

Para estimularmos seu sistema visual, apresentamos uma imagem que compreende grande parte do campo visual, particularmente sua área fronto-equatorial de maior sensibilidade. Esta imagem é mostrada por dois monitores do tipo XY TEKTRONIX dispostos perpendicularmente ${ }^{\dagger}$. A mosca é colocada a uma distância de aproximadamente $6 \mathrm{~cm}$ em relação aos monitores (Figura 2.7a).

A imagem composta por $256 \times 256$ pixels, denominada "monet", a ser mostrada em ambos monitores é gerada por uma matriz de mesmo número de elementos contendo 8 bits de níveis de intensidade (0 à 255). Como estimularemos a mosca com movimentos horizontais, estamos apenas interessados em gerar imagens com contraste nesta direção. Desta forma, escolhemos compor esta imagem por barras verticais. A posição, largura e intensidade destas barras são escolhidas de forma aleatória a fim de diminuir a dependência dos resultados obtidos com propriedades particulares da imagem (Figura 2.7b).

O "monet" gerado se deslocará rigidamente no eixo horizontal em intervalos de $\delta t=$ $2 m s$. Ou seja, a taxa de varredura vertical da imagem é de $500 \mathrm{~Hz}$, muito superior às taxas encontradas em monitores convencionais $(60-85 H z)$. Para o olho humano, taxas

†Monitor TEKTRONIX 608 de deflexão eletrostática e fósforo verde $P_{31}$. Área útil de $9,8 \times 12,2 \mathrm{~cm}$ e chamada área de qualidade $9 \times 11 \mathrm{~cm}$ contendo $256 \times 256$ pixels. Luminosidade máxima de $240 \mathrm{~cd} . \mathrm{m}^{-2} \mathrm{e}$ tempo de decaimento $340 \mu$ s à $10 \%$ (73) 

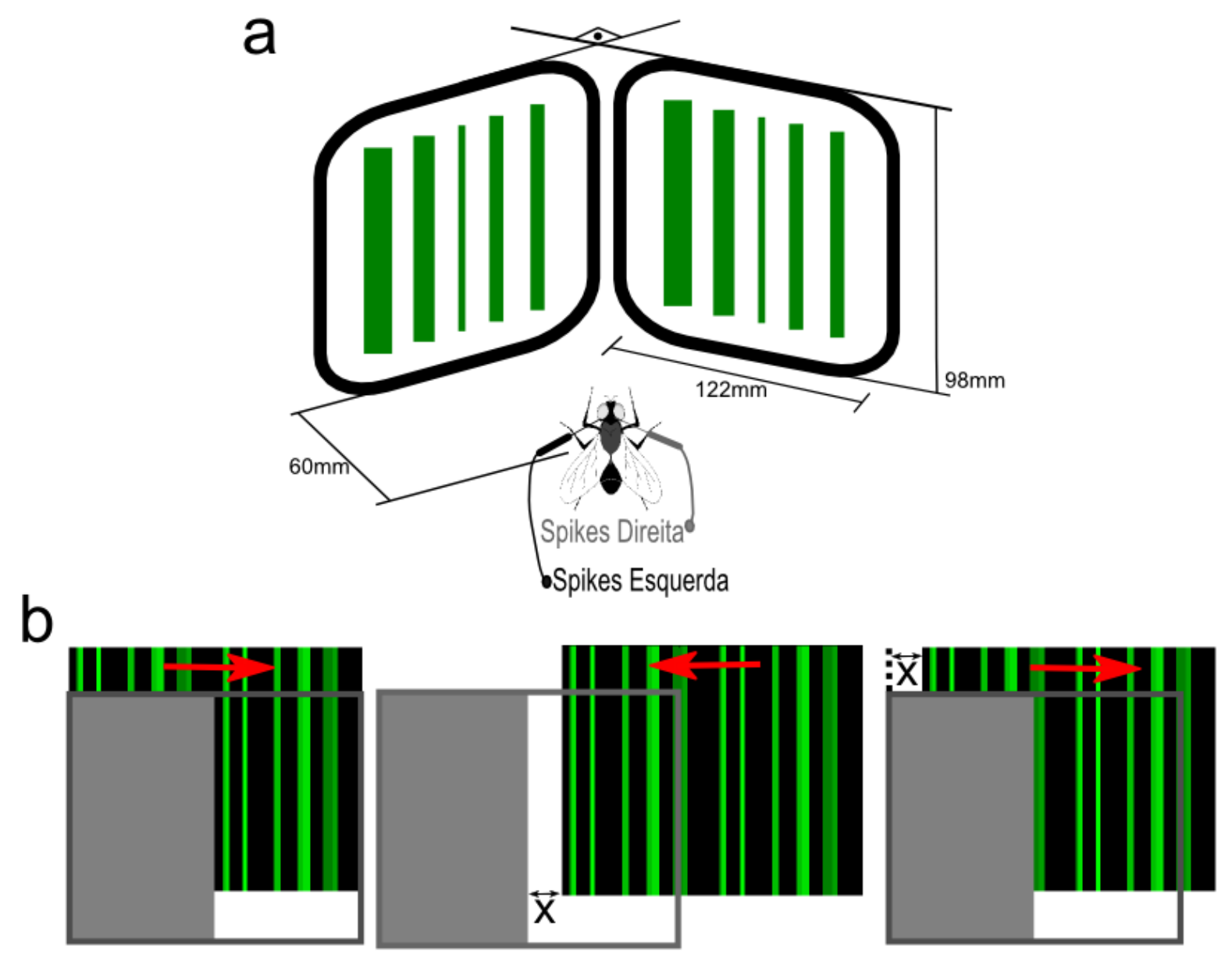

Figura 2.7 - Estímulo visual. (a) Disposição dos dois monitores e da mosca. Os monitores são dispostos formando um ângulo de $90^{\circ}$. A mosca é fixada em uma posição e distância tal que sua área de maior sensibilidade seja estimulada. Intensidade luminosa medida neste ponto é de $4 \mathrm{~cd} . \mathrm{m}^{-2}$ (medida realizada com luxímetro MLM 1333 Minipa). (b) Imagem gerada de forma aleatória. A imagem é formada por $256 \times 256$ pixels com 256 níveis de intensidade. Há a necessidade de repetirmos os pixels da primeira metade da imagem para implementarmos condições periódicas de contorno ao movimento. Ao ultrapassar em " $x$ " posições a metade do deslocamento máximo permitido, a imagem é deslocada instantaneamente para a posição " $x$ " em relação a origem.

superiores a 15 - 30 quadros por segundo são suficientes para termos uma sensação de movimento contínuo da imagem. Devido à processos evolutivos, o sistema visual da mosca é capaz de detectar movimentos numa menor escala temporal do que o humano. Para tal, foi desenvolvido um sistema de geração de estímulos com taxa atualização na escala temporal do neurônio H1, seu período refratário de $2 m s$ (43).

Esse sistema de geração de estímulos é constituído por duas partes $(33,53)$ :

1. Computador Hospedeiro: Responsável pela interface do hardware dedicado com 
o usuário, fornecimento da posição do estímulo na taxa de $500 \mathrm{~Hz}$ e armazenamento dos dados coletados durante um experimento. Fornecemos a imagem a ser carregada pelo "VSImG" e um arquivo contendo as sucessivas posições que esta ocupará no monitor. Ao fim de um experimento, este computador possui armazenado os instantes " $t_{i}$ " dos spikes disparados, tanto para um ou para dois neurônios registrados simultaneamente.

2. Gerador de Estímulos Visuais (VSImG): Consiste de dois monitores TEKTRONIX e um hardware dedicado. Este gerador atinge a frequiência necessária para o experimento. A cada $2 m s$ inicia-se a varredura de um novo quadro. Neste instante o VSImG envia um sinal solicitando a próxima posição para o computador hospedeiro, registra este tempo no arquivo "TELA.dat" e fornece ao Conversor Digital Analógico (DAC) a próxima posição (com um quadro de antecedência). O DAC toma a posição fornecida pelo computador hospedeiro ("POS.dat") e a converte em uma voltagem de $0-5 \mathrm{~V}$, que será fornecida ao VSImG (as posições contidas neste arquivo possuem 15bits de resolução, 32768 possíveis posições). Esta voltagem será somada à varredura horizontal do sistema, causando assim um deslocamento na posição do monet.

O arquivo "POS.dat" é obtido através da integração de uma seqüencia de velocidades geradas a partir de uma distribuição Gaussiana de média zero e correlação temporal $\tau$, conhecida como distribuição de Ornstein-Uhlenbeck (74) (Apêndice A). Com este procedimento, geramos um conjunto $\mathcal{S}$ de centenas estímulos de $10 \mathrm{~s}$ de duração, $\mathcal{S}:\left\{S_{i}\right\}$, que são combinados de diferentes formas para obtermos experimentos de aproximadamente 40 minutos. Uma forma de combinarmos estes estímulos é escolhermos um determinado $S_{i}$ do nosso conjunto $\mathcal{S}$ e o repetirmos várias vezes intercalado por $S_{j \neq i}$. Desta forma podemos analisar as diferenças entre as respostas geradas por um mesmo estímulo $S_{i}$ e inibirmos a adaptação a este com $S_{j}(12)$.

Ao considerarmos as altas velocidades de rotação atingidas pela mosca $\left(\sim 3000^{\circ} s^{-1}\right)$, necessitamos realizar longos deslocamentos na imagem, maiores do que a extensão do monitor, tornando-os proibitivos. Para contornar esta dificuldade e conseguirmos simular este tipo de movimento em nosso sistema de geração de estímulo, aplicamos a este condições periódicas de contorno. Estas condições implicam em utilizarmos monets periódicos e apenas parte da área útil do monitor (Figura 2.7b).

Uma vez tendo as condições necessárias para gerarmos os estímulos condizentes com o sistema visual da mosca e suas particularidades de vôo, resta-nos fazer a aquisição dos 
sinais neurais obtidos como resposta a estes estímulos.

\subsection{Aquisição de dados}

Para aquisição do sinal neural necessitamos seguir um procedimento de preparação da mosca a fim de ter acesso ao neurônio H1. Em seguida, dispomos de um aparato experimental para captura, amplificação, filtragem, discriminação e registro deste sinal. Estes procedimentos são descritos a seguir $(33,53-56)$.

\subsubsection{Micromanipulação da mosca}

Para aquisição, selecionamos uma mosca da primeira geração criada em nosso laboratório com 5 a 15 dias de vida. Após ser imobilizada, tendo suas asas e patas coladas com cera de dentista, esta mosca é introduzida e fixada a um tubo plástico, de tal forma a ficar com apenas sua cabeça e parte de seu corpo para fora deste tubo (Figura 2.8a). Por tratarmos de estímulos visuais, uma posterior imobilização de sua cabeça, fixando a direção de sua visão, é essencial. Este tubo plástico é fixado em um suporte e levado a um microscópio óptico com capacidade de aumento de 6,6 vezes onde será realizada uma microcirurgia. Com a utilização de um pequeno bisturi, três incisões são feitas na parte posterior de sua cabeça, retirando a cápsula de quitina que a envolve. Este procedimento nos dá acesso a um hemisfério de seu cérebro. A fina camada de gordura presente na região é retirada assim como o músculo próximo ao pescoço responsável por ruído devido suas contrações periódicas. O mesmo procedimento é feito nos dois hemisfério de sua cabeça.

Após a microcirurgia descrita e com acesso visual ao seu cérebro, levamos a mosca à nossa mesa de aquisição em um suporte em frente ao monitor de video. Esta mesa contém outro microscópio e um micromanipulador manufaturado pela equipe da oficina mecânica do Instituto de Física de São Carlos. O micromanipulador tem três eixos de liberdade 


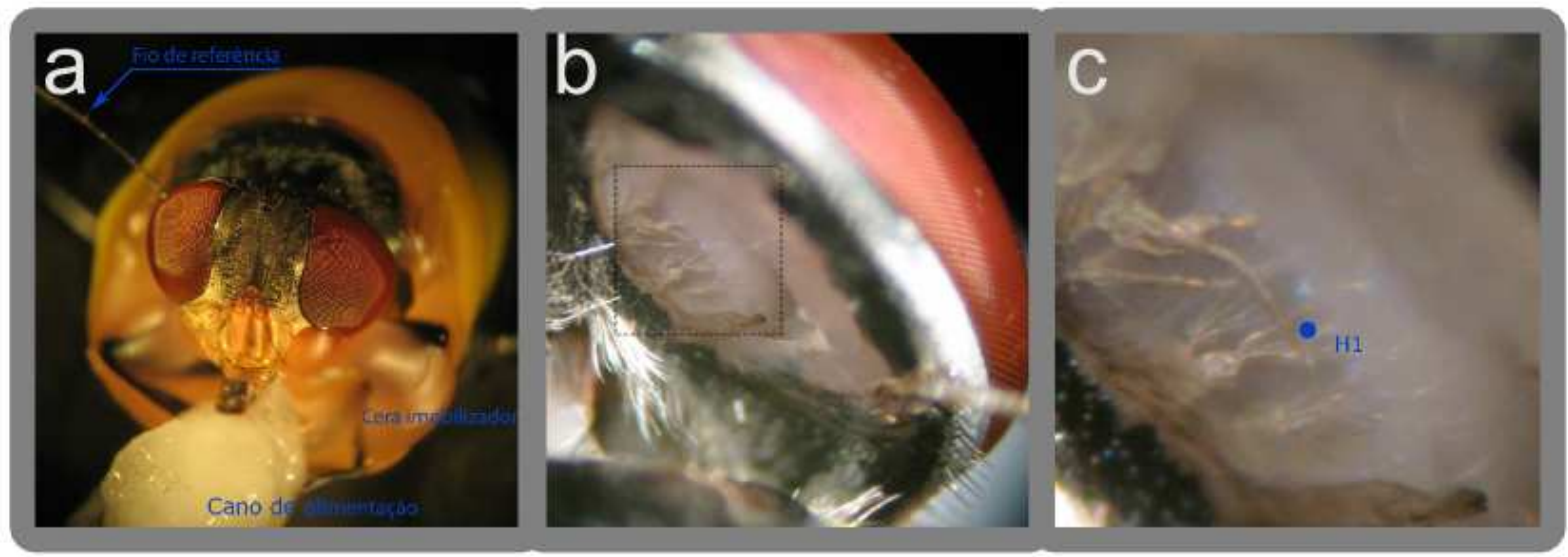

Figura 2.8 - Imobilização e microcirurgia da mosca. (a) Mosca imobilizada com cera. Podemos ver o cano pelo qual a mosca alimenta-se ao longo dos experimentos e o fio de prata de referência introduzido em sua cabeça. (b) Parte posterior da cabeça da mosca após microcirurgia. Novamente podemos observar o fio de referência no canto inferior direito da imagem. Quadrado pontilhado em maior detalhe em (c). Observamos as traquéias que fornecem oxigenação ao cérebro e a localização aproximada do neurônio H1. Adaptado de (53).

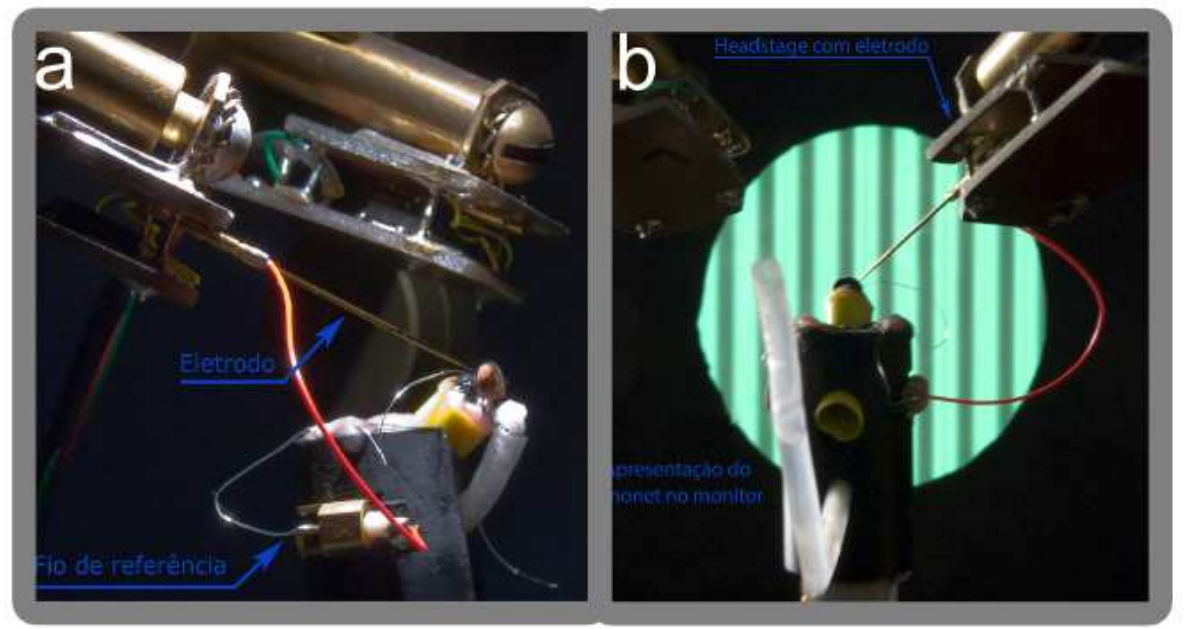

Figura 2.9 - Montagem final do experimento. (a) Mosca imobilizada e alimentada, com o eletrodo e o fio de referência de prata inseridos em sua cabeça. (b) Visão posterior da montagem experimental. Adaptado de (53).

fazendo com que possamos introduzir um micro-eletrodo ${ }^{\ddagger}$ nas proximidades do neurônio H1. Esta localização é facilitada ao visualizarmos as traquéias que cobrem a placa lobular responsáveis pela oxigenação do cérebro (Figura 2.8b,c). Para manter a mosca viva por um longo período de tempo, neste suporte é introduzido um tubo plástico ao alcance de sua boca que conduzirá uma mistura de água e açúcar para alimentá-la durante os

¥ $\overline{\text { Micro-eletrodo de Tungstênio FHC } \sharp \mathrm{UEW}}$ MHGSEKP1M, $2-5 M \Omega$, isolamento em verniz de epoxi. 
experimentos (Figura 2.9a).

A aquisição eletrofisiológica é feita extracelularmente. Medimos um sinal de $\sim 20-$ $100 \mu V$. A identificação do neurônio é feita pelas características de sua resposta, como direção e sentido preferenciais de estimulação. A vantagem do registro extracelular é a possibilidade de medirmos a atividade elétrica sem danificar o tecido nervoso e comprometer a dinâmica interna da célula. Este tipo de aquisição é muito freqüente in vivo por ser menos invasivo. Em contrapartida, este processo é mais suscetível a ruídos eletromagnéticos e à atividade de neurônios vizinhos. A complexa tarefa de tratamento deste sinal é descrita a seguir.

\subsubsection{Tratamento do sinal neural}

A aquisição e tratamento do sinal neural pode ser dividida nas cinco etapas apresentadas a seguir (Figura 2.10).

1. Captação: No meio fisiológico (hemolinfa), a intensidade dos disparos do neurônio H1 caem de dezenas de milivolts para a ordem de $20-100 \mu \mathrm{V}$. Dado o grande número de neurônios presentes na placa lobular, é de extrema importância ter um alto grau de seletividade do sinal. Para tal, a captação deste sinal é feita por meio de um micro-eletrodo de alta impedância, entre $2-5 M \Omega$. Um micro-eletrodo capaz de captar um sinal de tão baixa amplitude acaba inevitavelmente captando ruídos intrínsecos do sistema biológico (neurônios vizinhos, outras estruturas tais como músculos, traquéias, movimentação do animal, ruído térmico) bem como ruídos eletromagnéticos externos ao sistema devido a equipamentos eletrônicos, lâmpadas fluorescentes, fiação da rede elétrica, entre outros. Assim, uma vez captado, esse sinal passa pelas etapas seguintes de tratamento.

\section{Amplificação:}

(a) Amplificador Diferencial: Foram utilizados o pré-amplificador "INA111 BurrBrow" e o amplificador operacional "OPA604 - BurrBrown" localizados no primeiro estágio de tratamento do sinal, o headstage (Figura 2.9b), imediatamente após o micro-eletrodo. Isto é feito para reduzir capacitâncias parasitas e 
a interferência de ruídos externos ao longo da transmissão do sinal sem amplificação. As duas entradas desse amplificador são: o micro-eletrodo, posicionado em uma região próxima ao neurônio H1, e um fio de referência de prata, posicionado na hemolinfa dentro da cabeça da mosca. Esta configuração permite a eliminação de ruídos comuns a essas duas entradas. Este amplificador também atua como um filtro passa alta, para freqüências acima de $300 \mathrm{~Hz}$. A saída deste módulo terá um ganho de voltagem 100 vezes.

(b) Amplificador Inversor: Nessa etapa, foi utilizado o amplificador operacional "OPA604 - BurrBrown" de baixo ruído. O sinal de saída do estágio anterior é amplificado novamente 100 vezes.

Ao fim da etapa de amplificação, o sinal pré-filtrado terá sido amplificado 10.000 vezes, atingindo valores da ordem de $1 V$.

3. Filtragem: Foram usados filtros do tipo Bessel de terceira ordem, com freqüência de corte em $300 \mathrm{~Hz}$ e $7 \mathrm{KHz}$.

4. Discriminação: Antes da discriminação do sinal, este passa por um monitor de audio e por um osciloscópio a fim de facilitar a preparação do experimento, durante a localização do H1.

Utiliza-se um discriminador de janela de amplitude ajustável manualmente, com um limiar inferior (LI) e superior (LS) (Figura 2.10). Se a amplitude do sinal estiver compreendida nesta janela um pulso digital padrão TTL de largura fixa de $10 \mu s$ é gerado (75). Temos assim a digitalização por discriminação do sinal captado.

5. Registro dos tempos de ocorrência: Nesta etapa atribuímos para cada spike seu respectivo instante de ocorrência " $t_{i}$ " com o auxílio do Hardware Digital Dedicado. Temos a nossa disposição dois sistemas de aquisição cujos relógios registram os tempos com 32bits ou 64bits com resolução da ordem de $1 \mu$ s. O instante de cada disparo é registrado em um arquivo de dados no Computador Hospedeiro.

Com os procedimentos para o tratamento do sinal neural registrado e a geração do estímulo adequado, realizamos uma série de experimentos a fim de caracterizar o processo de codificação realizado pelo neurônio H1. Ilustramos estes experimentos nos próximos capítulos. 


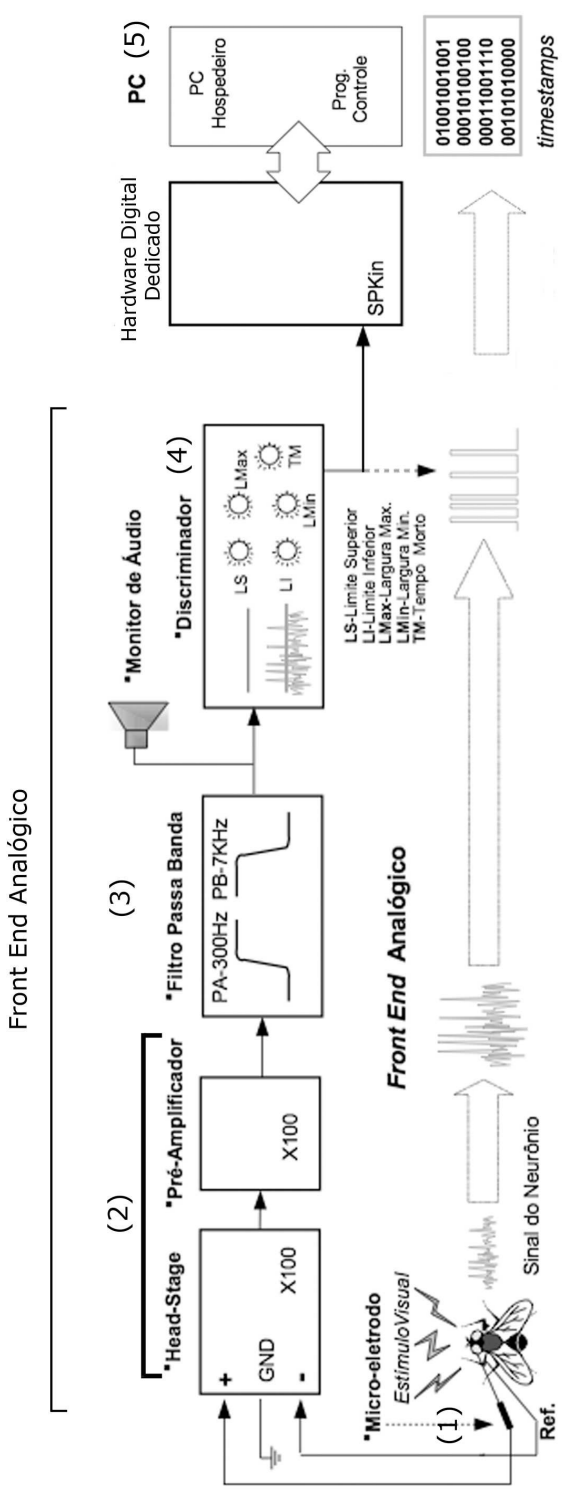

Figura 2.10 - Etapas de aquisição do sinal neural. (1) Captação. (2) Amplificação. (3) Filtragem. (4) Discriminação. (5) Registro. Adaptado de $(33,53)$. 


\section{Acuidade do Sistema Visual da Mosca}

Um dos mecanismos utilizado pela mosca para controlar seu vôo é computar seu deslocamento a partir da variação do fluxo óptico recebido por seus olhos compostos. Com que precisão o sistema visual da mosca é capaz de detectar estes movimentos? Ou seja, qual a mínima variação do fluxo percebida por seu sistema visual? Devemos esclarecer esta questão para melhor entendermos esse organismo altamente adaptado, possuidor de características responsáveis por sua sobrevivência e evolução por milhões de anos (4).

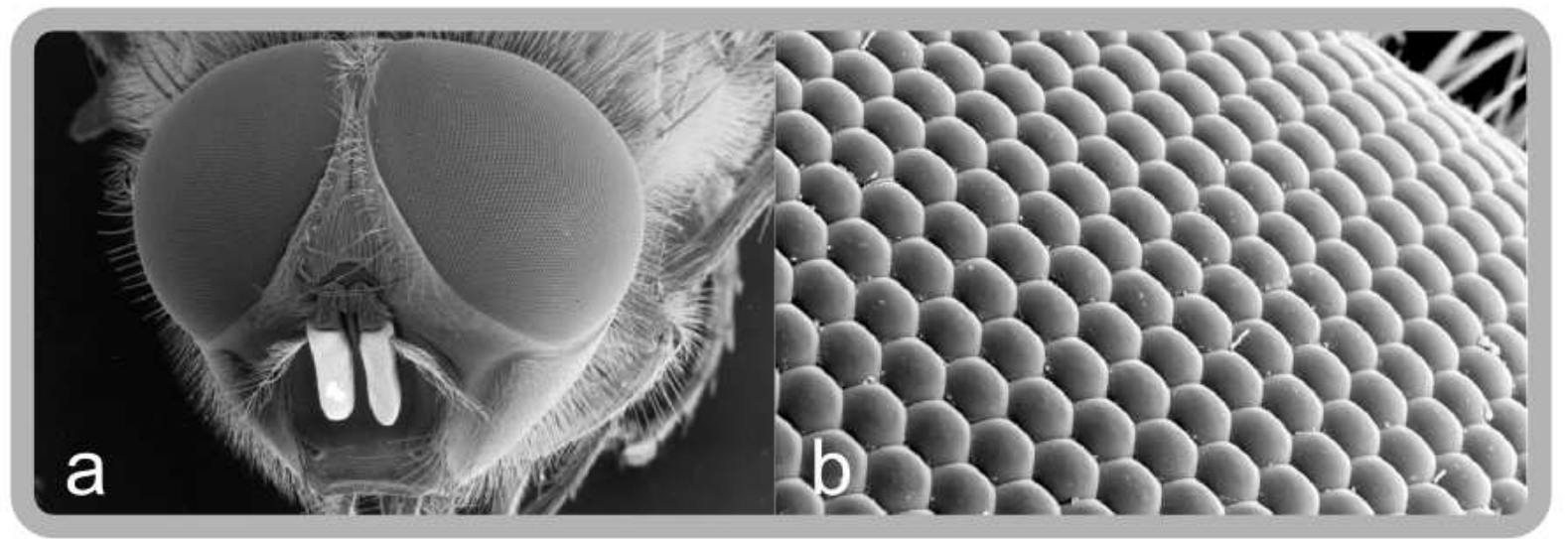

Figura 3.1 - Olhos compostos. (a) Cabeça da mosca, aumento de aproximadamente $20 \times$. (b) Superfície do olho composto da mosca mostrando cada omatídeo, aumento de aproximadamente $375 \times$. "Copyright - University of Bath UK", imagens reproduzidas com autorização.

Estudamos particularmente a resposta neural do sistema formado pelos dois neurônios $H 1$ localizados na placa lobular do cérebro da mosca. Este sistema é responsável pela detecção de movimentos horizontais no sentido de trás para frente de sua cabeça. A atividade destes neurônios é decorrência dos vários estágios de processamento ilustrados no capítulo anterior. A eficiência de cada um destes estágios está sujeita às condições do ambiente, como as variações de temperatura $(14,30,76,77)$ e intensidade luminosa $(76,78,79)$, assim como o tempo de vida do organismo analisado (76). O primeiro destes estágios é o olho composto da mosca e seus omatídeos (Figura 3.1). 
Cada omatídeo de abertura $\Delta \phi$ aponta em uma certa direção de seu campo visual e é responsável pela captação de luz proveniente deste ângulo. Quanto menor a abertura $\Delta \phi$ do omatídeo, maior sua seletividade espacial à luz e, conseqüentemente, maior sua precisão visual. Em contrapartida, quanto menor sua abertura, menos luz pode ser captada e menor será sua sensibilidade à luz (80). O balanço entre seletividade-sensibilidade atinge o limite físico da difração da luz captada $(44,45,81-83)$. Isto fez com que este organismo evoluísse, desenvolvendo circuitos elétricos responsáveis por multiplicar os sinais provenientes de omatídeos vizinhos, aumentando sua sensibilidade sem a perda de seletividade à luz (68, $70)$.

Utilizamos nosso sistema de geração de estímulos para apresentar para a mosca um padrão descorrelacionado de barras verticais. A posição desta imagem varia de acordo com uma função senoidal de freqüência fixa $1 \mathrm{~Hz}$. Com a escolha desta freqüência teremos um período de meio segundo contendo estímulos positivos e meio segundo de estímulos negativos, período suficiente para caracterizar a resposta neural a ambos os estímulos. Também com esta escolha, como veremos posteriormente, somos capaz de atingir velocidades suficientes para caracterizar o limite inferior de percepção da mosca. Os deslocamentos desta imagem são feitos de forma rígida, ou seja, o padrão de barras apresentado não varia, apenas sua posição é alterada. Ao diminuirmos sistematicamente a amplitude do sinal senoidal e monitorarmos a taxa de disparo do neurônio $H 1$, mediremos a amplitude mínima de movimento percebida pela mosca. Apresentamos alguns dos valores utilizados de amplitude na tabela a seguir.

Tabela 2 - Amplitudes do estímulo. Diferentes amplitudes do estímulo apresentado. Cada uma dessas amplitudes foi apresentada quinze vezes e logo em seguida diminuída pela metade.

\begin{tabular}{||c|r||c|c||}
\hline \multicolumn{4}{|c|}{ Amplitudes } \\
\hline \hline$\sharp$ & $\boldsymbol{\Delta} \boldsymbol{\theta}\left(^{\boldsymbol{o}}\right)$ & $\sharp$ & $\mathbf{\Delta} \boldsymbol{\theta}\left(^{\boldsymbol{o}}\right)$ \\
\hline $\mathbf{0 1}$ & 61,0000 & $\mathbf{0 7}$ & 0,9531 \\
\hline $\mathbf{0 2}$ & 30,5000 & $\mathbf{0 8}$ & 0,4766 \\
\hline $\mathbf{0 3}$ & 15,2500 & $\mathbf{0 9}$ & 0,2383 \\
\hline $\mathbf{0 4}$ & 7,6250 & $\mathbf{1 0}$ & 0,1191 \\
\hline $\mathbf{0 5}$ & 3,8125 & $\mathbf{1 1}$ & 0,0596 \\
\hline $\mathbf{0 6}$ & 1,9063 & $\mathbf{1 2}$ & 0,0298 \\
\hline
\end{tabular}

O sinal senoidal (posição do estímulo) é apresentado por sete segundos seguido por três segundos no qual a imagem fica estática (posição constante, velocidade nula). Esta 
seqüencia é repetida por quinze vezes para cada amplitude apresentada na Tabela 2 (Figura 3.2). Ao diminuirmos a amplitude do sinal senoidal, diminuímos sua velocidade máxima. Variamos esta amplitude até atingirmos deslocamentos de apenas uma unidade dos 15bits possíveis. Nesta configuração teremos amplitude $\Delta \theta_{\min } \simeq 0,002^{\circ} \mathrm{e}$ $\omega_{\min }=\Delta \theta_{\min } /(1 b i n) \simeq 1^{o} . s^{-1}$. Estas são a amplitude e velocidade mínimas atingidas por nosso gerador de estímulos*.

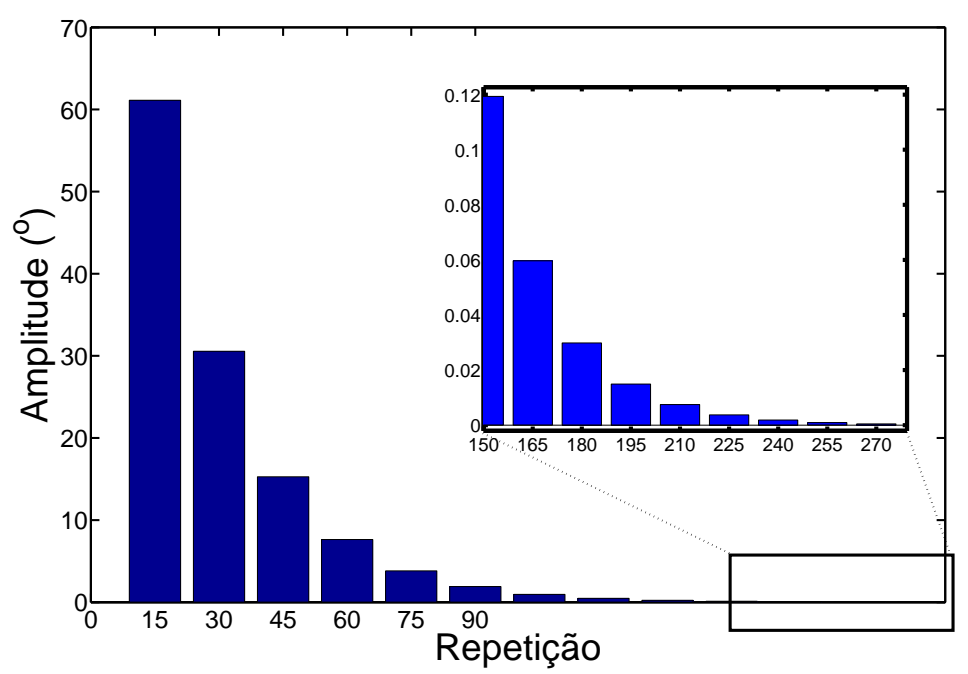

Figura 3.2 - Variação da amplitude do estímulo. A amplitude do sinal senoidal é diminuída pela metade a cada 15 repetições do estímulo. Vemos em detalhe que este processo é repetido até amplitudes praticamente nulas.

Com a escolha deste sinal senoidal, definimos três regiões características do estímulo: (a) região de velocidades negativas na qual o neurônio $H 1$ é inibido; (b) região em que o neurônio $H 1$ é estimulado, velocidades positivas; (c) região de velocidade nula, presenciamos apenas disparos espontâneos do neurônio $\mathrm{H} 1^{\dagger}$. Vemos em detalhe exemplos destas três regiões na Figura 3.3. Na Figura 3.4 observamos a atividade do neurônio H1 como resposta a este estímulo. Percebemos que as respostas contidas nas regiões de estímulo positivo e negativo aproximam-se àquela de disparos espontâneos, velocidade nula, ao diminuirmos a amplitude do sinal senoidal. Determinaremos a precisão do sistema visual pelo ponto em que não somos capaz de distinguir a resposta do neurônio proveniente destes três estímulos distintos. Neste ponto a mosca já não é capaz de inferir a direção de movimento do estímulo.

Medimos a atividade neural pela sua taxa de disparo. Calculamos o valor médio e

$* \overline{\Delta \theta_{\min }=\frac{\Delta P=1}{\Delta P_{\max }} \times \frac{\Delta X}{R} \times \frac{180}{\pi}\left[{ }^{\circ}\right] \text {. Onde } \Delta X}=64 \mathrm{~mm}$ é a excursão máxima do estímulo na tela do monitor, $R=60 \mathrm{~mm}$ a distância da mosca ao monitor e $\Delta P_{\max }=2^{15}$.

†Velocidades positivas têm sentido de trás para frente da cabeça da mosca e negativas o sentido contrário. 


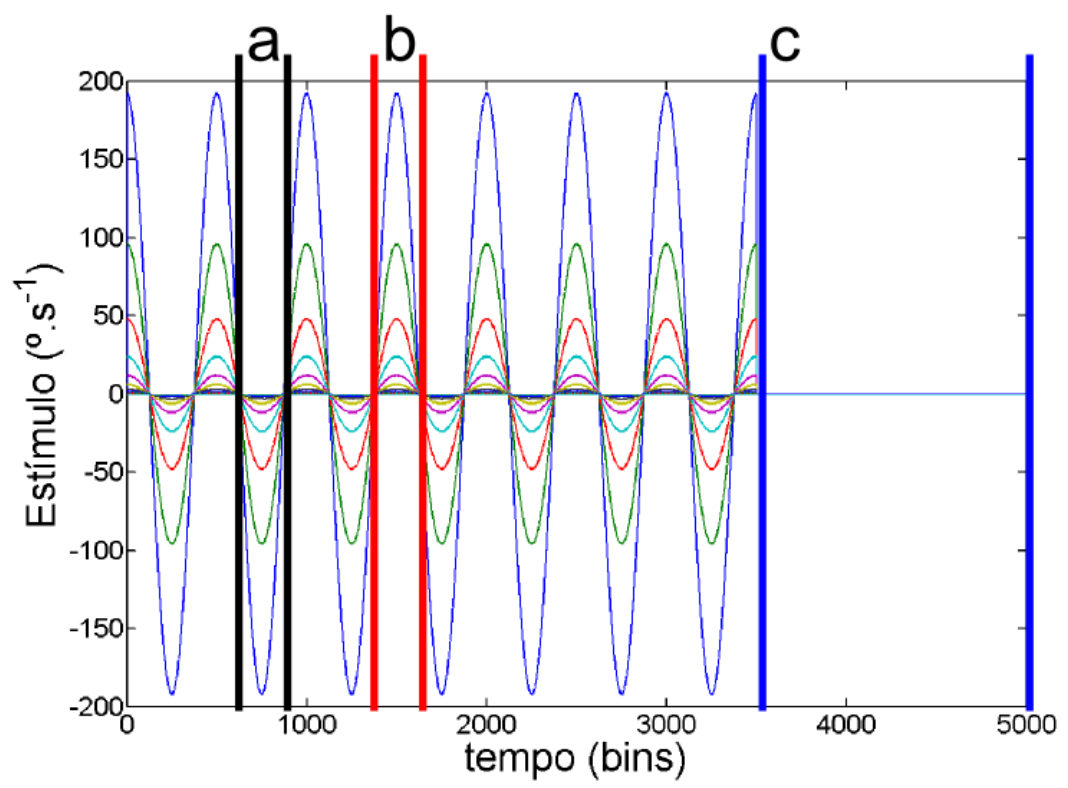

Figura 3.3 - Seqüencia de estímulos. A cada 10 segundos (5000bins) iniciamos uma seqüencia do estímulo. Cada seqüencia é composta por um sinal senoidal de 7 segundos de duração com freqüência de $1 H z$, seguido por 3 segundos de velocidade nula. (a) Região delimitada pelas barras pretas contendo velocidades negativas (inibição do neurônio). (b) Região de ativação do neurônio, delimitada por barras vermelhas. (c) Região de velocidade nula delimitada pelas barras azuis, apenas registramos disparos espontâneos do neurônio H1. Variamos a amplitude do sinal a cada 15 repetições.

seu desvio quadrático médio a partir das quinze repetições do estímulo de mesma amplitude. Efetuamos este cálculo para as regiões (a), (b) e (c) do estímulo. Repetimos este procedimento para os diferentes valores de amplitude utilizados. Os resultados podem ser observados na Figura 3.5.

Observamos que os valores das taxas de disparo, ao considerarmos seus respectivos erros, igualam-se aproximadamente para a nona amplitude utilizada. Ao consultarmos a Tabela 2, identificamos esta amplitude como sendo $\widetilde{\Delta \theta} \simeq 0,25^{\circ}$. O sinal senoidal com esta amplitude apresenta velocidade de pico de apenas $\omega=2 \pi \times \widetilde{\Delta \theta} \times(1 H z) \simeq 1,5^{o} \cdot s^{-1}$. Como esperado, também observamos na Figura 3.5 a taxa espontânea de disparo possuindo sempre valores entre as taxas de ativação e inibição do neurônio.

É evidente que o valor encontrado para o limite $\widetilde{\Delta \theta}$ depende de nossas condições experimentais - temperatura, contraste, intensidade luminosa, tempo de vida do organismo, etc. Por exemplo, ao apresentarmos uma imagem de contraste horizontal zero para a mosca, esta não detectará movimentos e apenas mediremos disparos espontâneos provenientes de seu neurônio $H 1$, independentemente da velocidade e amplitude do estímulo. 


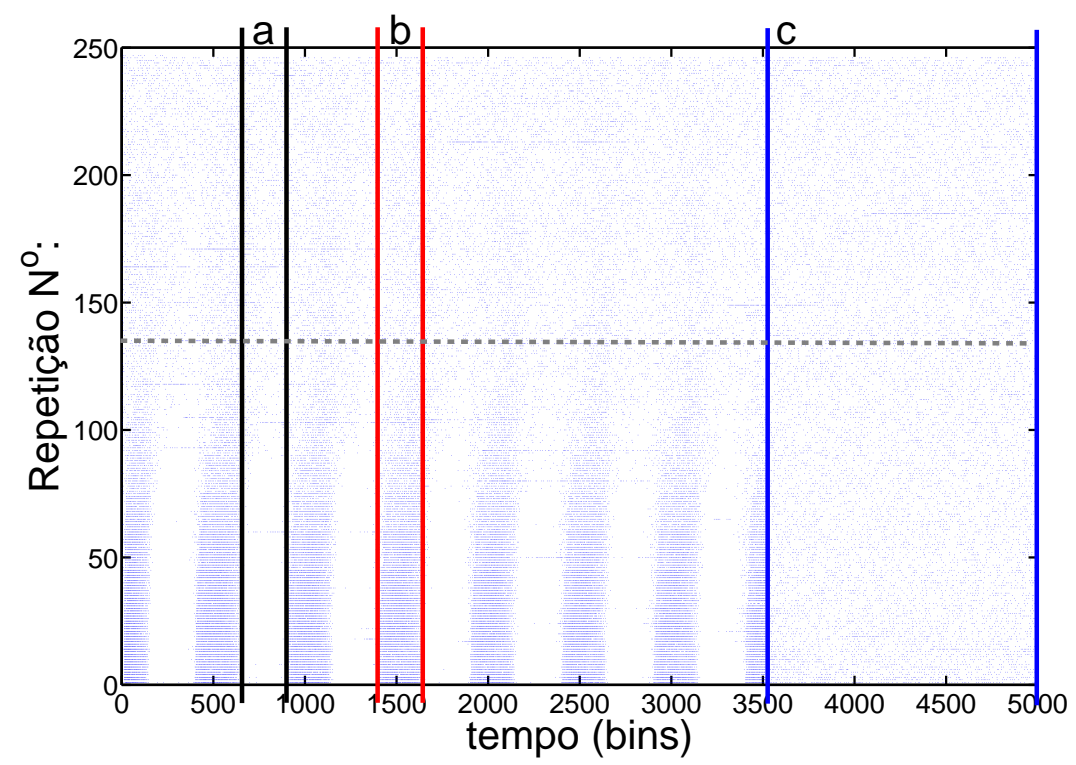

Figura 3.4 - Degradação da resposta neural. Delimitamos as regiões de inibição (a), ativação (b) e de disparo espontâneo (c) do neurônio H1. Notamos que não há distinção entre estas regiões após diminuirmos a amplitude do sinal senoidal até certo limiar. Valor aproximado do limiar marcado pela linha cinza tracejada.

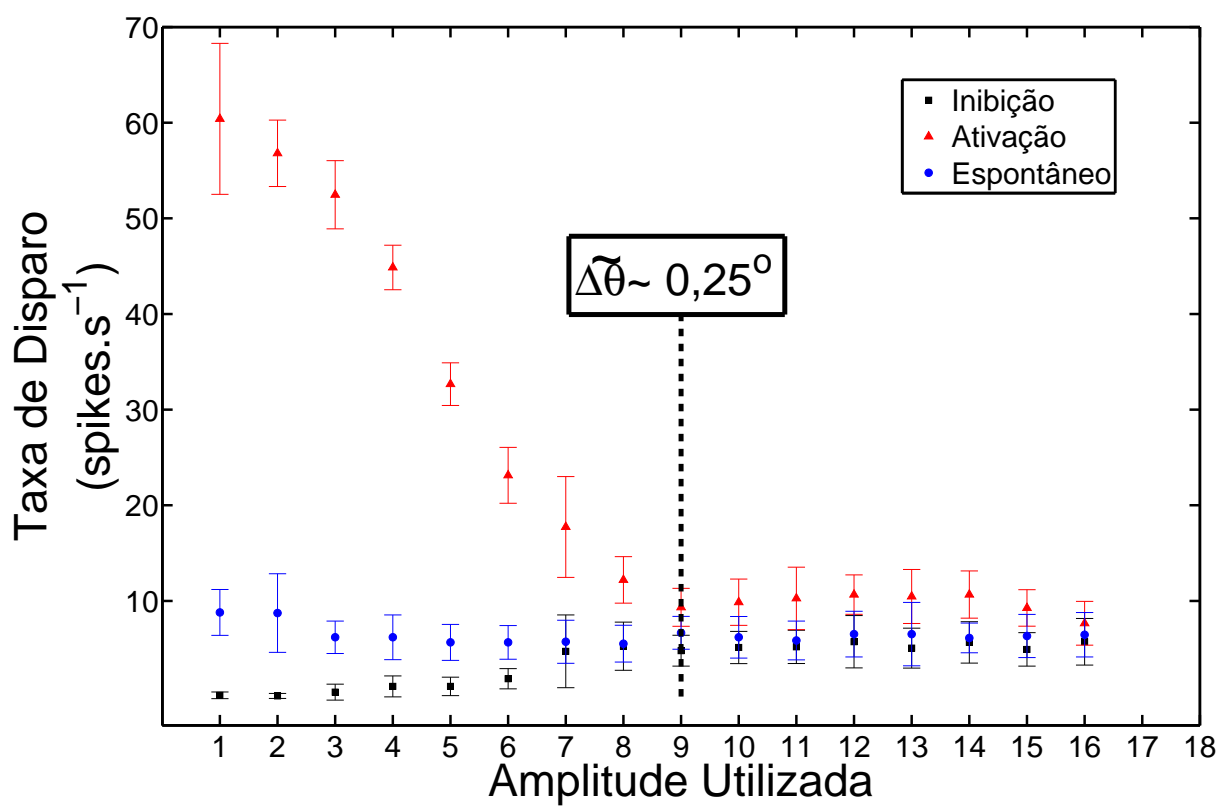

Figura 3.5 - Comparação entre taxas de disparo. Comparamos a taxa de disparo dos diferentes estímulos apresentados para a mosca. Os valores utilizados para as amplitudes encontram-se na Tabela 2. Em preto a taxa referente à inibição, em vermelho à ativação e em azul ao disparo espontâneo do neurônio H1. Calculamos as barras de erro através das diferenças presentes entre as repetições do estímulo. Vemos que as taxas igualam-se aproximadamente para amplitude $\widetilde{\Delta \theta} \simeq 0,25^{\circ}$. 
Desta forma, apresentamos um método, dadas as condições experimentais, para determinarmos quais os limites de detecção do organismo estudado e adequarmos nosso estímulo a suas limitações.

Estimamos de forma geométrica a abertura média dos omatídeos que compõem os olhos compostos da espécie estudada ${ }^{\ddagger}$, resultado em acordo com (84). Se considerarmos cada olho sendo composto por aproximadamente 5000 omatídeos e que estes estão dispostos numa rede regular de aproximadamente $70 \times 70$, cada um terá abertura de $120^{\circ} / 70 \simeq 1,7^{\circ}$ - consideramos a superfície de cada olho ocupando $120^{\circ}$ em cada direção e em cada hemisfério do campo visual (57). Desta forma sua abertura omatidial estimada é da ordem $\Delta \phi=1-2^{\circ}$ e muitas vezes considerada a precisão de seu sistema visual. Podemos afirmar que, sob nossas condições experimentais - temperatura, $23^{\circ} \mathrm{C}$; luminância, $4 c d . m^{-2}$; tempo de vida, 5 dias; imagem, 2.7(b) - há atividade do neurônio $H 1$ mesmo para deslocamentos de amplitude da ordem de quatro a oito vezes menores do que a abertura média $\Delta \phi$. Ou seja, ao projetarmos nossos experimentos, devemos considerar este alcance como sendo a efetiva precisão do sistema visual da mosca.

A atividade do neurônio $H 1$ como resposta a estes pequenos deslocamentos deve-se a um efeito coletivo da rede de omatídeos. Ao efetuarmos deslocamentos menores do que a abertura $\Delta \phi$ sobre uma imagem presente em grande parte do campo visual da mosca, e.g. nosso padrão de barras, ocorrerá variação de fluxo óptico em um número de omatídeos suficiente para causar atividade do neurônio $H 1$.

A velocidade mínima do estímulo, detectada pelo sistema visual da mosca sob nossas condições experimentais, é surpreendente. Uma mosca pode atingir velocidades, durante vôos de perseguição, até três ordens de magnitude maiores do que o valor " $\omega$ " encontrado, velocidades de até $3000^{\circ} \cdot s^{-1}(31,35-37)$. Este resultado revela que seu sistema visual está pelo menos adaptado a atuar em uma faixa de velocidades de $[1,5-3000]^{o} . s^{-1}$. O valor encontrado para o limite inferior deve variar com as condições experimentais apresentadas. Esta faixa de atuação é uma característica importante deste sistema que também deve ser considerada no processo de geração de estímulos.

Ambas características apontadas neste capítulo sobre o processo de detecção de movimento revelam uma grande precisão do sistema visual da mosca Chrysomya megacephala. Estas propriedades esclarecem algumas questões sobre os limites sensoriais deste organismo e mostram que nosso sistema de geração de estímulos satisfaz seus requisitos.

‡Uma tabela com o valor encontrado para diversas espécies de insetos pode ser encontrado em (80). 


\section{Reconstrução do Estímulo a partir do Trem de Pulsos}

Organismos vivos constroem uma representação do mundo exterior a partir das respostas de seu sistemas sensoriais afim de reagir às rápidas variações do ambiente. Em muitos casos a resposta do sistema sensorial é codificada em uma seqüencia de potenciais de ação, trem de pulsos. Se representarmos o mundo exterior por uma função dependente do tempo $s(t)$, estes sistemas sensoriais agem como um conversor analógico-digital. O processo inverso, decodificação da resposta neural, consiste em receber um conjunto de trens de pulsos e gerar uma estimativa $s_{e}(t)$ do estímulo. Neste capítulo estudamos este processo utilizando-se das respostas dos dois neurônios H1 da mosca.

A reconstrução do estímulo a partir da resposta neural requer a computação e subseqüente inversão de funções de correlação spike-spike. A dimensão das matrizes que representam estas funções podem se tornar proibitivamente grandes ao registrarmos múltiplos neurônios simultaneamente. Nas próximas seções apresentamos um eficiente método para reduzir estas funções de correlação. Esta aproximação tem baixo custo computacional, evita a inversão de grandes matrizes e nos dá um excelente resultado para a reconstrução do estímulo. Testamos a qualidade de nossa reconstrução sobre estímulos de rotação e translação.

Cada neurônio H1 é sensível a movimentos horizontais de trás para frente da cabeça da mosca, como mostrado na Figura 4.1. Em movimentos de translação o fluxo óptico recebido pelos olhos da mosca estimulam igualmente os dois neurônios H1 e devido sua interação ser inibitória, cada neurônio reduz efetivamente a atividade do outro. Em contraste, no movimento de rotação um neurônio é inibido enquanto o outro é excitado, fazendo com que o sistema formado pelos dois neurônios H1 atuem como um eficiente detector de rotação (9-11). O comportamento destes neurônios a ambos os estímulos pode ser visto no raster-plot da Figura 4.1. Mesmo ao registrarmos apenas um neurônio H1 podemos simular a resposta do H1 contralateral, já que a inversão do sentido do estímulo induz uma resposta no H1 ipsilateral típica de um H1 contralateral (72). Comparando as Figuras 4.1(b) e 4.1(c) vemos que este fato ocorre em uma boa aproximação. 


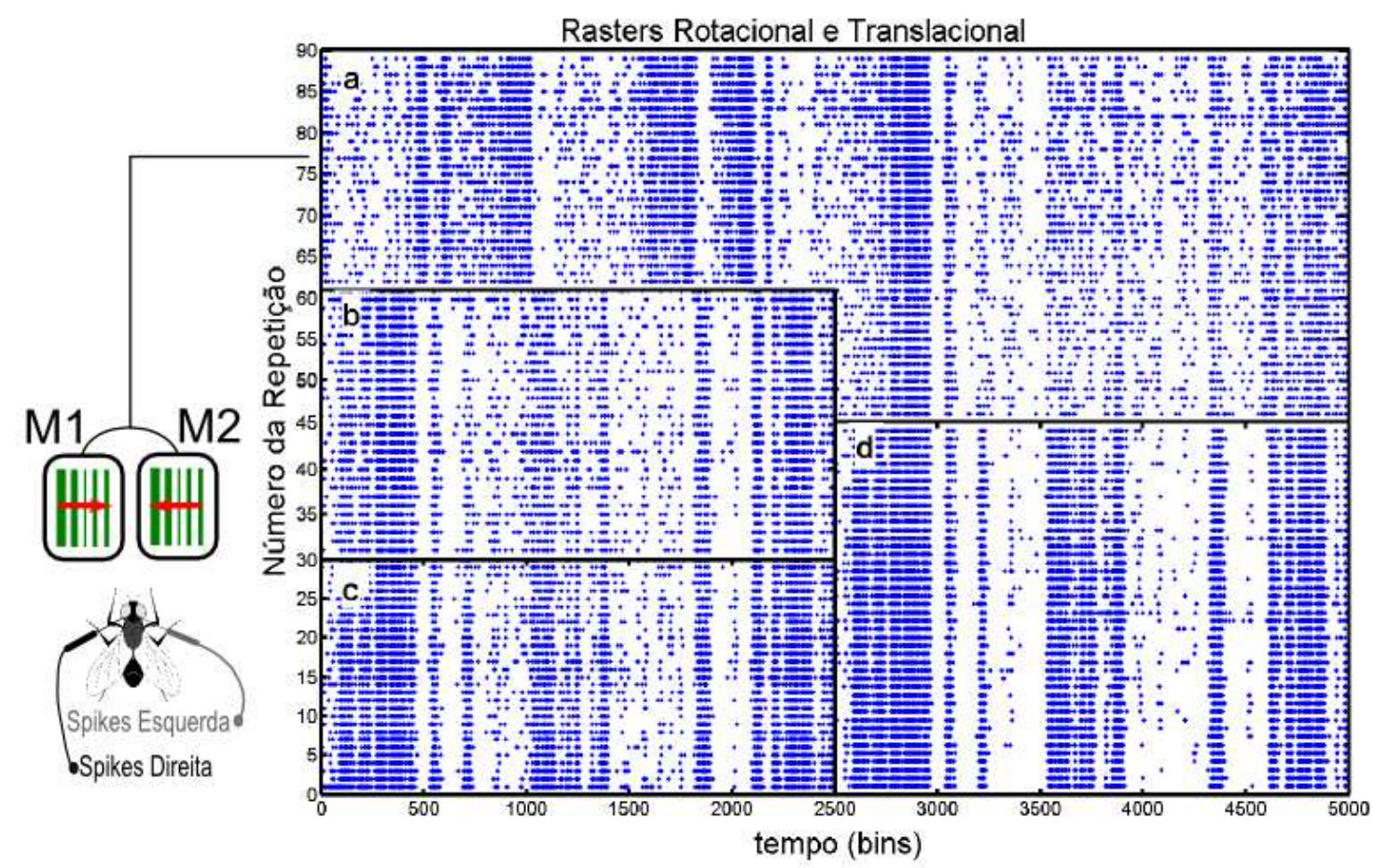

Figura 4.1 - Sensibilidade de movimento dos dois neurônios H1. Cada olho vê um monitor mostrando um padrão de barras que se move rigidamente. Os estímulos nos monitores M1 e M2 correspondem a um movimento de translação no qual ambos os neurônios estão sendo excitados. Invertendo o estímulo gerado pelo monitor M1, geramos um estímulo rotacional que inibe a resposta do neurônio esquerdo. Vemos também um "raster-plot" da atividade dos dois neurônios $\mathrm{H} 1$ sob a ação dos estímulos rotacional e de translação, cada ponto representa um spike. O mesmo estímulo dependente do tempo $s(t)$ é mostrado repetidamente para a mosca. O eixo horizontal indica tempos de zero até 5000bins $=10$ segundos. O eixo vertical representa o número da repetição do estímulo $s(t)$. (a) $\mathrm{H} 1$ direito sujeito ao estímulo $s_{d}(t)=s(t)$. (b) $\mathrm{H} 1$ esquerdo sujeito ao estímulo rotacional, i.e. o estímulo do monitor esquerdo $s_{e}(t)=s(t)$. (c) $\mathrm{H} 1$ direito sujeito ao sinal rotacional invertido $s_{d}(t)=-s(t)$ para simular a resposta vista em (b). (d) $\mathrm{H} 1$ esquerdo sujeito ao estímulo de translação $s_{e}(t)=-s(t)$.

\subsection{Uma estimativa do estímulo}

Primeiramente ilustramos o procedimento de reconstrução do estímulo $s(t)$ a partir da resposta de um único neurônio H1. Representamos sua resposta como um trem de pulsos $\rho(t)=\sum_{i=1}^{N_{s}} \delta\left(t-t_{i}\right)$. Onde $N_{s}$ é o número total de spikes gerados pelo neurônio ao longo do experimento. A forma mais simples de reconstrução do estímulo é via uma transformação linear (72), 


$$
s_{e}(t)=\int_{-\infty}^{\infty} k_{1}(\tau) \rho(t-\tau) d \tau
$$

com o núcleo $k_{1}(\tau)$ a ser determinado. Por simplicidade usamos uma reconstrução acausal, i.e. integramos $\rho(t-\tau)$ em $\pm \infty$. Essencialmente os mesmos resultados são obtidos na reconstrução causal* .

A equação 4.1 representa o primeiro termo da série Volterra (46):

$$
s_{e}(t)=\int_{-\infty}^{\infty} k_{1}(\tau) \rho(t-\tau) d \tau+\int_{-\infty}^{\infty} k_{2}\left(\tau_{1}, \tau_{2}\right) \rho\left(t-\tau_{1}\right) \rho\left(t-\tau_{2}\right) d \tau_{1} d \tau_{2}+\ldots
$$

Não há prova de convergência para esta expansão. Entretanto, heuristicamente podemos afirmar que esta é válida se o número médio de spikes que ocorrem durante um período igual ao tempo de correlação do estímulo é pequeno (72). Esta grandeza é medida por,

$$
\eta=\langle r\rangle \tau_{c}
$$

onde $\langle r\rangle$ e $\tau_{c}$ são a taxa média de disparos do neurônio e o tempo de correlação do estímulo, respectivamente. Para valores pequenos de $\eta$ cada spike carrega individualmente informação sobre o estímulo. Em nossos experimentos obtemos $\eta \sim 0,6-0,8$. Para estes valores esperamos que efeitos de correlação spike-spike de mais alta ordem, introduzidos por $k_{2}$, tornem-se relevantes.

Para obtermos o núcleo $k_{1}$ e posteriormente $k_{2}^{\dagger}$, escolhemos minimizar o seguinte funcional $\chi^{2}$,

$$
\chi^{2}\left(k_{1}, k_{2}\right)=\left\langle\int d t\left[s(t)-s_{e}(t)\right]^{2}\right\rangle_{S} \equiv\left\langle\left[s(t)-s_{e}(t)\right]^{2}\right\rangle_{t} .
$$

Onde $\langle\bullet\rangle_{S}$ representa a média sobre a distribuição de estímulos. Esta média é omitida ao considerarmos o sistema ergódico. Numericamente a integral no tempo é substituída pela soma sobre $N_{w} \sim 10^{5}$ janelas temporais de tamanho $T_{w}$. Tipicamente $T_{w} \sim 100$ milissegundos.

\footnotetext{
* Neste caso a equação 4.1 torna-se: $s_{e}(t)=\int_{-t_{0}}^{\infty} k_{1}(\tau) \rho(t-\tau) d \tau$.

${ }^{\dagger}$ Podemos incluir o termo de segunda ordem $k_{2}$ como uma correção ao termo de primeira ordem, $s_{1}(t)=$ $k_{1} \star \rho(t)$, ou resolver o sistema acoplado 4.5. O símbolo $\star$ representa uma convolução como na equação 4.1
} 
Uma vez que o funcional da equação 4.4 é quadrático, as equações que o minimizam são lineares:

$$
\delta \chi / \delta k_{j}=0 ; j=1,2
$$

Ao manter apenas $k_{1}$, obtemos:

$$
\begin{gathered}
\chi^{2}=\left\langle\left[s(t)-s_{e}(t)\right]^{2}\right\rangle_{t} \\
\frac{\delta \chi^{2}}{\delta k_{1}(\tau)}=\left\langle 2\left[s(t)-s_{e}(t)\right] \frac{\delta s_{e}(t)}{\delta k_{1}\left(\tau^{\prime}\right)}\right\rangle_{t}=0 \\
\left\langle s(t) \frac{\delta s_{e}(t)}{\delta k_{1}\left(\tau^{\prime}\right)}\right\rangle_{t}=\left\langle s_{e}(t) \frac{\delta s_{e}(t)}{\delta k_{1}\left(\tau^{\prime}\right)}\right\rangle_{t} .
\end{gathered}
$$

Para determinar ambos os lados desta igualdade calculamos,

$$
\begin{aligned}
\frac{\delta s_{e}(t)}{\delta k_{1}\left(\tau^{\prime}\right)} & =\frac{\delta\left(\int_{-\infty}^{\infty} k_{1}(\tau) \rho(t-\tau) d \tau\right)}{\delta k_{1}\left(\tau^{\prime}\right)} \\
& =\int_{-\infty}^{\infty} \frac{\delta k_{1}(\tau)}{\delta k_{1}\left(\tau^{\prime}\right)} \rho(t-\tau) d \tau \\
& =\int_{-\infty}^{\infty} \delta\left(\tau-\tau^{\prime}\right) \rho(t-\tau) d \tau \\
\frac{\delta s_{e}(t)}{\delta k_{1}\left(\tau^{\prime}\right)} & =\rho\left(t-\tau^{\prime}\right) .
\end{aligned}
$$

Substituindo este resultado em 4.6 obtemos:

$$
\left\langle s(t) \rho\left(t-\tau^{\prime}\right)\right\rangle_{t}=\int_{-\infty}^{\infty} d \tau k_{1}(\tau)\left\langle\rho(t-\tau) \rho\left(t-\tau^{\prime}\right)\right\rangle_{t}
$$

Podemos resolver a equação anterior de duas maneiras:

1. Utilizando o teorema da convolução. A transformada de Fourier de duas funções convoluídas no domínio do tempo é igual ao produto das transformadas das duas funções no domínio da freqüência.

$$
\begin{aligned}
F\left[\left\langle s(t) \rho\left(t-\tau^{\prime}\right)\right\rangle_{t}\right] \times T_{w} & =\tilde{s}(\omega) \tilde{\rho}^{*}(\omega) \\
F\left[\left\langle\rho(t-\tau) \rho\left(t-\tau^{\prime}\right)\right\rangle_{t}\right] \times T_{w} & =\tilde{\rho}(\omega) \tilde{\rho}^{*}(\omega) \\
\tilde{k}_{1}(\omega) & =\frac{\tilde{s}(\omega) \tilde{\rho}^{*}(\omega)}{\tilde{\rho}(\omega) \tilde{\rho}^{*}(\omega)} \\
k_{1}(t) & =F^{-1}\left[\tilde{k}_{1}(w)\right],
\end{aligned}
$$


onde a transformada de Fourier é definida como $\tilde{g}(\omega)=\int d t g(t) e^{\imath \omega t}$ e sua inversa $g(t)=\int(d \omega / 2 \pi) \tilde{g}(\omega) e^{-\imath \omega t}$.

2. Ou podemos resolver 4.8 de forma matricial. Definindo,

$$
\begin{aligned}
S R_{\tau} & \equiv\left\langle s(t) \rho\left(t-\tau^{\prime}\right)\right\rangle_{t} \\
R_{\tau \tau^{\prime}} & \equiv\left\langle\rho(t-\tau) \rho\left(t-\tau^{\prime}\right)\right\rangle_{t}
\end{aligned}
$$

obtemos:

$$
k_{1}(\tau)=R_{\tau \tau^{\prime}}^{-1} \cdot S R_{\tau}
$$

Através de ambos os métodos podemos determinar o núcleo de primeira ordem $k_{1}$ e, a partir da equação 4.1 , obter uma estimativa $s_{e}(t)$ do estímulo $s(t)$.

Vejamos o que acontece caso registremos simultaneamente ambos H1. Primeiramente obtemos dois trens de pulsos, $\rho_{1}(t)$ e $\rho_{2}(t)$. A equação expandida 4.2 generaliza-se para:

$$
s_{e}(t)=K_{1} \star \rho_{1}(t)+K_{2} \star \rho_{2}(t)+K_{11} \star \rho_{1} \star \rho_{1}(t)+K_{12} \star \rho_{1} \star \rho_{2}(t)+K_{22} \star \rho_{2} \star \rho_{2}(t)+\ldots
$$

Nesta equação incluímos o núcleo $K_{12}$, o qual deve ser importante para codificar efeitos correlacionando $\rho_{1}$ e $\rho_{2}^{\ddagger}$.

Em primeira ordem, mantendo apenas $K_{1}$ e $K_{2}$ na expansão 4.12, teremos:

$$
s_{e}(t)=K_{1} \star \rho_{1}(t)+K_{2} \star \rho_{2}(t)=\sum_{a=1}^{2} K_{a} \star \rho_{a}(t) .
$$

Equivalentemente à equação 4.8 obtemos as seguintes equações:

$$
S_{b}\left(t_{2}\right)=\sum_{a=1}^{2} \int_{\infty}^{\infty} d t_{1} K_{a}\left(t_{1}\right) R_{a b}\left(t_{1}, t_{2}\right) ; b=1,2 .
$$

Onde,

$$
\begin{aligned}
S R_{b}\left(t_{2}\right) & =\left\langle s\left(t_{1}\right) \rho_{b}\left(t_{1}-t_{2}\right)\right\rangle_{t_{1}} ; b=1,2 \\
R_{a b}\left(t_{1}, t_{2}\right) & =\left\langle\rho_{a}\left(t-t_{1}\right) \rho_{b}\left(t-t_{2}\right)\right\rangle_{t} ; a, b=1,2 .
\end{aligned}
$$

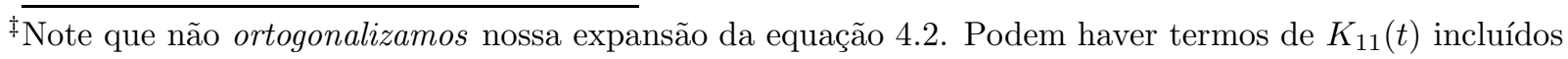
em $K_{1}(t)$. 
Devido a invariância translacional no tempo, $R_{a b}\left(t_{1}, t_{2}\right)$ é apenas uma função da diferença: $R_{a b}\left(t_{1}, t_{2}\right)=R_{a b}\left(t_{1}-t_{2}\right)$. Esta propriedade está presente em todas as funções de correlação envolvendo $\rho(t)$. Pelo método do teorema da convolução, obtemos as seguintes equações:

$$
\begin{gathered}
\tilde{s}(\omega){\tilde{\rho_{1}}}^{*}(\omega)=\tilde{K}_{1}(\omega)\left[\tilde{\rho}_{1}(\omega){\tilde{\rho_{1}}}^{*}(\omega)\right]+\tilde{K}_{2}(\omega)\left[{\tilde{\rho_{1}}}(\omega){\tilde{\rho_{2}}}^{*}(\omega)\right] \\
\tilde{s}(\omega){\tilde{\rho_{2}}}^{*}(\omega)=\tilde{K}_{1}(\omega)\left[{\tilde{\rho_{2}}}(\omega){\tilde{\rho_{1}}}^{*}(\omega)\right]+\tilde{K}_{2}(\omega)\left[\tilde{\rho}_{2}(\omega){\tilde{\rho_{2}}}^{*}(\omega)\right] .
\end{gathered}
$$

Cuja solução é dada por,

$$
\begin{aligned}
& \tilde{K}_{1}(\omega)=\frac{\left[\tilde{s}(\omega){\tilde{\rho_{1}}}^{*}(\omega)\right]\left\|{\tilde{\rho_{2}}}^{*}(\omega)\right\|^{2}-\left[\tilde{s}(\omega){\tilde{\rho_{2}}}^{*}(\omega)\right]\left[{\tilde{\rho_{1}}}(\omega){\tilde{\rho_{2}}}^{*}(\omega)\right]}{\left.\left\|\tilde{\rho_{1}}(\omega)\right\|\right|^{2}\left\|{\tilde{\rho_{2}}}(\omega)\right\|^{2}-\left\|\tilde{\rho_{1}}(\omega){\tilde{\rho_{2}}}^{*}(\omega)\right\|^{2}} \\
& \tilde{K}_{2}(\omega)=\frac{\left[\tilde{s}(\omega){\tilde{\rho_{2}}}^{*}(\omega)\right]\left\|{\tilde{\rho_{1}}}^{*}(\omega)\right\|^{2}-\left[\tilde{s}(\omega){\tilde{\rho_{1}}}^{*}(\omega)\right]\left[{\tilde{\rho_{2}}}(\omega){\tilde{\rho_{1}}}^{*}(\omega)\right]}{\left\|{\tilde{\rho_{1}}}(\omega)\right\|^{2}|| \tilde{\rho}_{2}(\omega)\left\|^{2}-\right\|{\tilde{\rho_{1}}}(\omega){\tilde{\rho_{2}}}^{*}(\omega) \|^{2}} .
\end{aligned}
$$

Alternativamente poderíamos resolver 4.14 através de sua solução matricial.

Uma vez que a contribuição de segunda ordem é pequena, podemos finalmente incluir os termos $K_{11}, K_{12}$ e $K_{22}$ da equação 4.12 pertubativamente e reconstruirmos $s_{2}(t)=$ $s(t)-s_{1}(t), s_{1}(t)=k_{1} \star \rho(t)$. Equivalentemente à 4.8 e 4.14 , resolvemos as seguintes equações:

$$
S R_{a b}^{(2)}\left(t_{1}, t_{2}\right)=\int d t_{3} d t_{4} \sum_{c, d=1}^{2} K_{c d}\left(t_{1}, t_{2}\right) R_{a b c d}^{(4)}\left(t_{1}, t_{2}, t_{3}, t_{4}\right) ; a, b=1,2
$$

Onde,

$$
\begin{aligned}
S R_{a b}^{(2)}\left(t_{1}, t_{2}\right)= & \int d t\left\langle s_{2}(t) \rho_{a}\left(t-t_{1}\right) \rho_{b}\left(t-t_{2}\right)\right\rangle ; a, b=1,2 \\
R_{a b c d}^{(4)}\left(t_{1}, t_{2}, t_{3}, t_{4}\right)= & \int d t\left\langle\rho_{a}\left(t-t_{1}\right) \rho_{b}\left(t-t_{2}\right) \rho_{c}\left(t-t_{3}\right) \rho_{d}\left(t-t_{4}\right)\right\rangle ; \\
& a, b, c, d=1,2 .
\end{aligned}
$$

Resolvemos o sistema 4.19 pelo método matricial. Apesar deste sistema ser linear, encontramos dificuldade em resolvê-lo devido ao grande número de elementos contidos nas matrizes a serem invertidas. Teremos que inverter as seguintes matrizes:

$$
\mathcal{M}_{I J} \equiv R_{a b c d}^{(4)}\left(t_{1}, t_{2}, t_{3}, t_{4}\right)
$$


onde $I=\left[a, b, t_{1}, t_{2}\right]$ e $J=\left[c, d, t_{3}, t_{4}\right]$ são índices compostos que rotulam ambos neurônios e os índices de tempo. Ao computarmos a função de correlação usando uma janela temporal de $T_{w}=128$ bins, teremos $128^{4} \times 2^{4} \sim 5 \times 10^{9}$ elementos contidos na matriz $\mathcal{M}_{I J}$. Estas matrizes podem se tornar proibitivamente grandes, especialmente se registrarmos mais do que dois neurônios.

Apresentamos a seguir uma aproximação para $R_{a b c d}^{(4)}\left(t_{1}, t_{2}, t_{3}, t_{4}\right)$ de baixo custo computacional, que evita a inversão de grandes matrizes e nos dá um excelente resultado para a reconstrução do estímulo.

\subsection{Escolhendo um conjunto adequado de funções}

Expandimos os núcleos e as funções de correlação em um conjunto completo de funções $f_{\mu}(t), \mu=1,2, . ., n_{f}$ :

$$
\begin{aligned}
K_{a b}\left(t_{1}, t_{2}\right) & =\sum_{\mu . \nu}^{n_{f}} f_{\mu}\left(t_{1}\right) f_{\nu}\left(t_{2}\right) \mathcal{D}_{\mu \nu}^{a b} \\
S R_{a b}^{(2)}\left(t_{1}, t_{2}\right) & =\sum_{\mu . \nu}^{n_{f}} f_{\mu}\left(t_{1}\right) f_{\nu}\left(t_{2}\right) \mathcal{S}_{\mu \nu}^{a b} \\
R_{a b c d}^{(4)}\left(t_{1}, t_{2}, t_{3}, t_{4}\right) & =\sum_{\alpha \beta \mu . \nu}^{n_{f}} f_{\alpha}\left(t_{1}\right) f_{\beta}\left(t_{2}\right) f_{\mu}\left(t_{3}\right) f_{\nu}\left(t_{4}\right) \mathcal{R}_{\alpha \beta \mu \nu}^{a b c d} .
\end{aligned}
$$

Substituindo as expansões acima na equação 4.19, obtemos um conjunto linear de equações a ser resolvido para determinarmos $\mathcal{D}_{\mu \nu}^{a b}$ :

$$
\mathcal{S}_{\mu \nu}^{a b}=\sum_{c d, \alpha \beta} \mathcal{R}_{\alpha \beta \mu \nu}^{a b c d} \mathcal{D}_{\alpha \beta}^{c d}
$$

Usualmente a expansão de Fourier é escolhida, i.e. $f_{\omega}=e^{\imath \omega t}$. Entretanto, aproveitamos nossa liberdade de escolha de uma maneira mais vantajosa. Uma vez que nossa função de dois pontos $R\left(t_{1}, t_{2}\right)$ é real, positiva ${ }^{\S}$ e simétrica em $\left[t_{1}, t_{2}\right]$, esta contém um conjunto completo de auto-funções $h_{\mu}(t)$ :

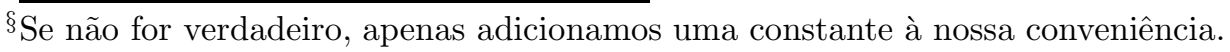




$$
\int d t_{2} R\left(t_{1}, t_{2}\right) h_{\mu}\left(t_{2}\right)=r_{\mu} h_{\mu}\left(t_{1}\right)
$$

com auto-valores $r_{\mu}$. Desta forma, escolhemos nossas funções como $f_{\mu}(t)=h_{\mu}(t) / \sqrt{r_{\mu}}$, que satisfaçam:

$$
\int d t_{1} d t_{2} f_{\mu}\left(t_{1}\right) R\left(t_{1}, t_{2}\right) f_{\nu}\left(t_{2}\right)=\delta_{\mu \nu}
$$

Esta escolha evita a necessidade de inversão das matrizes $R^{(4)}\left(t_{1}, t_{2}, t_{3}, t_{4}\right)$ se estas puderem ser escritas a partir de $R\left(t_{1}, t_{2}\right)$.

Apresentamos em detalhe nas próximas seções como esta aproximação é feita tanto para o caso de apenas um neurônio quanto para o caso em que registramos o sinal neural de ambos neurônios H1.

\subsection{Aproximação "Gaussiana" para um H1}

Nesta seção apresentamos uma aproximação que evita o cálculo exato da matriz $R^{(4)}\left(t_{1}, t_{2}, t_{3}, t_{4}\right) \equiv R_{1111}^{(4)}\left(t_{1}, t_{2}, t_{3}, t_{4}\right)$. Como registramos a resposta de apenas um neurônio $\mathrm{H} 1$, omitimos os índices $a, b, \ldots$, pois todos são igual a 1.

Para que a escolha das funções $f_{\mu}$ feita na seção anterior, torne-se útil, temos que expressar nossa função de quatro pontos $R^{(4)}$ em termos de $R(t) \equiv R_{11}\left(t_{1}, t_{2}\right)$. Se nosso processo de geração de spikes fosse Gaussiano, teríamos ${ }^{\mathbb{I}}$ :

$$
R^{(4)}(1,2,3,4)=R(1,2) R(3,4)+R(1,3) R(2,4)+R(1,4) R(2,3)-2\langle\rho(t)\rangle^{4},
$$

onde $\langle\rho(t)\rangle$ é apenas uma constante, devido sua invariância translacional no tempo.

Isto sugere a seguinte aproximação para $R^{(4)}$ :

$$
R^{(4)}(1,2,3,4)=A[R(1,2) R(3,4)+R(1,3) R(2,4)+R(1,4) R(2,3)]-B,
$$


onde $A$ e $B$ são parâmetros a serem ajustados" .

Realizamos o procedimento de minimização de $\chi^{2}$ (eq. 4.6) agora em função de $\mathcal{D}_{\mu \nu} \equiv$ $\mathcal{D}_{\mu \nu}^{11}$, definido na equação 4.23 ,

$$
\begin{array}{r}
s_{e}(t)=\int d t_{1} d t_{2}\left(\sum_{\mu, \nu}^{n_{f}} f_{\mu}\left(t_{1}\right) f_{\nu}\left(t_{2}\right) \mathcal{D}_{\mu \nu}\left(t_{1}, t_{2}\right)\right) \rho\left(t-t_{1}\right) \rho\left(t-t_{2}\right) \\
\frac{\delta s_{e}(t)}{\delta \mathcal{D}_{\alpha \beta}\left(t_{3}, t_{4}\right)}=\int d t_{3} d t_{4} f_{\alpha}\left(t_{3}\right) f_{\beta}\left(t_{4}\right) \rho\left(t-t_{3}\right) \rho\left(t-t_{4}\right) .
\end{array}
$$

Substituindo as equações anteriores em $\mathcal{R}_{\mu \nu \alpha \beta}=\left\langle s_{e}(t) \frac{\delta s_{e}(t)}{\delta \mathcal{D}_{\alpha \beta}\left(t_{3}, t_{4}\right)}\right\rangle_{t}$ e utilizando 4.28 e 4.30 , obtemos,

$$
\mathcal{R}_{\mu \nu \alpha \beta}=A\left(\delta_{\mu \nu} \delta_{\alpha \beta}+2 \delta_{\mu \alpha} \delta_{\nu \beta}\right)-2 B n_{\alpha} n_{\beta} n_{\mu} n_{\nu}
$$

onde $n_{\mu}=\int d t f_{\mu}(t)\langle\rho(t)\rangle$.

Substituindo esta expressão em 4.26 e usando a abreviação $\mathcal{S}_{\mu \nu} \equiv \mathcal{S}_{\mu \nu}^{11}$, efetuamos sua soma e obtemos a seguinte equação para determinarmos os coeficientes $\mathcal{D}_{\mu \nu}$,

$$
\mathcal{S}_{\mu \nu}=A\left[\operatorname{tr}(\mathcal{D}) \delta_{\mu \nu}+2 \mathcal{D}_{\mu \nu}\right]-2 B D_{n n} n_{\nu} n_{\mu}
$$

onde $\operatorname{tr}(\mathcal{D}) \equiv \sum_{\mu} \mathcal{D}_{\mu \mu}$ e $D_{n n} \equiv \sum_{\alpha \beta} n_{\alpha} \mathcal{D}_{\alpha \beta} n_{\beta}$. Não podemos determinar $\mathcal{D}_{\mu \nu}$ diretamente desta equação sem conhecermos os valores de $\operatorname{tr}(\mathcal{D})$ e $D_{n n}$. Para resolver este sistema procedemos da seguinte forma:

1. Calculamos o traço de $\mathcal{S}_{\mu \nu}$ para obter $\operatorname{tr}(\mathcal{D})$ e

2. Multiplicamos a equação 4.34 por $\left[n_{\mu}, n_{\nu}\right]$ e somamos ambos os índices para obter $D_{n n}$.

Desta forma obtemos,

$$
\mathcal{D}_{\mu \nu}=\left[\mathcal{S}_{\mu \nu} / A-\operatorname{tr}(\mathcal{D}) \delta_{\mu \nu}+2 B n_{\mu} n_{\nu} D_{n n}\right] / 2
$$

com

\footnotetext{
\| $\overline{\text { Qualquer estrutura construída apenas por }} R\left(t_{1}, t_{2}\right)$ pode ser usada em nosso método.
} 


$$
\begin{aligned}
\operatorname{tr}(\mathcal{D}) & =\left[2\left(1-n_{4}\right) \operatorname{tr}(\mathcal{S})+2 n_{2} n_{\mu} \mathcal{S}_{\mu \nu} n_{\nu}\right] / \Delta, \\
D_{n n} & =\left[(n+2) n_{\mu} \mathcal{S}_{\mu \nu} n_{\nu}-\operatorname{tr}(\mathcal{S}) n_{2}\right] / \Delta, \\
\Delta & =2\left(T_{w}+2\right)\left(1-n_{4}\right)+2 n_{2} \\
n_{2} & \equiv \sum_{\mu} n_{\mu} n_{\mu} ; n_{4} \equiv\left(n_{2}\right)^{2} ; \operatorname{tr}(\mathcal{S}) \equiv \sum_{\mu} \mathcal{S}_{\mu \mu}
\end{aligned}
$$

A qualidade da aproximação realizada na equação 4.30 é inesperadamente boa mesmo a geração de spikes não sendo Gaussiana. Analisamos esta qualidade em mais detalhes nas próximas seções.

\subsection{Aproximação "Gaussiana" para dois H1}

Ao registrarmos a resposta dos dois neurônios $\mathrm{H} 1$ simultaneamente introduzimos uma série de fatores que envolvem termos cruzados de $\rho_{1}(t)$ e $\rho_{2}(t)$. Estes termos aumentam consideravelmente a complexidade do sistema de equações a ser resolvido (eq. 4.19). A solução deste sistema na sua forma matricial pode ser escrita da seguinte forma**:

$$
\begin{aligned}
S R_{I}^{(2)} & =\mathcal{M}_{I J} \cdot K_{J} \\
K_{J} & =\mathcal{M}_{I J}^{-1} \cdot S R_{I}^{(2)}
\end{aligned}
$$

O vetor $S R_{I}^{(2)}$ e a matriz $\mathcal{M}_{I J}$ podem ser expressos como:

$$
\begin{aligned}
S R_{I}^{(2)} & \equiv\langle S C D\rangle_{34} \equiv\left\langle s(t) \rho_{C}\left(t-t_{3}\right) \rho_{D}\left(t-t_{4}\right)\right\rangle \\
\mathcal{M}_{I J} & \equiv\langle A B C D\rangle_{1234} \equiv\left\langle\rho_{A}\left(t-t_{1}\right) \rho_{B}\left(t-t_{2}\right) \rho_{C}\left(t-t_{3}\right) \rho_{D}\left(t-t_{4}\right)\right\rangle
\end{aligned}
$$

Podemos reescrever a equação 4.36,

\footnotetext{
** Usamos a mesma notação de índice composto como na equação 4.22 .
} 


$$
\begin{aligned}
\langle S 11\rangle_{34} & =K_{11}\left[\langle 1111\rangle_{1234}+\langle 1112\rangle_{1234}+\langle 1122\rangle_{1234}\right] \\
\langle S 12\rangle_{34} & =K_{12}\left[\langle 1211\rangle_{1234}+\langle 1212\rangle_{1234}+\langle 1222\rangle_{1234}\right] \\
\langle S 22\rangle_{34} & =K_{22}\left[\langle 2211\rangle_{1234}+\langle 2212\rangle_{1234}+\langle 2222\rangle_{1234}\right]
\end{aligned}
$$

onde cada termo $\langle A B C D\rangle_{1234}$ é posteriormente expandido conforme $4.30^{\dagger \dagger}$.

No caso particular dos dois neurônios H1, podemos simplificar o sistema de equações obtido ao negligenciar os termos $R^{12}=\langle 12\rangle_{a b}$. Seu efeito é certamente muito pequeno quando comparado com $R^{11}$ ou $R^{22}$. Mesmo para estímulos de translação, onde ambos neurônios disparam em sincronia, o pico dominante visto em $R^{11}$ e $R^{22}$ não é obtido na função $R^{12}$, Figura 4.2. Isto ocorre devido esta sincronia não ser exata e a ausência deste pico faz com que sua contribuição seja mínima.

Vemos o efeito de $R^{12}$ em $K_{12}$. A matriz $K_{12}$ é da ordem de cinco vezes menor do que $K_{11}$ ou $K_{22}$, como ilustrado na Figura 4.3. Desta forma, podemos desacoplar nossas equações e obter seus núcleos de forma independente para cada neurônio:

$$
\begin{aligned}
& \langle S 11\rangle_{34}=\tilde{K}_{11}\left\{A_{1111}\left[\langle 11\rangle_{12}\langle 11\rangle_{34}+\langle 11\rangle_{13}\langle 11\rangle_{24}+\langle 11\rangle_{14}\langle 11\rangle_{23}\right]-B_{1111}\right\} \\
& \langle S 22\rangle_{34}=\tilde{K}_{22}\left\{A_{2222}\left[\langle 22\rangle_{12}\langle 22\rangle_{34}+\langle 22\rangle_{13}\langle 22\rangle_{24}+\langle 22\rangle_{14}\langle 22\rangle_{23}\right]-B_{2222}\right\}
\end{aligned}
$$

A qualidade de nossa representação Gaussiana depende do ajuste de nossa aproximação à função experimental e conseqüentemente, do conhecimento das constantes $A_{1111}$, $B_{1111}, A_{2222}$ e $B_{2222}$. Esta aproximação não faria sentido caso fosse necessário o cálculo exato da função de quatro pontos - exatamente o que gostaríamos de evitar, especialmente para tamanhos de janela $T_{W}$ grandes. Sendo assim, ajustamos as constantes $A_{a b c d}$ e $B_{a b c d}$ utilizando apenas a primeira linha da matriz $R_{a b c d}^{(4)}$. Como pode ser visto na Figura 4.4, pelo menos no caso do neurônio H1, a dependência destas constantes com a largura $T_{W}$ é de aproximadamente 0,05\%, sendo completamente negligenciável. Esta pequena variação torna possível calcularmos facilmente estes parâmetros em janelas menores e utilizá-los em maiores $T_{W}$. Na Figura 4.5 mostramos o ajuste feito sobre a primeira linha da matriz $R_{1111}^{(4)}$. Como citado anteriormente, obtemos um perfeito ajuste ao transformamos a função de quatro pontos puramente Gaussiana na função experimental, utilizando-se dos parâmetros $A_{1111}$ e $B_{1111}$.

${ }^{\dagger} \overline{\langle A B\rangle_{12} \equiv\left\langle\rho_{A}\left(t-t_{1}\right) \rho_{B}\left(t-t_{2}\right)\right\rangle}$ 


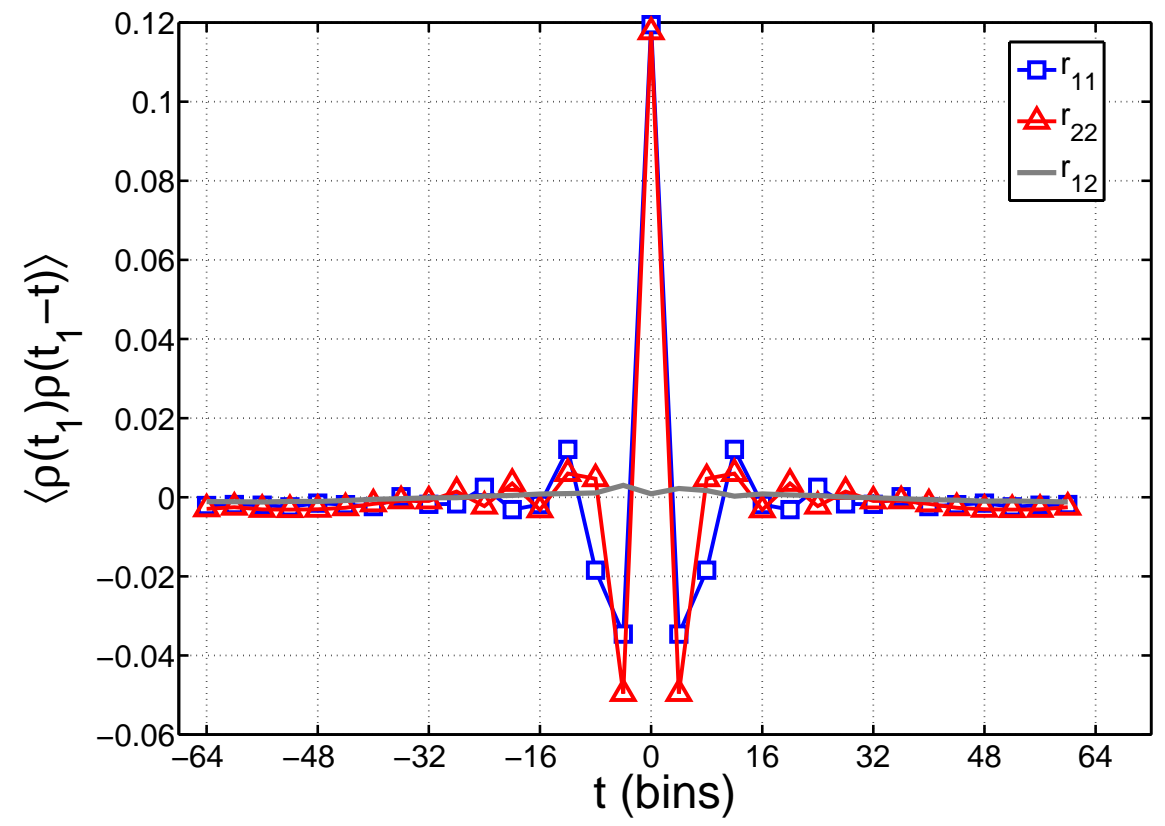

Figura 4.2- $\boldsymbol{R}^{11}, \boldsymbol{R}^{22}$ e $\boldsymbol{R}^{12}$. Comparação entre as funções de correlação $R^{a b}(t)=\int d t_{1}\left\langle\rho_{a}\left(t_{1}-\right.\right.$ t) $\left.\rho_{b}\left(t_{1}\right)\right\rangle$.

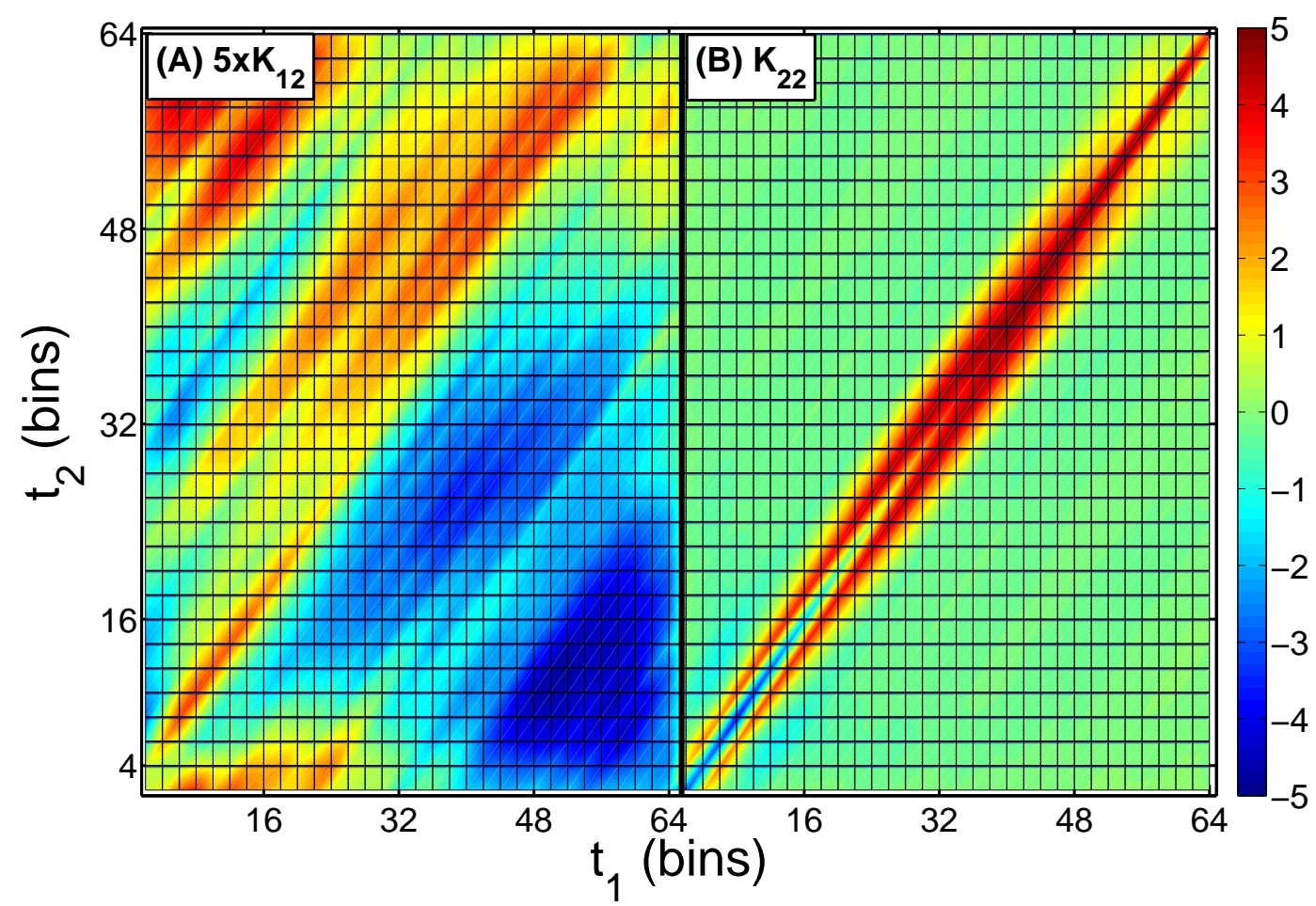

Figura 4.3 - Núcleos de segunda ordem. Núcleos de segunda ordem $K_{22}$ e uma versão reescalada de $K_{12}$ para $T_{w}=64$. (a) $5 \times K_{12}$, (b) $K_{22}$. Note que $K_{22} / K_{12} \sim 5$. 


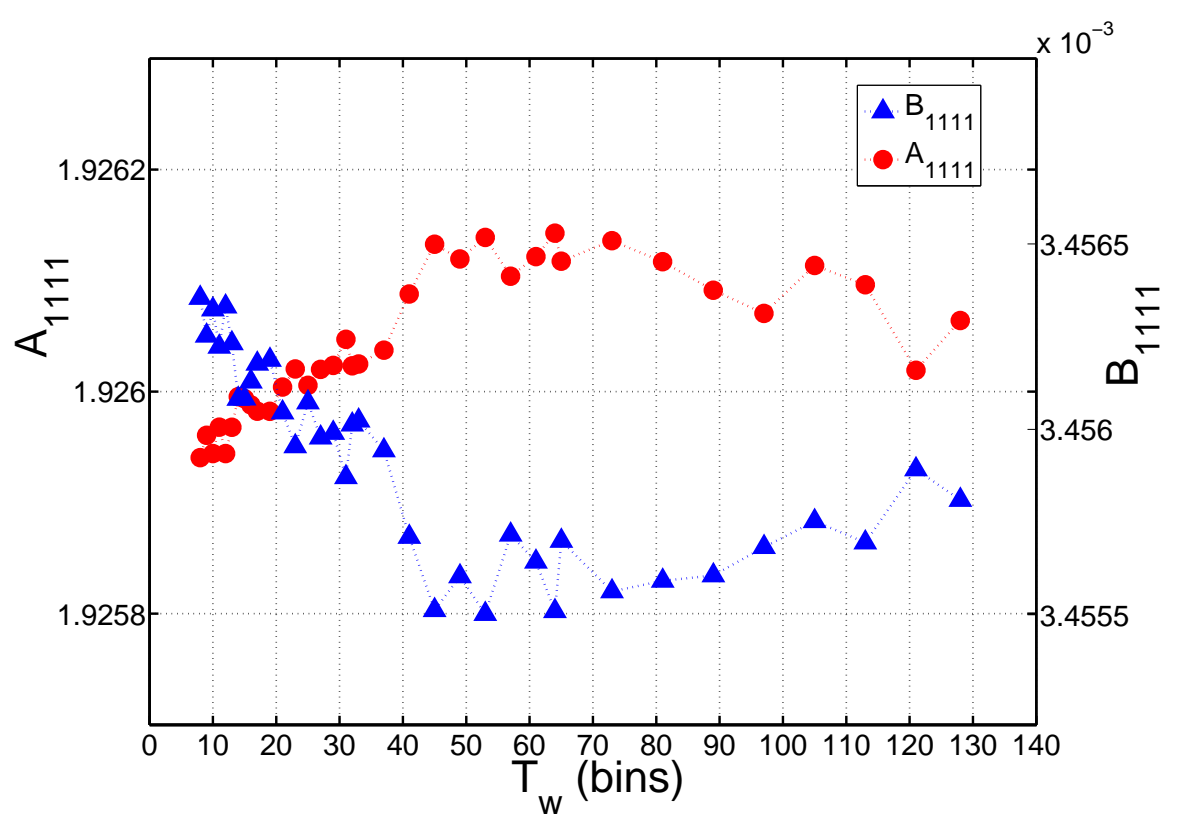

Figura 4.4 - Parâmetros $\boldsymbol{A}_{1111}$ e $\boldsymbol{B}_{1111}$. Dependência dos parâmetros $A_{1111}$ e $B_{1111}$ com a largura da janela $T_{w}$. Um comportamento similar é obtido para os parâmetros $A_{2222}$ e $B_{2222}$. Note que a variação é da ordem de apenas $0,05 \%$.

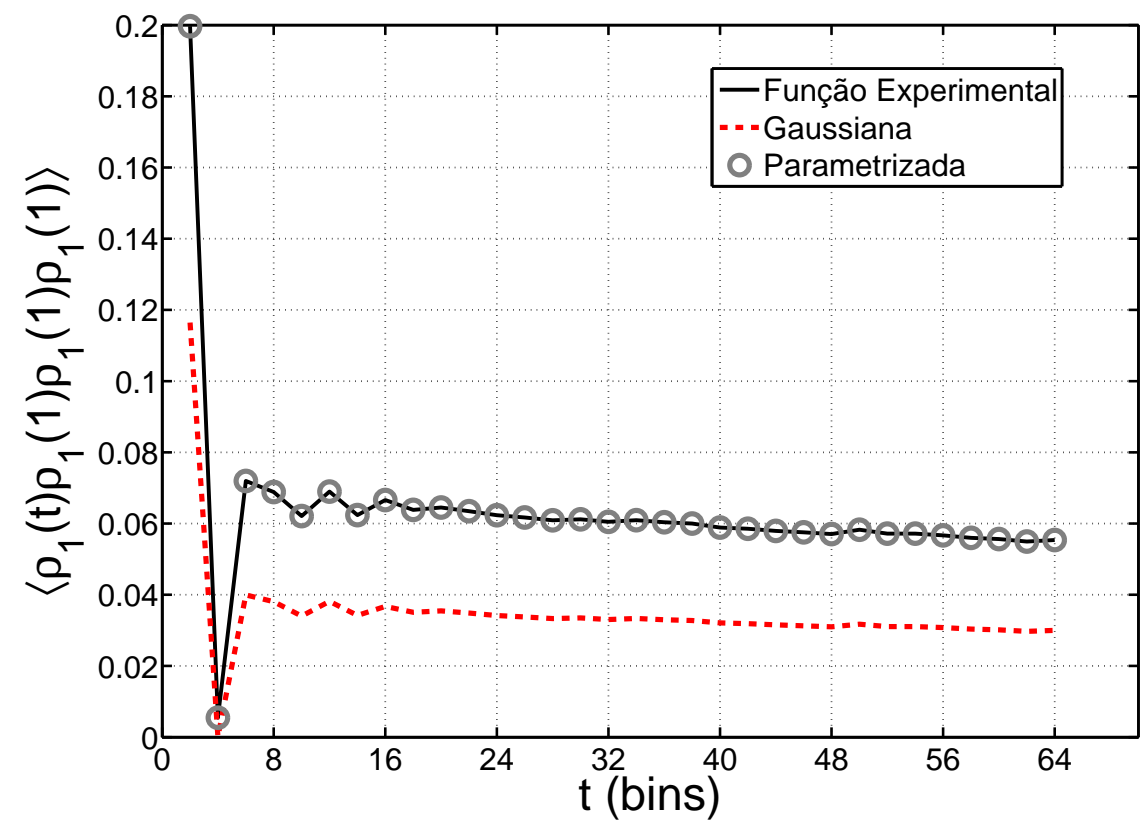

Figura 4.5 - Função de 4-pontos e sua aproximação Gaussiana parametrizada. Apresentamos a primeira linha da matriz $R_{1111}^{(4)}$ para a largura de janela $T_{w}=64$ bins. A linha contínua representa a função de 4-pontos experimental, a linha tracejada é sua aproximação Gaussiana (sem parametrização - usando a equação 4.29) e os círculos representam sua aproximação Gaussiana parametrizada (equação 4.30). 


\subsection{Reconstruindo o estímulo da mosca e medindo sua qualidade}

Utilizamos aquisições com $\eta \sim 0,8-\tau \sim 10 \mathrm{~ms}$ e $\langle r\rangle \sim 80$ spikes.s ${ }^{-1}$ - para testar a qualidade de nossa reconstrução.

Selecionamos uma amostra significativa do experimento, um segundo de duração, para visualizarmos sua reconstrução. Na Figura 4.6 mostramos a reconstrução de primeira ordem do estímulo $s(t)$ usando apenas $K_{1}$ e $K_{2}$ e sua reconstrução de segunda ordem, onde o efeito de $K_{11}$ e $K_{22}$ é adicionado, com e sem a aproximação Gaussiana parametrizada. Concluímos:

- A reconstrução a partir da função de quatro pontos experimental é muito similar a reconstrução utilizando sua representação Gaussiana;

- O processo de reconstrução é incapaz de reproduzir as rápidas variações do estímulo na escala de 2 milissegundos. Mesmo os termos de mais alta ordem não eliminam esta deficiência.

- Os núcleos de segunda ordem ocasionam uma melhora na reconstrução, vemos que a linha preta na Figura 4.6 é uma melhor aproximação do estímulo do que a azul;

Apesar de atestarmos visualmente a qualidade das reconstruções, necessitamos medila de forma numérica. Naturalmente, utilizamos $\chi^{(2)}=\left\langle\int d t\left[s_{e}(t)-s(t)\right]^{2}\right\rangle$ da equação 4.4 como medida de qualidade, já que utilizamos sua minimização na determinação dos núcleos $K_{a}$ e $K_{a b}$. A melhora da reconstrução devido aos núcleos de segunda ordem pode ser expressa por:

$$
\delta \chi^{(2)} \equiv \frac{\chi_{1}^{(2)}-\chi_{12}^{(2)}}{\chi_{1}^{(2)}}
$$

onde $\chi_{1}^{(2)}$ contém apenas termos de primeira ordem - $\chi_{1}^{(2)}=\left\langle\int d t\left[s_{1}(t)-s(t)\right]^{2}\right\rangle-$ e os termos de segunda ordem são adicionados em $\chi_{12}^{(2)}=\left\langle\int d t\left[s_{1}(t)+s_{2}(t)-s(t)\right]^{2}\right\rangle$. A partir desta razão determinamos a contribuição dos termos de segunda ordem como sendo de aproximadamente $8 \%$. A diferença entre $\delta \chi^{(2)}$ utilizando as funções de correlação exata ou Gaussiana é de apenas $~ 0.5 \%$. 


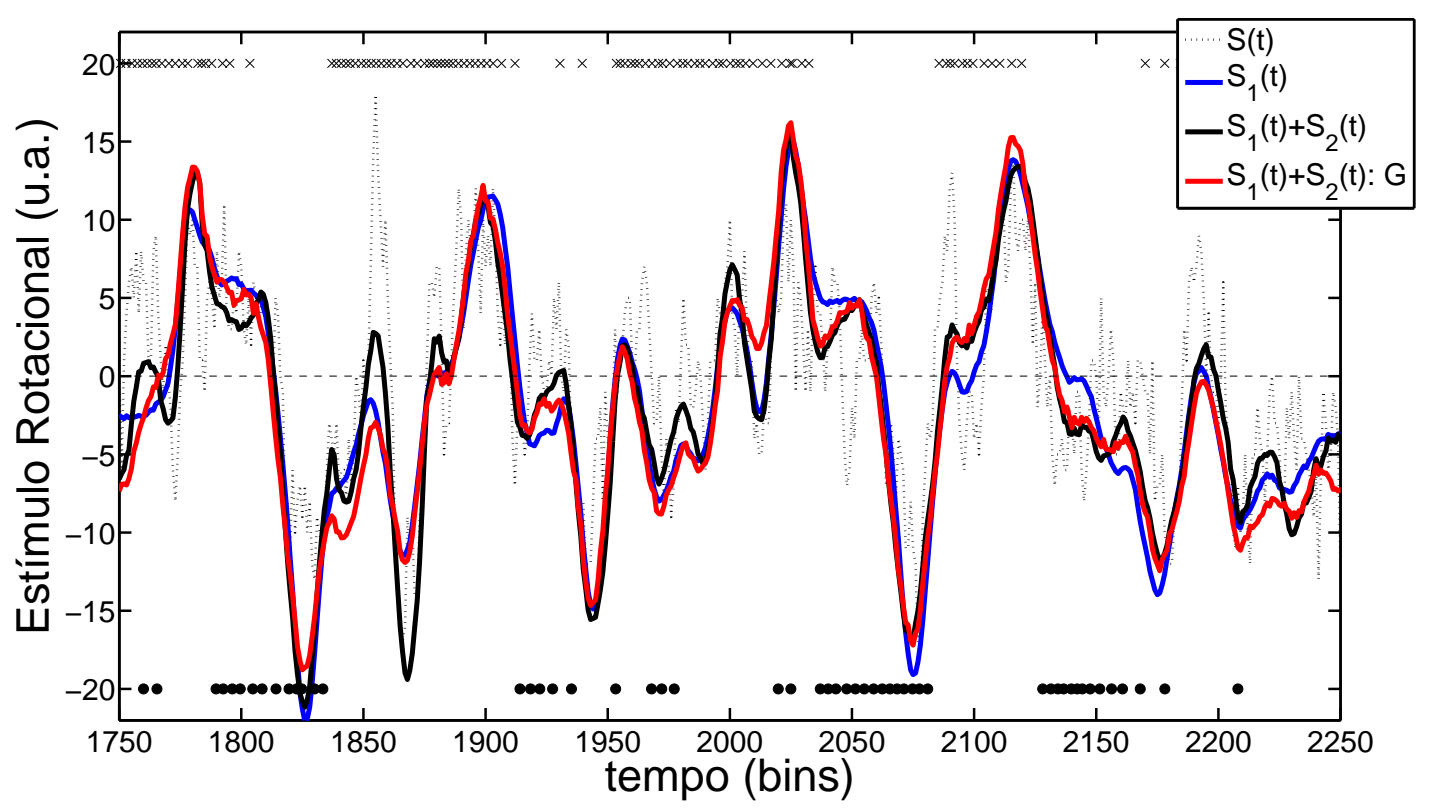

Figura 4.6 - Reconstrução do estímulo rotacional. Reconstrução do estímulo rotacional com os núcleos $K_{1}, K_{2}$ e $K_{11}, K_{22}$, usando a função de quatro pontos experimental e sua aproximação Gaussiana parametrizada. Linha pontilhada em preto: $S(t)$, estímulo de entrada a ser reconstruído. Linha azul: $S_{1}(t)$, reconstrução usando apenas $K_{1}$ e $K_{2}$. Linha preta: $S_{1}(t)+S_{2}(t)$, reconstrução usando núcleo de segunda ordem experimental. Linha vermelha: $S_{1}(t)+S_{2}(t): G$, reconstrução de segunda ordem usando núcleos Gaussianos parametrizados. Os símbolos $\times$ e $\bullet$ representam os disparos do neurônio direito e esquerdo, respectivamente.

Percebemos que a adição dos termos $K_{11}$ e $K_{22}$ em nossa reconstrução do estímulo é mais significativa em certos instantes de tempo. Desta forma, medimos:

$$
\begin{aligned}
\chi_{1}^{2}(t, \Delta T) & \equiv\left\langle\left[s_{1}(t)-s(t)\right]^{2}\right\rangle_{t \rightarrow t+\Delta T} \\
\chi_{12}^{2}(t, \Delta T) & \equiv\left\langle\left[s_{1}(t)+s_{2}(t)-s(t)\right]^{2}\right\rangle_{t \rightarrow t+\Delta T}
\end{aligned}
$$

Ou seja, testaremos localmente a contribuição dos núcleos de segunda ordem. Fizemos um histograma dos possíveis valores da razão $\chi_{1}^{2} / \chi_{12}^{2}$, Figura 4.7. Vemos que a fração de instantes decresce ao aumentarmos a contribuição dos termos de segunda ordem, $\chi_{12}^{2}<\chi_{1}^{2}$. Apenas em aproximadamente $6 \%$ do estímulo temos a razão $\chi_{1}^{2} / \chi_{12}^{2}=1$, instantes em que a contribuição de segunda ordem é nula. Para os demais valores da razão $\chi_{1}^{2} / \chi_{12}^{2}$ apresentados, a contribuição de $K_{11}$ e $K_{22}$ é sempre favorável à reconstrução do estímulo.

A qualidade da reconstrução do estímulo é bem visível para estímulos rotacionais, entretanto, é muito menor para os estímulos de translação (Figura 4.8). Para estímulos 
positivos, correspondendo ao movimento não realístico de vôo para trás da mosca, ambos neurônios disparam vigorosamente. Em contrapartida, para estímulos negativos, ambos neurônios são inibidos e não disparam. O perfil destes trens de pulsos faz com que o estímulo seja apenas reconstruído de forma efetiva nos instantes de atividade, explicando a baixa qualidade de sua reconstrução.

Os núcleos $K_{a}$ e $K_{a b}$ de translação são similares aos de rotação. No estímulo de rotação $K_{1} \sim-K_{2}$ e $K_{11} \sim-K_{22}$, para o caso de translação temos,

$$
\begin{aligned}
& K_{1}{ }^{(\text {trans })} \sim K_{2}{ }^{\left.{ }^{(t r a n s}\right)} \sim K_{1}{ }^{(r o t)}, \\
& K_{11}{ }^{(\text {trans })} \sim K_{22}{ }^{\left.{ }^{\text {trans }}\right)} \sim K_{11}{ }^{(\text {rot })} \text {. }
\end{aligned}
$$

A representação Gaussiana funciona igualmente bem para este caso.

Em suma, nossa representação Gaussiana da função de quatro pontos, em termos de funções de dois pontos, evita os problemas computacionais encontrados no cálculo e posterior inversão das funções de correlação spike-spike, dando-nos uma excelente estimativa do estímulo apresentado para a mosca. Correlações entre as respostas dos dois neurônios H1 da mosca podem ser desconsideradas, já que contribuem em apenas $\sim 1 \%$. Ambas reconstruções, usando a função de quatro pontos experimental e sua representação Gaussiana, são muito similares e seus $\chi^{2}$ diferem em apenas 0,5\%. Apesar da média de $\chi^{2}$ sobre todo o experimento ter uma melhora de apenas $8 \%$, podemos afirmar que os termos de segunda ordem sempre aumentam a qualidade da reconstrução. Observamos que estes termos podem representar uma melhora na reconstrução de até $100 \%$ em instantes especiais do estímulo, resultado medido através do $\chi^{2}$ dependente do tempo. 


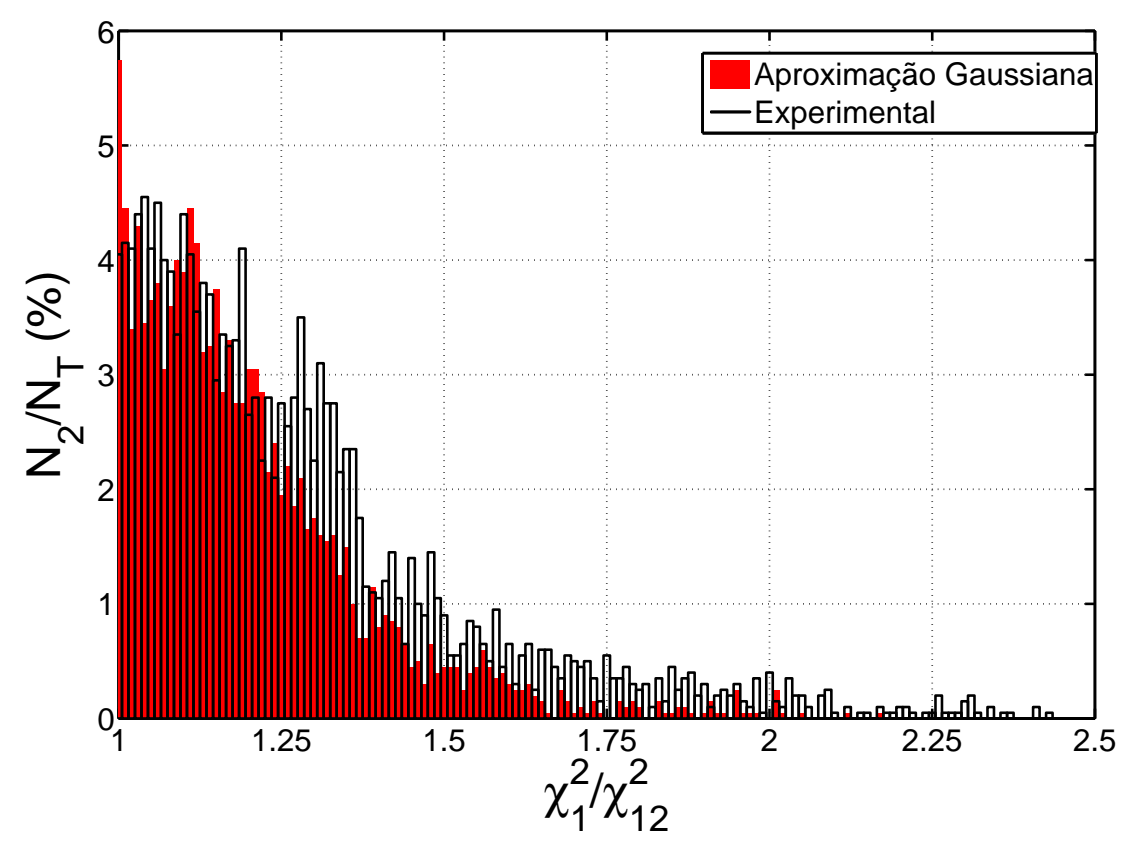

Figura 4.7 - Contribuição de $K_{11}$ e $K_{22}$. Para o movimento de rotação, medimos $\chi^{2}$ em janelas de largura $\Delta T=128 \mathrm{~ms}$. Contabilizamos a fração de instantes $-N_{2} / N_{T}$ que assumem diferentes valores de $\chi_{1}^{2} / \chi_{12}^{2}$ ( $N_{T}$ : duração do experimento em bins). Vemos que em apenas $6 \%$ do tempo a contribuição de $K_{11}$ e $K_{22}$ não é relevante.

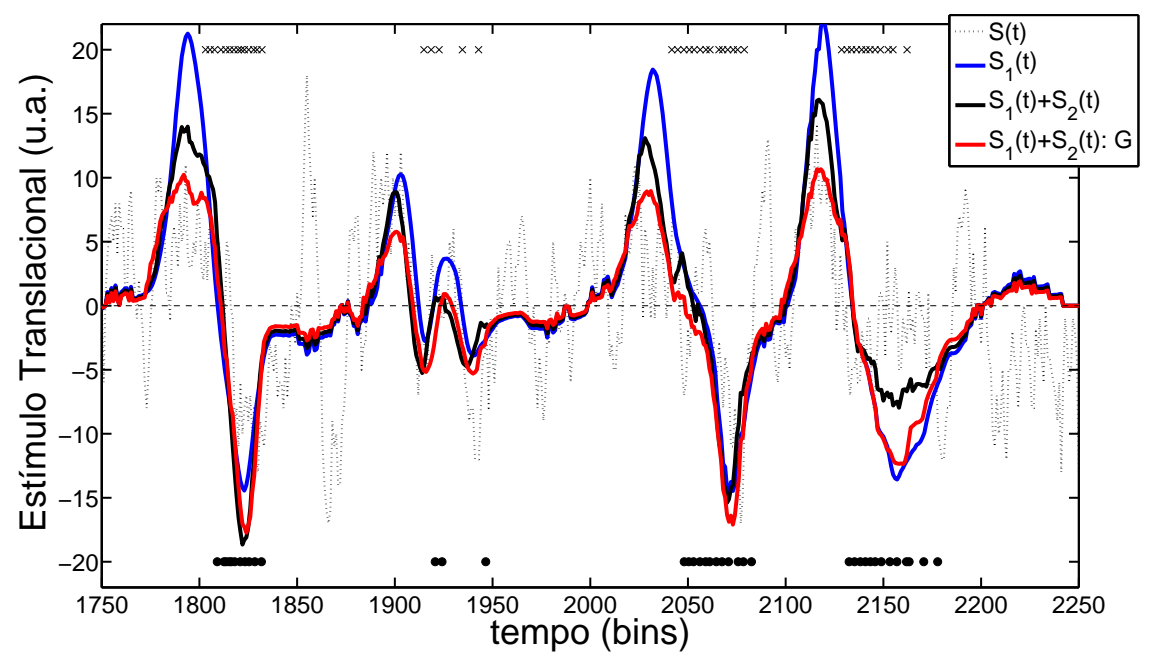

Figura 4.8 - Reconstrução do estímulo de translação. Reconstrução do estímulo de translação com os núcleos $K_{1}, K_{2}$ e $K_{11}, K_{22}$, usando a função de quatro pontos experimental e sua aproximação Gaussiana parametrizada. Linha pontilhada em preto: $S(t)$, estímulo de entrada a ser reconstruído. Linha azul: $S_{1}(t)$, reconstrução usando apenas $K_{1}$ e $K_{2}$. Linha preta: $S_{1}(t)+S_{2}(t)$, reconstrução usando núcleo de segunda ordem experimental. Linha vermelha: $S_{1}(t)+S_{2}(t): G$, reconstrução de segunda ordem usando núcleos Gaussianos parametrizados. Os símbolos $\times$ e $\bullet$ representam os disparos do neurônio direito e esquerdo, respectivamente. 


\section{Redução Dimensional no Espaço de Estímulos}

Ao analisar qualquer sistema biológico deparamos-nos com uma dificuldade crucial: a dimensão do espaço de estímulos é enorme e qualquer análise necessita reduzi-la. Esta redução não deve perder propriedades importantes do estímulo, mas sim, preservar aqueles atributos que sejam cruciais para executar adequadamente a tarefa para a qual o particular sistema biológico foi criado. Acontece que em geral não sabemos quais são estes atributos.

Supondo que o neurônio H1 tenha uma memória da ordem de 40 milissegundos, 20bins, sabendo que temos 16bits de possíveis velocidades no monitor e que deslocamos a imagem a cada dois milissegundos, segue-se que o nosso espaço de estímulos possui um conjunto da ordem de $\left(2^{16}\right)^{20}$ elementos. É absolutamente necessário reduzir este número astronômico, pois é difícil imaginar que o sistema formado pelos dois neurônios $H 1$ seja capaz de codificar eficientemente todos estes elementos. A redução realizada neste espaço consiste em agrupar estímulos, a princípio distintos, que apresentem características semelhantes.

Os dois neurônios $H 1$ trabalham de maneira complementar, formando um eficiente detector de movimentos de rotação. Desta forma, é razoável esperar que este sistema seja ao menos capaz de codificar um atributo essencial deste movimento, seu sentido - rotações horizontais para direita ou para esquerda. Para avaliar tal capacidade, efetuamos uma brusca redução no espaço de estímulos e apresentamos para a mosca um estímulo visual de 1bit. Este novo estímulo possui apenas esta característica essencial, velocidade positiva (rotações para direita) ou negativa (rotações para esquerda) a cada instante de tempo.

Estudamos como esta redução afeta as propriedades cruciais do estímulo ao observamos a resposta dos neurônios $H 1$ a estes diferentes estímulos, 1 - 16bits. Qual a quantidade de informação presente nestes trens pulsos? Qual a capacidade de reconstrução do estímulo a partir destas respostas? Com que eficiência este sistema é capaz de estimar o sentido do movimento? Estas são algumas questões que tentamos responder neste capítulo. 


\subsection{Geração do estímulo "Digital"}

Geramos uma série de estímulos a partir do processo de Ornstein-Uhlenbeck (Apêndice A). Estes estímulos possuem tempo de correlação " $\tau$ " iguais a 12, 25, 40 e 100 bins, conforme Figura 5.1. Geramos um conjunto de cem estímulos de dez segundos de duração para cada valor de " $\tau$ ". Escolhemos um estímulo que repete-se intercalado por outro deste mesmo conjunto, conforme descrito em seções anteriores, Figura 5.2.

O processo de Ornstein-Uhlenbeck nos fornece uma seqüencia de velocidades correlacionadas $S(t)$. A posição da imagem a cada instante de tempo é então obtida através da integração desta seqüencia. Nosso gerador de estímulos possui 15bits de resolução, ou seja, temos $N_{P}=2^{15}=32768$ possíveis valores de posição e conseqüentemente $N_{V}=\left(2 \times N_{P}-1\right) \sim 16 b i t s$ de possíveis velocidades*. A mosca deve codificar cada uma dessas velocidades em uma seqüencia de pulsos elétricos que são enviados ao seu sistema motor para reagir apropriadamente ao estímulo $S(t)$. Ao registrar a resposta dos neurônios $H 1^{ \pm}$teremos a cada instante de tempo apenas quatro possibilidades de resposta: disparo apenas de $H 1^{+}$, apenas de $H 1^{-}$, a ausência de disparos e disparos de ambos neurônios (Apêndice B.2). Desta forma, fica difícil acreditar que o sistema formado por estes dois neurônios seja capaz de codificar os 16bits de velocidades do estímulo.

O aspecto da codificação é ainda mais crítico ao considerarmos o tempo $T \simeq 20$ bins de integração do estímulo (8). Neste caso teremos $\left(N_{V}\right)^{T} \sim 2 \times 10^{96}$ possíveis seqüencias de velocidades que devem ser codificadas em apenas $4^{T} \sim 10^{12}$ possíveis seqüencias de pulsos. Este fato sugere que a codificação realizada por estes neurônios é baseada apenas em um certo subconjunto de propriedades mais relevantes do estímulo.

Reduzimos drasticamente o espaço dimensional de estímulos para investigar o efeito que a riqueza de propriedades deste espaço tem sobre a resposta neural. Modificamos os estímulos Gaussianos gerados para conter apenas dois valores de velocidade, $v^{ \pm}$. Nos instantes em que o estímulo Gaussiano $S(t)$ é negativo substituímos seu valor por $v^{-}$. Nos instantes de velocidade positiva, substituímos $S(t)$ por $v^{+}=\left|v^{-}\right|$, Figura 5.3(a). Denominamos este novo estímulo por "Digital", $S_{D}(t)$. A escolha de $v^{ \pm}$é feita tal que a excursão de ambos os estímulos, Gaussiano e "Digital", seja praticamente a mesma, Figura 5.3(b).

Esta redução no espaço de estímulos tem como objetivo avaliar a capacidade com que

*Todas as combinações das $N_{P}$ posições de forma positiva e negativa, mais velocidade nula. 


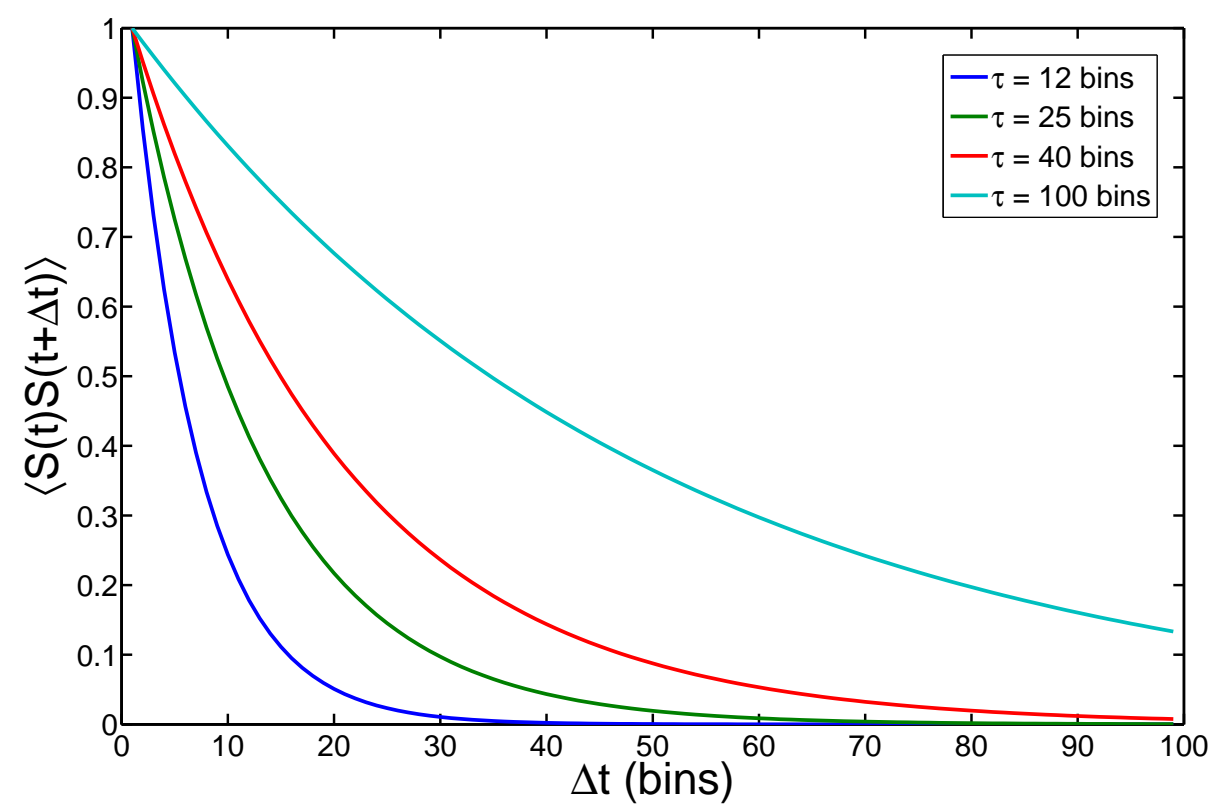

Figura 5.1 - Correlação do estímulo. Apresentamos para a mosca quatro estímulos gerados a partir de um processo de Ornstein-Uhlenbeck. A velocidade do estímulo a cada instante é obtida a partir de uma distribuição Gaussiana com 12, 25, 40 ou 100 bins de correlação temporal.

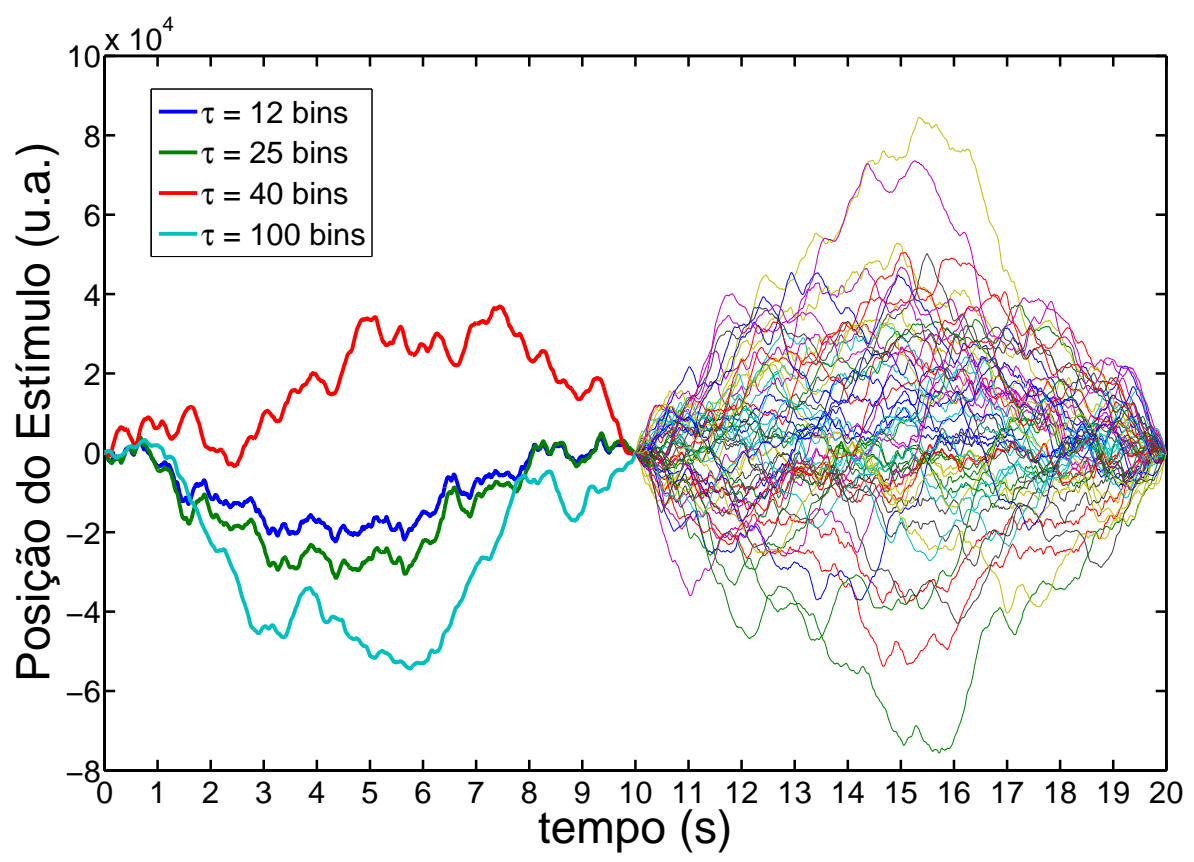

Figura 5.2 - Posição do estímulo. Posição dos diferentes estímulos apresentados para a mosca. Geramos uma série de cem estímulos para cada tempo de correlação " $\tau$ ". Os primeiros dez segundos de cada estímulo repete-se. Seus próximos dez segundos é gerado de forma aleatória com mesmo tempo de correlação. 

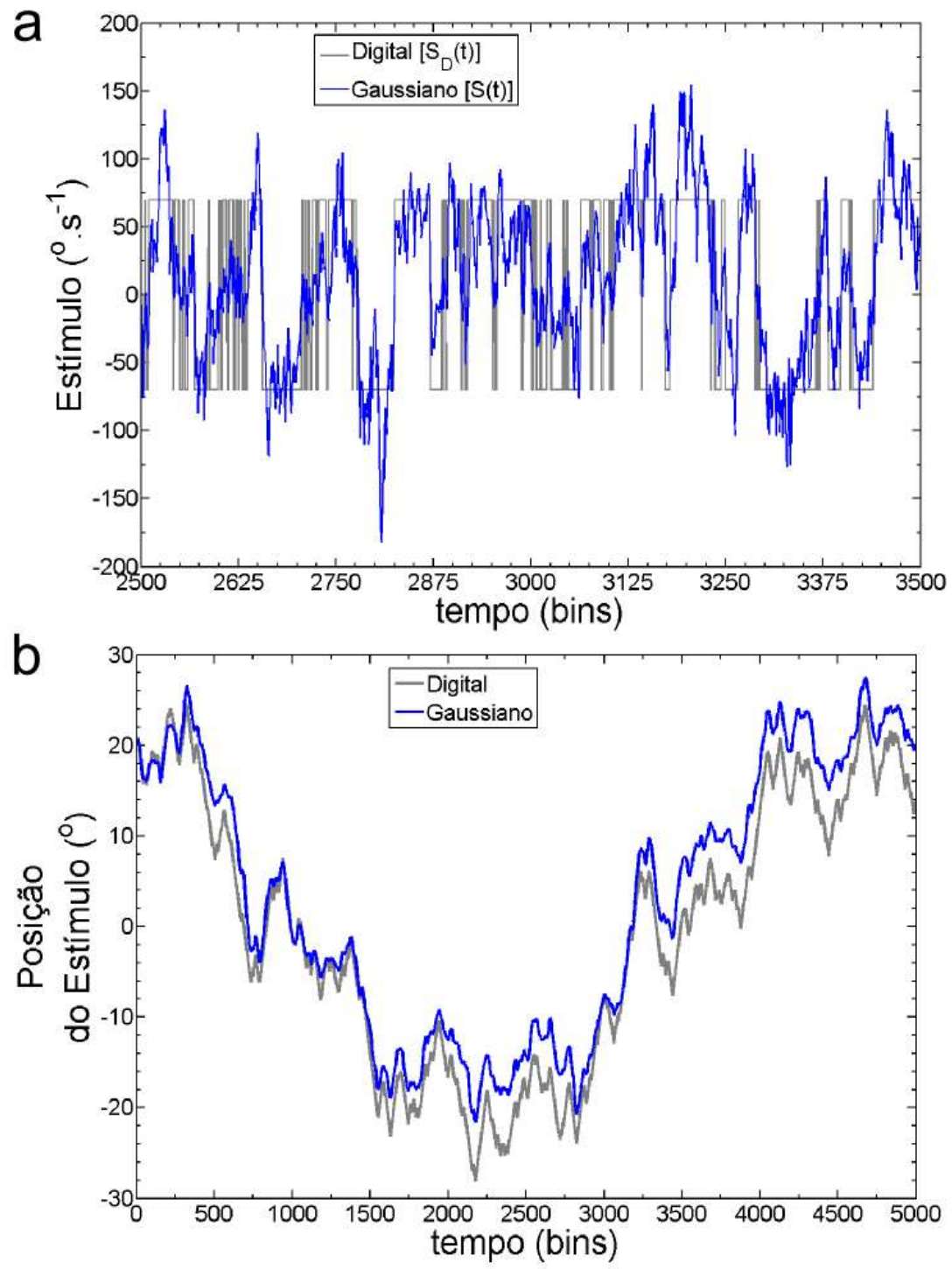

Figura 5.3 - “Digitalização" do estímulo. Comparação entre os estímulos apresentados à mosca. (a) Trecho de dois segundos (1000bins) do estímulo Gaussiano gerado e sua versão "Digital". Nos instantes de tempo em que a velocidade do estímulo é negativa substituímos seu valor por $v^{-}$e para velocidades positivas, substituímos por $v^{+}=\left|v^{-}\right|$. (b) A escolha de $v=v^{ \pm}$é feita tal que a excursão total de ambos estímulos ao longo do experimento seja próxima.

os neurônios $H 1$ codificam o sentido do movimento de auto-rotação da mosca, rotações positivas e negativas. Esta análise é feita na próxima seção utilizando diferentes métodos para comparar os trens de pulsos obtidos como resposta a essas duas versões de estímulo, $S(t)$ e $S D(t)$. 


\subsection{Resposta neural ao estímulo "Digital"}

Efetuamos uma significativa redução no espaço dimensional de estímulos ao "digitalizálo". Evidenciamos as conseqüências que esta redução traz à atividade dos neurônios $H 1^{ \pm}$ao compararmos as respostas geradas a ambos os estímulos - $R$ : resposta devido a $S(t) ; R_{D}$ : resposta devido a $S_{D}(t)$ - Figura 5.4. Após esta redução, com que qualidade podemos reconstruir o estímulo responsável pela geração destas respostas? Com que eficiência podemos estimar o sentido de movimento? As respostas $R$ e $R_{D}$ trazem a mesma quantidade de informação sobre os estímulos? Para responder estas questões utilizamos a reconstrução linear do estímulo, apresentada no capítulo anterior, e a teoria da informação $(42,47,48)$, descrita em detalhes no Apêndice B.

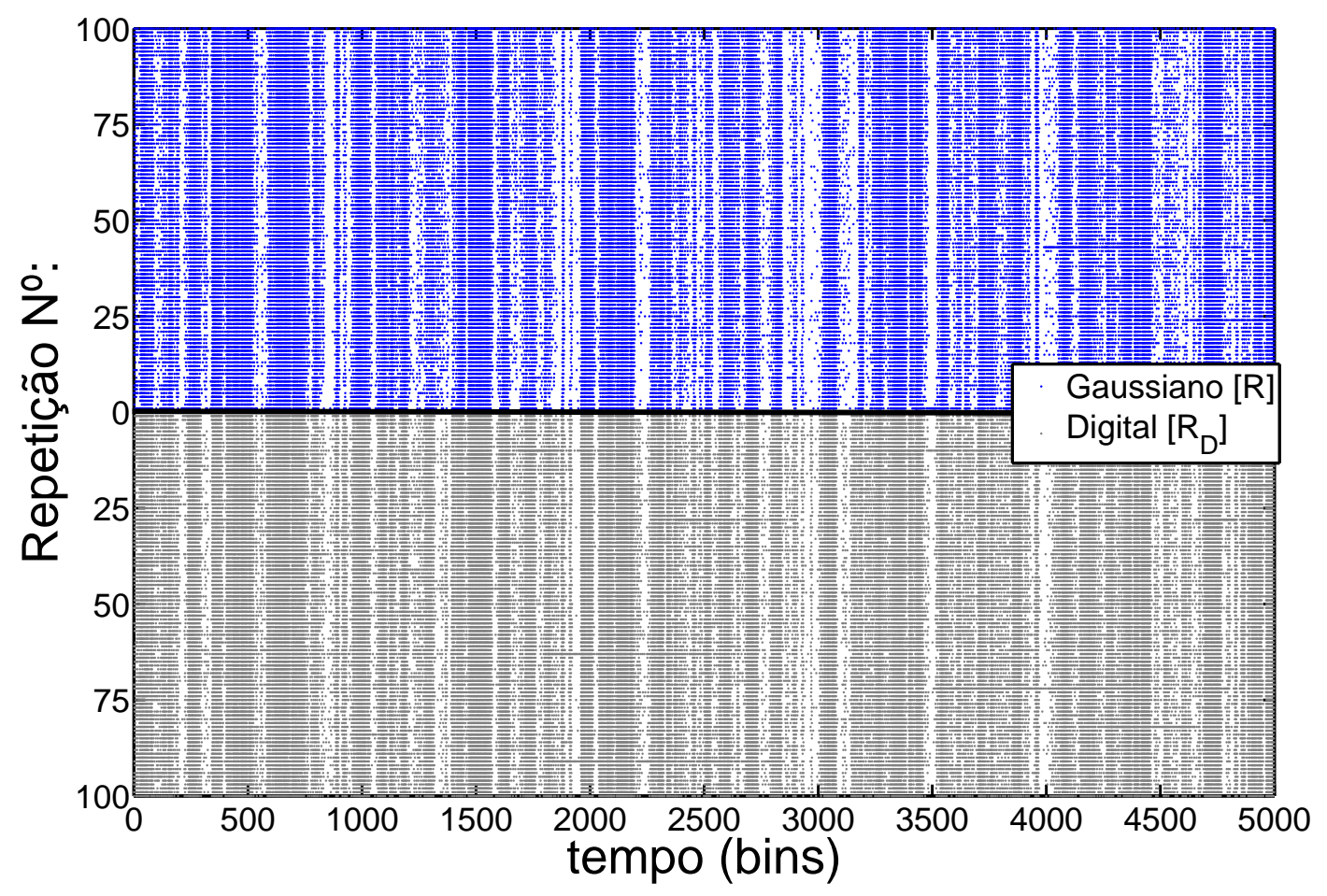

Figura 5.4 - Resposta ao estímulo "Digital". Comparação entre a resposta do neurônio $H 1^{+}$ aos estímulos Gaussiano e "Digital" (tempo de correlação $\tau=12$ bins). Vemos através do raster plot a semelhança entre as respostas geradas a ambos os estímulos. Verificamos em mais detalhes as diferenças entre estas respostas nas próximas seções. A mesma semelhança é encontrada para $\mathrm{H}^{-}$e para os diferentes tempos de correlação " $\tau$ ". 


\subsubsection{Reconstrução linear de $S(t)$ e $S_{D}(t)$}

O processo de reconstrução linear é capaz de extrair as propriedades do estímulo que originam a atividade neural. Necessitamos conhecer tais propriedades para utilizá-las na geração de uma estimativa do estímulo a partir de trens de pulsos. Caso apresentemos um estímulo com propriedades não codificadas pelos neurônios $H 1$, por exemplo uma componente vertical de movimento, veremos que estas propriedades serão eliminadas de sua estimativa, por não estarem presentes na função de correlação estímulo-resposta. Ou seja, caso as reconstruções de estímulos distintos forem próximas, podemos afirmar que suas diferenças não pertencem às propriedades codificadas pelos neurônios $H 1$. Verificamos se a redução realizada no espaço de estímulos mantém as propriedades cruciais de seus elementos ao comparar as estimativas referentes aos estímulos Gaussiano e sua versão "Digital".

Para cada tempo de correlação " $\tau$ " efetuamos dois experimentos: um no qual apresentamos o estímulo Gaussiano, $S(t)$, e outro em que apresentamos o estímulo denominado "Digital", $S_{D}(t)$. Como resposta ao estímulo Gaussiano, obtemos dos neurônios $H 1^{ \pm}$os trens de pulsos $\rho_{1}(t)$ e $\rho_{2}(t)$. Denotamos por $\rho_{1 D}(t)$ e $\rho_{2 D}(t)$ as respostas dos neurônios ao estímulo $S_{D}(t)$. Construímos uma estimativa destes estímulos através das seguintes reconstruções lineares,

$$
\begin{aligned}
S_{e}(t) & =\int_{-\infty}^{\infty} K 1\left(t^{\prime}\right) \rho_{1}\left(t-t^{\prime}\right) d t^{\prime}+\int_{-\infty}^{\infty} K 2\left(t^{\prime}\right) \rho_{2}\left(t-t^{\prime}\right) d t^{\prime} \\
S_{e D}(t) & =\int_{-\infty}^{\infty} \tilde{K} 1\left(t^{\prime}\right) \rho_{1 D}\left(t-t^{\prime}\right) d t^{\prime}+\int_{-\infty}^{\infty} \tilde{K} 2\left(t^{\prime}\right) \rho_{2 D}\left(t-t^{\prime}\right) d t^{\prime} .
\end{aligned}
$$

Os núcleos $K^{\prime} s$ e $\tilde{K}^{\prime}$ 's são obtidos através da equação 4.18 .

Na Figura 5.5 ilustramos algumas das funções de correlação envolvidas na solução da equação 4.18 e a subseqüente reconstrução linear dos estímulos Gaussiano e "Digital", com tempo de correlação $\tau=12$ bins. Os resultados obtidos para as estimativas $S_{e}(t)$ e $S_{e D}(t)$ são extremamente próximos. A mesma semelhança entre as reconstruções é obtida para os diferentes tempos de correlação " $\tau$ ". Numericamente representamos a semelhança entre as reconstruções $S_{e}(t)$ e $S_{e D}(t)$ a partir de um coeficiente de correlação ${ }^{\dagger}$, apresentado na

${ }^{\dagger}$ Correlação entre $x_{1}$ e $x_{2}: R\left(x_{1}, x_{2}\right)=\frac{C\left(x_{1}, x_{2}\right)}{\sqrt{C\left(x_{1}, x_{1}\right) C\left(x_{2}, x_{2}\right)}}, \operatorname{com} C\left(x_{1}, x_{2}\right)=E\left[\left(x_{1}-\left\langle x_{1}\right\rangle\right)\left(x_{2}-\left\langle x_{2}\right\rangle\right)\right]$. "E[X]" representa o valor esperado da variável " $X$ ". 
Tabela 3 para os diferentes valores de " $\tau$ ".

Tabela 3 - Correlação entre $S_{e}(t)$ e $S_{e D}(t)$. Correlação entre as reconstruções lineares do estímulo Gaussiano e "Digital" para os diferentes tempos de correlação " $\tau$ ".

\begin{tabular}{|c|c|}
\hline $\boldsymbol{\tau}$ (bins) & Correlação (\%) \\
\hline \hline 12 & 79 \\
\hline 25 & 80 \\
\hline 40 & 89 \\
\hline 100 & 86 \\
\hline
\end{tabular}

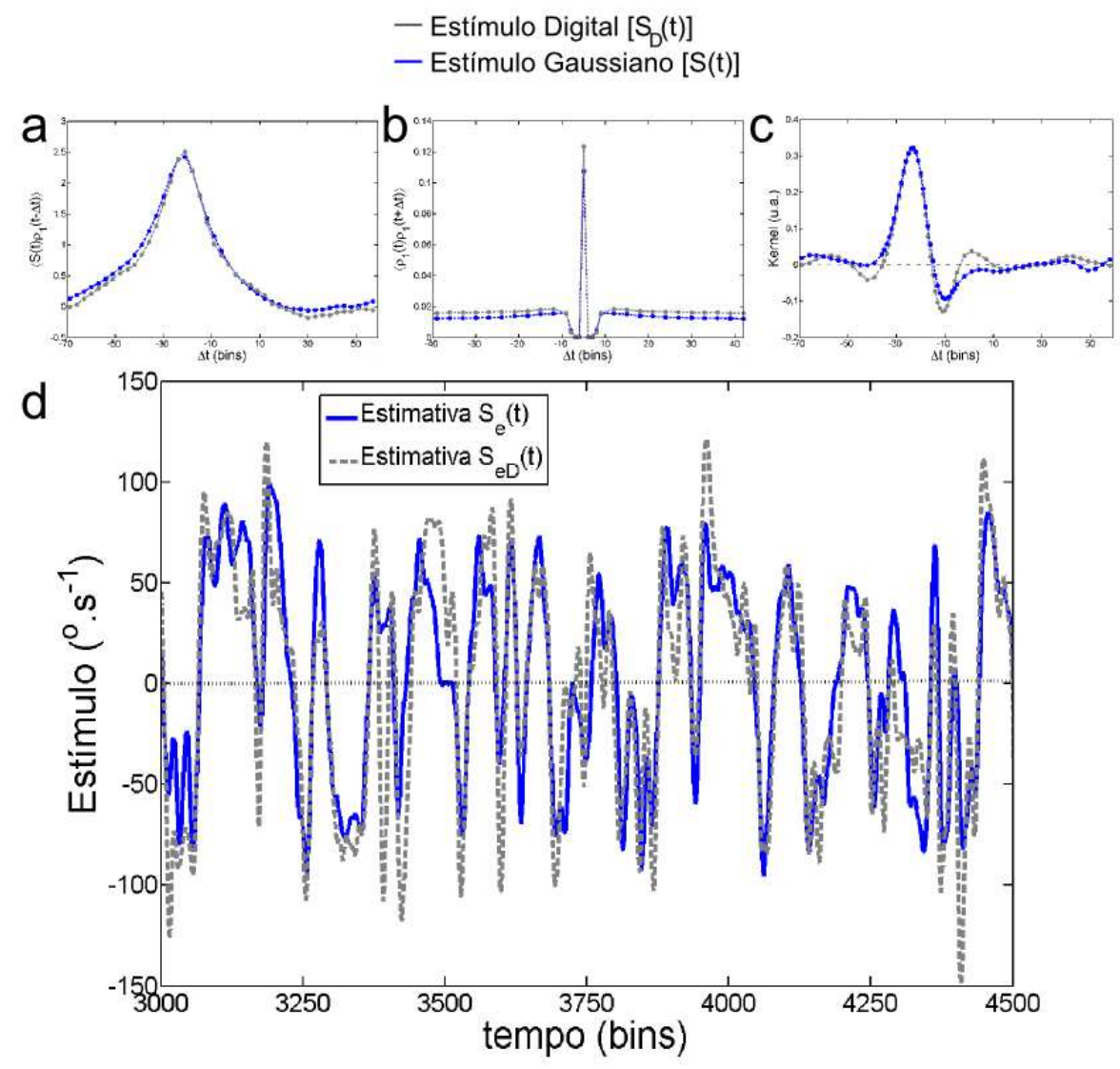

Figura 5.5 - Reconstrução do estímulo “Digital”. Em (a) e (b) vemos respectivamente as funções de correlação estímulo-resposta e resposta-resposta para ambos os estímulos, Gaussiano e "Digital". Utilizamos estas funções para o cálculo do núcleo de reconstrução linear do estímulo visto em (c). (d) Comparação entre as reconstruções lineares do estímulo $(\tau=12 b i n s)$.

As estimativas $S_{e}(t)$ e $S_{e D}(t)$ estão correlacionadas da ordem de $80-90 \%$. Estes números indicam que grande parte das propriedade essenciais do estímulo Gaussiano, codificadas pela atividade dos neurônios $H 1$, continuam presentes no estímulo "Digital" e em 
sua resposta, pelo menos aquelas propriedades que podem ser reconstruídas linearmente através das equações 5.1 e 5.2. Ou seja, apesar da complexidade do estímulo Gaussiano apresentado, os neurônios $H 1$ essencialmente codificam o sentido de movimento deste estímulo, característica comum aos estímulos $S(t)$ e $S_{D}(t)$.

Analisamos a eficiência da codificação realizada pelos neurônios $H 1$ através da quantidade de instantes nos quais a reconstrução linear do estímulo, $S_{e D}(t)$, descreve corretamente o sentido do movimento de rotação, $S_{D}(t)$. Obtemos até $85 \%$ de estimativas corretas do sentido de movimento. Isto demonstra que o sistema formado pelos dois neurônios $H 1$ é extremamente eficiente nesta tarefa, indicando mais uma vez que esta seja sua principal função. A percentagem de coincidências entre os sentidos destes estímulos para os diferentes valores de " $\tau$ " são apresentados a seguir na Tabela 4.

Tabela 4 - Coincidências entre o sentido de $S_{D}(t)$ e $S_{e D}(t)$. Medimos a percentagem de coincidências entre os sentidos do movimento de rotação $S_{D}(t)$ e $S_{e D}(t)$ para os diferentes tempos de correlação " $\tau$ ". Estimamos corretamente até $85 \%$ do sentido de movimento.

\begin{tabular}{|c|c|}
\hline $\boldsymbol{\tau}$ (bins) & Coincidências (\%) \\
\hline \hline 12 & 82 \\
\hline 25 & 85 \\
\hline 40 & 85 \\
\hline 100 & 77 \\
\hline
\end{tabular}

Mostramos que a principal tarefa do sistema formado pelos dois neurônios $H 1$ é codificar o sentido de movimento de rotação. Mostramos também que estes neurônios realizam esta tarefa com extrema eficiência, 85\%. Na próxima seção evidenciamos novamente este fato ao calcular e comparar a quantidade de informação referente aos estímulos $S(t)$ e $S_{D}(t)$ contida nas respostas destes neurônios.

\subsubsection{Codificação de $S(t)$ e $S_{D}(t)$}

Toda informação relevante aos neurônios $H 1$ a respeito dos estímulos $S(t)$ e $S_{D}(t)$ é codificada respectivamente nos trens de pulsos $R$ e $R_{D}$. Caso a redução efetuada no espaço de estímulos preserve os atributos cruciais de seus elementos, atributos necessários 
para executar adequadamente a tarefa para a qual os neurônios $H 1$ foram designados, a mesma quantidade de informação sobre estes estímulos deve ser codificada em ambas as respostas, Figura 5.6.

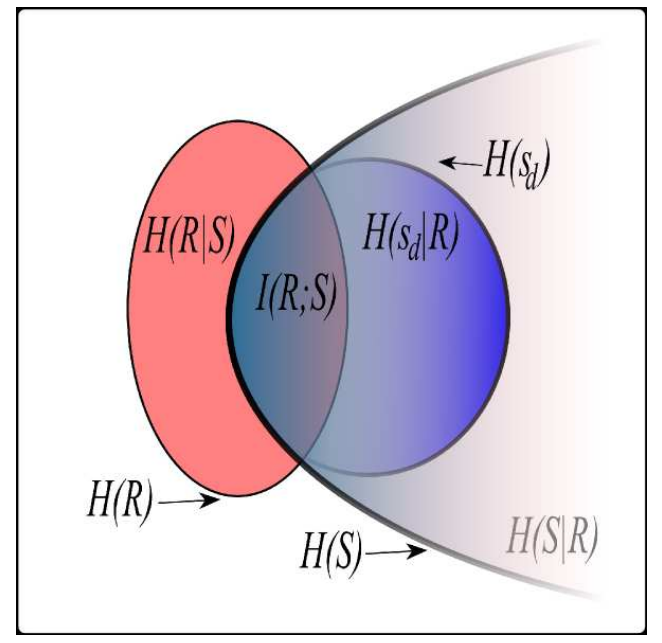

Figura 5.6 - Diagrama de Venn. Em azul representamos os conjuntos dos estímulos $S$ e $S_{D}$. Em vermelho representamos os conjuntos de respostas $R$ e $R_{D}$. Ao efetuarmos a "digitalização" do estímulo $S(t)$, reduzimos de forma brusca a dimensão do espaço de estímulos. Esta redução não ocorre no espaço de respostas, $R \equiv R_{D}$. A diferença entre o espaço de todas as possíveis respostas $\{H(R)\}$ e o espaço de respostas a um dado estímulo $\{H(R \mid S)\}$ nos dá a quantidade de informação codificada na resposta sobre o estímulo. O mesmo procedimento pode ser feito com o espaço de estímulos.

Informação sobre o estímulo é codificada na resposta neural pelo tempo de ocorrência de seus pulsos. Vemos de forma qualitativa na Figura 5.4 que o neurônio $H 1$ responde similarmente aos estímulos $S(t)$ e $S_{D}(t)$, ou seja, a estrutura temporal e conseqüentemente a quantidade de informação contida em suas respostas, são semelhantes.

Ao calcular a informação contida nos trens de pulsos $R$ e $R_{D}$, confirmamos a similaridade entre estes trens de pulsos de forma quantitativa. Este procedimento consiste em calcularmos a variabilidade com que os neurônios respondem a diferentes estímulos, "Entropia Total" - H(R), e em seguida a compararmos com a variabilidade com que estes neurônios respondem a um determinado estímulo, "Entropia do Ruído" - $H(R \mid S)$. O valor da Entropia do Ruído é menor ou igual ao valor da Entropia Total. A diferença entre estes valores representa a "Informação" codificada na resposta sobre o estímulo, equações 5.3, 5.4 e 5.5. O procedimento para o cálculo destas grandezas pode ser visto em detalhes no Apêndice B e apresentamos seus resultados nas Figuras 5.7 e 5.8. 


$$
\begin{aligned}
H(r) & =-\sum_{r} p(r) \log _{2} p(r) \\
H(r \mid s) & =-\sum_{s} p(s) \sum_{r} p(r \mid s) \log _{2} p(r \mid s) \\
I(r ; s) & =H(r)-H(r \mid s) \\
& r:\left\{R, R_{D}\right\} ; s:\left\{S, S_{D}\right\}
\end{aligned}
$$

Em suma, obtemos para os diferentes tempos de correlação " $\tau$ " os resultados apresentados na Tabela 5 .

Tabela 5 - Informação transmitida sobre $\boldsymbol{S}(\boldsymbol{t})$ e $\boldsymbol{S}_{\boldsymbol{D}}(\boldsymbol{t})$. " $I_{g}$ " e " $I_{D}$ " referem-se respectivamente às taxas de informação transmitidas quando o estímulo Gaussiano e "Digital" são apresentados. " $|\Delta I| / I_{g}$ " mostra a diferença entre os valores obtidos para as taxas de informação, $|\Delta I| / I_{g} \sim 10 \%$.

\begin{tabular}{|c|c|c|c|}
\hline $\boldsymbol{\tau}$ (bins) & $\boldsymbol{I}_{\boldsymbol{g}}$ (bits. $\left.^{-\mathbf{1}}\right)$ & $\boldsymbol{I}_{\boldsymbol{D}}$ (bits. $\left.^{-\mathbf{1}}\right)$ & $|\boldsymbol{\Delta I}| / \boldsymbol{I}_{\boldsymbol{g}}(\boldsymbol{\%})$ \\
\hline \hline 12 & 93 & 98 & 5 \\
\hline 25 & 75 & 82 & 9 \\
\hline 40 & 87 & 92 & 6 \\
\hline 100 & 94 & 83 & 12 \\
\hline
\end{tabular}

As taxas com que os neurônios $H 1$ transmitem informação sobre os estímulos $S(t)$ e $S_{D}(t)$ são muito próximas, diferença de aproximadamente $10 \%$, uma diferença contida nos erros deste procedimento. Desta forma podemos afirmar que, apesar da brusca redução realizada sobre o estímulo, a quantidade de informação codificada sobre o estímulo "Digital" em seu trem de pulsos é a mesma quantidade codificada pelos neurônios quando o estímulo Gaussiano é apresentado. Mais uma vez podemos afirmar que o sistema formado pelos dois neurônios $H 1$ é em maior parte responsável pela codificação do sentido de movimento de auto-rotação, devido esta ser a propriedade comum entre $S(t)$ e $S_{D}(t)$, 


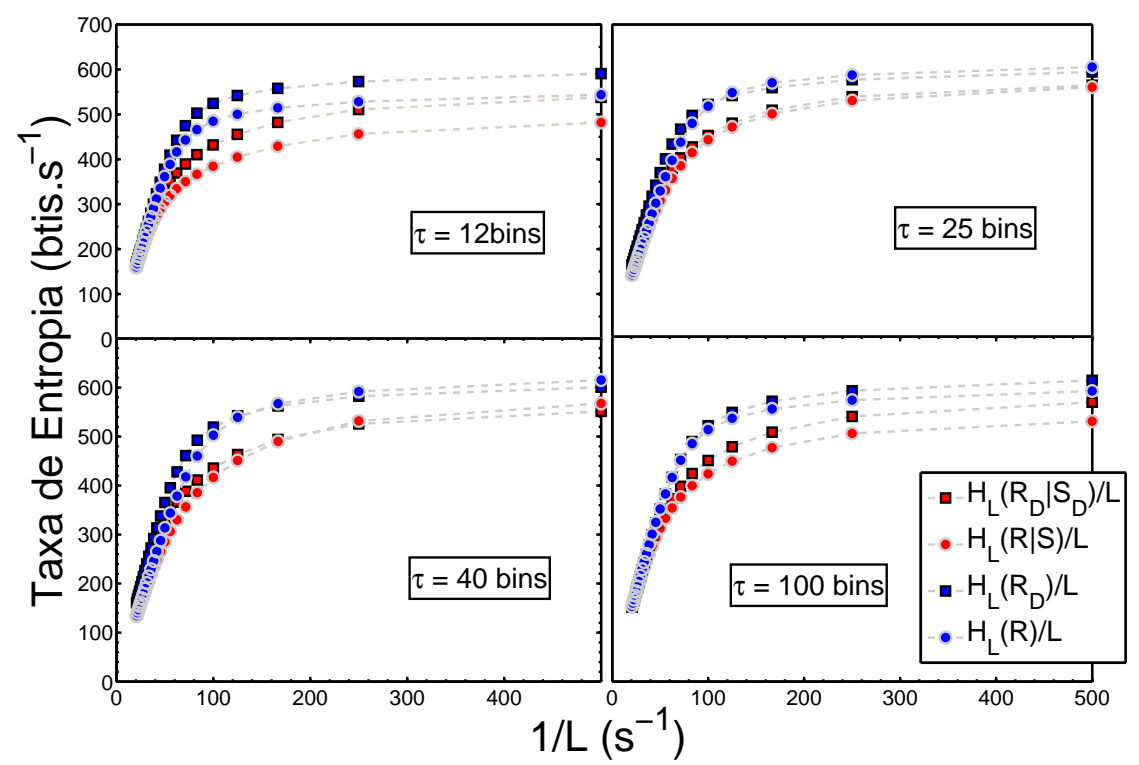

Figura 5.7 - Taxa de Entropia Total e do Ruído de $S(t)$ e $S_{D}(t)$. Calculamos a taxa de Entropia Total e do Ruído para os estímulos Gaussiano e "Digital" de diferentes tempos de correlação " $\tau$ ". A cor azul representa a Entropia Total e vermelho a Entropia do Ruído. Os símbolos "o" representam estas taxas para $S(t)$ enquanto que os símbolos " $\square$ " representam $S_{D}(t)$. Obtemos praticamente os mesmos resultados para os diferentes estímulos.
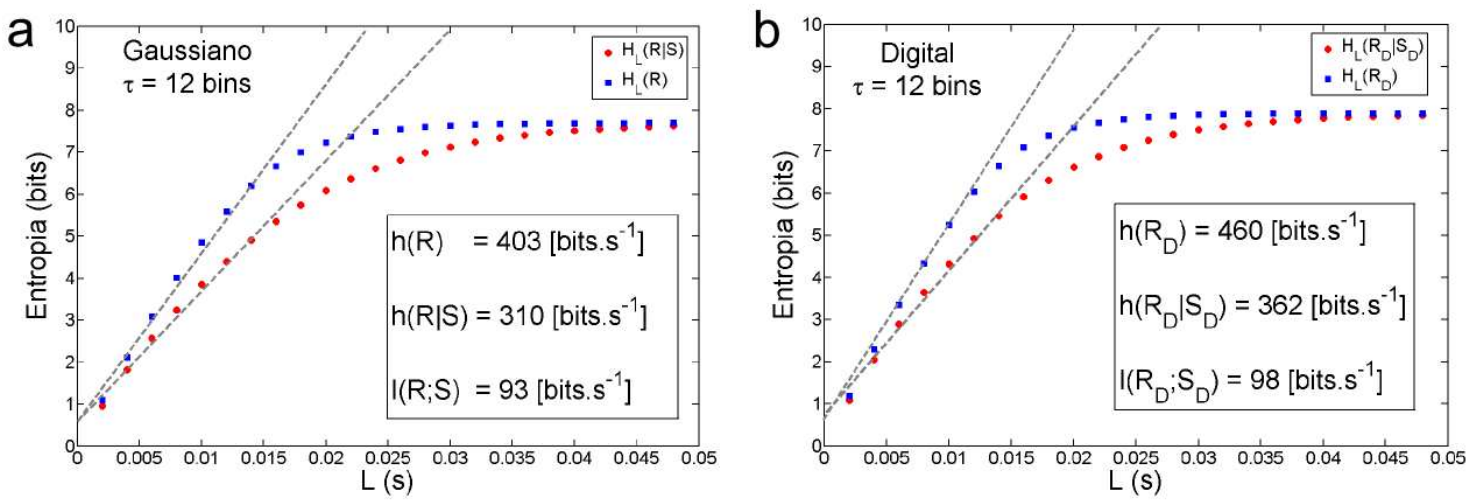

Figura 5.8 - Taxa de Informação de $S(t)$ e $S_{D}(t), \tau=12 b i n s$. Extrapolação linear realizada para obter diretamente do coeficiente angular suas taxas de entropia. As taxas de informação são obtidas pela subtração $i(r ; s)=h(r)-h(r \mid s)$. Obtemos aproximadamente o mesmo valor para a informação transmitida para ambos os estímulos apresentados. Os mesmo resultados são obtidos para os diferentes tempos de correlação " $\tau$ ". 


\section{Conclusões}

No presente trabalho apresentamos resultados que compreendem: os limites com que a detecção de movimento horizontal é realizada pelo sistema visual da mosca Chrysomya megacephala, resultado que afeta diretamente os processos de geração de estímulo; técnicas para análise e redução de dados neurais, resultado essencial para viabilizar o cálculo de funções de correlação spike-spike de mais altas ordens; e finalmente, resultados sobre o processo de codificação do estímulo em trens de pulsos, resultado que nos possibilita uma imensa redução dimensional no espaço de estímulos. Para estudar esse sistema biológico dispomos de ferramentas de instrumentação eletrônica capazes de realizar a captação de dados de forma confiável, precisa e pouco invasiva. Estas foram desenvolvidas por nossa equipe de instrumentação eletrônica (33) e as descrevemos no capítulo 2, juntamente com uma breve descrição sobre o sistema visual da mosca, desde seus fotoreceptores até o neurônio $H 1$.

No capítulo 3 investigamos a acuidade do sistema visual da mosca. Desenvolvemos um método para observar a atividade do neurônio $H 1$ em diferentes estados de excitação. Ao compararmos as taxas de disparos referentes aos estados de atividade, inibição e repouso, vemos que estas taxas igualam-se ao apresentarmos um estímulo senoidal de amplitude $\widetilde{\Delta \theta} \sim 0,25^{\circ}$ e de velocidade $\omega \sim 1,5^{\circ} . s^{-1}$. O valor encontrado para $\widetilde{\Delta \theta}$ é surpreendente, uma vez que a abertura angular dos omatídeos que formam o olho composto da mosca é da ordem de $1-2^{o}(84)$. Desta forma, podemos afirmar que o sistema visual da mosca é capaz de detectar movimento mesmo para estímulos de amplitude da ordem de quatro a oito vezes menor do que sua abertura interomatidial. A velocidade com que a mosca foi capaz de detectar movimentos também é admirável, uma vez que a mosca pode atingir velocidades até três ordens de magnitude maiores do que este valor durante seu vôo. Isto mostra que seu sistema visual está extremamente adaptado a uma grande faixa de atuação de velocidades, $\sim 1,5-3000^{\circ} . s^{-1}$. Estas medidas esclarecem algumas questões sobre os limites sensoriais deste organismo sob nossas condições experimentais e mostram que nosso sistema de geração de estímulos satisfaz seus requisitos.

Toda informação visual relevante aos neurônios $H 1$ da mosca é codificada em seu 
trem de pulsos. No capítulo 4 construímos uma estimativa do estímulo apresentado para a mosca a partir dos trens de pulsos registrados simultaneamente de ambos neurônios $H 1$, processo de decodificação neural. Utilizamos para construir esta estimativa a expansão de Volterra até segunda ordem, onde faz-se necessário o cálculo dos termos $\left\langle\rho_{a}\left(t_{1}\right) \rho_{b}\left(t_{2}\right) \rho_{c}\left(t_{3}\right) \rho_{d}\left(t_{4}\right)\right\rangle$. Apresentamos um método que evita o cálculo e posterior inversão destas matrizes, tarefa computacionalmente árdua. Este método consiste em expandir nossas variáveis em termos das auto-funções das matrizes de correlação spikes-spike. Desconsideramos os termos que correlacionam as respostas de diferentes H1, estes termos representam apenas $1 \%$ da reconstrução do estímulo. A qualidade de nossa representação Gaussiana é evidenciada ao compararmos seu resultado com o obtido sem aproximações, suas reconstruções diferem em apenas $0,5 \%$. Podemos concluir que apesar de contribuir em apenas $8 \%$, os termos de segunda ordem sempre trazem uma melhora à reconstrução do estímulo.

No capítulo 5 analisamos quais propriedades do estímulo são realmente relevantes aos dois neurônios $H 1$, ou seja, quais atributos do estímulo são codificados em sua resposta neural. Primeiramente geramos uma série de estímulos Gaussianos. Em seguida, abdicamos de nossa liberdade de 16bits, fornecida por nosso gerador de estímulos, para gerar um estímulo com velocidades $v=v^{ \pm}$, estímulo "Digital" de apenas 1bit. Este estímulo reduzido contém apenas o sentido de movimento do estímulo Gaussiano em cada instante de tempo. Constatamos que o papel principal dos neurônios $H 1$ é a detecção e codificação do sentido de movimento ao verificarmos a semelhança entre os trens de pulsos gerados como resposta a estes dois distintos estímulos. A alta correlação entre as reconstruções lineares de ambos os estímulos, valor da ordem de 80-90\%, indica que as propriedades codificadas do estímulo Gaussiano continuam presentes no estímulo "Digital". Este fato é reforçado ao encontramos a mesma quantidade de informação sobre estes estímulos contida em ambos os trens de pulsos, uma diferença contida nos erros envolvidos desta medida - $10 \%$. Ou seja, confirmamos por dois métodos distintos, Reconstrução Linear do Estímulo e Teoria da Informação, que apesar da riqueza presente inicialmente nos estímulos, a propriedade comum aos estímulos Gaussiano e "Digital" - seu sentido de movimento - é o atributo realmente relevante a ser codificado pelos neurônios $H 1$. Ao considerarmos esta sendo a tarefa realizada pelos $H 1$, determinamos que estes a realizam com $85 \%$ de eficiência.

Os resultados apresentados abrem um leque de trabalhos futuros. Por exemplo, devemos desenvolver um modelo capaz de esclarecer o valor encontrado para a acuidade do sistema visual da mosca. Devemos explicar este resultado através do fluxo óptico recebido pelos omatídeos distribuídos geometricamente em seus olhos compostos, considerando a 
imagem mostrada nos monitores. A tremenda redução realizada sobre o espaço de estímulos faz com ambos os espaços, estímulos-respostas, tenham um número próximo de elementos. Este resultado torna factível a confecção de modelos de codificação do estímulo na resposta dos neurônios $H 1$. Estes modelos já estão sendo investigados e serão tópicos de futuras publicações. 


\section{Referências}

1 KANDEL, E. R.; SCHWARTZ, J.; JESSELL, T. Principles of neural science. New York: McGraw-Hill, 2000.

2 LAUGHLIN, S.; SEJNOWSKI, T. Communication in neuronal networks. Science, v. 301, n. 5641, p. 1870-1874, 2003.

3 FARROW, K.; HAAG, J.; BORST, A. Input organization of multifunctional motion-sensitive neurons in the blowfly. Journal of Neuroscience, v. 23, n. 30, p. 9805-9811, 2003.

4 BORST, A.; HAAG, J. Neural networks in the cockpit of the fly. Journal of Comparative Physiology A: Neuroethology, Sensory, Neural and Behavioral Physiology, v. 188, n. 6, p. 419-437, 2002.

5 FRYE, M. A.; DICKINSON, M. H. Fly flight: a model for the neural control of complex behavior. Neuron, v. 32, n. 3, p. 385-388, 2001.

6 HAAG, J.; BORST, A. Recurrent network interactions underlying flow-field selectivity of visual interneurons. Journal of Neuroscience, v. 21, n. 15, p. 5685-5692, 2001.

7 HAAG, J.; VERMEULEN, A.; BORST, A. The intrinsic elactrophysiological characteristics of fly lobula plate tangential cells: Iii. visual response properties. Journal of Computational Neuroscience, v. 7, n. 3, p. 213-234, 1999.

8 HAUSEN, K. The lobula-complex of the fly: structure, function and significance in visual behaviour. In: ALI, M. A. (Ed.). Photoreception and vision in invertebrates. New York: Plenum Press, 1982. v. 74.

9 HAUSEN, K. Motion sensitive interneurons in the optomotor system of the fly .1. the horizontal cells - structure and signals. Biological Cybernetics, v. 45, n. 2, p. 143-156, 1982. 
10 HAUSEN, K. Motion sensitive interneurons in the optomotor system of the fly .2. the horizontal cells - receptive-field organization and response characteristics. Biological Cybernetics, v. 46, n. 1, p. 67-79, 1982.

11 HAUSEN, K. Monokulare und binokulare bewegungsauswertung in der lobula plate der fliege. Verhandlungen der Deutschen Zoologischen Gesellschaft, p. 49-70, 1981.

12 KURTZ, R. et al. Adaptation accentuates responses of fly motion-sensitive visual neurons to sudden stimulus changes. Proceedings of the Royal Society of London B: Biological sciences, v. 276, n. 1673, p. 3711-3719, 2009.

13 KRAPP, H. G. Sensory integration: neuronal adaptations for robust visual self-motion estimation. Current Biology, v. 19, n. 10, p. R413-R416, 2009.

14 SPAVIERI, D. L. Effect of temperature and light on the representation of motion information in the fly's visual system. 2009. 89 p. Thesis (Doctoral) Ludwig-Maximilians Universität, München, 2009.

15 NEMENMAN, I. et al. Neural coding of natural stimuli: information at sub-millisecond resolution. Plos Computational Biology, v. 4, n. 3, p. 1-12, 2008.

16 HAAG, J.; BORST, A. Electrical coupling of lobula plate tangential cells to a heterolateral motion-sensitive neuron in the fly. Journal of Neuroscience, v. 28, n. 53, p. 14435-14442, 2008.

17 HOUGHTON, C.; SEN, K. A new multineuron spike train metric. Neural Computation, v. 20, n. 6, p. 1495-1511, 2008.

18 HUSTON, S. J.; KRAPP, H. G. Visuomotor transformation in the fly gaze stabilization system. PLoS Biology, v. 6, n. 7, p. 1468-1478, 2008.

19 CHURCHLAND, P. S.; SEJNOWSKI, T. J. The computational brain. Cambridge, Mass.: Massachusetts Institute of Technology Press, 1992.

20 LENTINK, D.; DICKINSON, M. Biofluiddynamic scaling of flapping, spinning and translating fins and wings. Journal of Experimental Biology, v. 212, n. 16, p. 2691-2704, 2009. 
21 LENTINK, D.; DICKINSON, M. Rotational accelerations stabilize leading edge vortices on revolving fly wings. Journal of Experimental Biology, v. 212, n. 16, p. 2705-2719, 2009.

22 REISER, M. B.; DICKINSON, M. A modular display system for insect behavioral neuroscience. Journal of Neuroscience Methods, v. 167, n. 2, p. 127-139, 2008 .

23 TAIRA, K. et al. Unsteadiness in flow over a flat plate at angle-of-attack at low reynolds numbers. In: AIAA AEROSPACE SCIENCES MEETING, 45, 2007, Reston, Virginia. Collection of technical papers. Reston, Virginia. AIAA Publisher, 2007. v. 13, p. 8791-8806.

24 DICKSON, W. B. et al. An integrative model of insect flight control. In: AIAA AEROSPACE SCIENCES MEETING, 44, 2006, Reston, Virginia. Collection of technical papers. Reston, Virginia. AIAA Publisher, 2006. v. 1, p. 431-449.

25 POELMA, C.; DICKSON, W. B.; DICKInSON, M. H. Time-resolved reconstruction of the full velocity field around a dynamically-scaled flapping wing. Experiments in Fluids, v. 41, n. 2, p. 213-225, 2006.

26 SRINIVASAN, M. V.; ZHANG, S. Visual motor computations in insects. Annual Review of Neuroscience, v. 27, p. 679-696, 2004.

27 DICKINSON, M. H.; LEHMANN, F. O.; SANE, S. P. Wing rotation and the aerodynamic basis of insect flight. Science, v. 284, n. 5422, p. 1954-1960, 1999.

28 BOEDDEKER, N. et al. Responses of blowfly motion-sensitive neurons to reconstructed optic flow along outdoor flight paths. Journal of Comparative Physiology A: Neuroethology, Sensory, Neural and Behavioral Physiology, v. 191, n. 12 , p. $1143-1155,2005$.

29 HATEREN, J. H. van et al. Function and coding in the blowfly h1 neuron during naturalistic optic flow. Journal of Neuroscience, v. 25, n. 17, p. 4343-4352, 2005.

30 TATler, B.; O'CARROLL, D. C.; LAUGHLin, S. Temperature and the temporal resolving power of fly photoreceptors. Journal of Comparative Physiology A: Neuroethology, Sensory, Neural and Behavioral Physiology, v. 186, n. 4, p. 399-407, 2000. 
31 SCHILSTRA, C.; HATEREN, J. V. Stabilizing gaze in flying blowflies. Nature, v. 395, n. 6703, p. 654, 1998.

32 MCCANN, G. D.; MACGINITIE, G. F. Optomotor response studies of insect vision. Proceedings of the Royal Society of London B: Biological sciences, v. 163, n. 992, p. 369-401, 1965.

33 ALMEIDA, L. O. B. Desenvolvimento de intrumentação eletrônica para estudos de codificações neurais no duto óptico em moscas. 2006. 86 p. Dissertação (Mestrado) - Instituto de Física de São Carlos, Universidade de São Paulo, São Carlos, SP, 2006.

34 WAGNER, H. Aspects of the free flight behaviour of houseflies (musca domestica). In: GEWECKE, M.; WENDLER, G. (Ed.). Insect locomotion. Berlin, Hamburg: Paul Parey, 1985. p. 223-232.

35 WEHRHAHN, C.; POGGIO, T.; BUlThOFF, H. Tracking and chasing in houseflies (musca) - an analysis of 3-d flight trajectories. Biological Cybernetics, v. 45, n. 2, p. 123-130, 1982.

36 BUELTHOFF, H.; POGGIO, T.; WEHRHAHN, C. 3-d analysis of the flight trajectories of flies (drosophila melanogaster). Zeitschrift Fur Naturforschung C: Journal of Biosciences, v. 35, n. 9-10, p. 811-815, 1980.

37 LAND, M. F.; COLLETT, T. S. Chasing behavior of houseflies (fannia canicularis) - description and analysis. Journal of Comparative Physiology, v. 89, n. 4, p. 331-357, 1974.

38 SHLENS, J. et al. Estimating information rates with confidence intervals in neural spike trains. Neural Computation, v. 19, n. 7, p. 1683-1719, 2007.

39 DOUGLASS, J. K.; STRAUSFELD, N. J. Retinotopic pathways providing motion-selective information to the lobula from peripheral elementary motiondetecting circuits. Journal of Comparative Neurology, v. 457, n. 4, p. 326-344, 2003.

40 BRENNER, N. et al. Synergy in a neural code. Neural Computation, v. 12, n. 7, p. 1531-1552, 2000.

41 BORST, A.; THEUNISSEN, F. E. Information theory and neural coding. Nature Neuroscience, v. 2, n. 11, p. 947-957, 1999. 
42 STRONG, S. P. et al. Entropy and information in neural spike trains. Physical Review Letters, v. 80, n. 1, p. 197-200, 1998.

43 STEVENINCK, R. D. R. V.; BIALEK, W. Real-time performance of a movement-sensitive neuron in the blowfly visual system: coding and information transfer in short spike sequences. Proceedings of the Royal Society B: Biological Sciences, v. 234, n. 1277, p. 379-414, 1988.

44 SRINIVASAN, M.; DVORAK, D. Spatial processing of visual information in the movement-detecting pathway of the fly: characteristics and functional significance. Journal of Comparative Physiology A, v. 140, n. 1, p. 1-23, 1980.

45 SNYDER, A.; STAVENGA, D.; LAUGHLIN, S. Spatial information capacity of compound eyes. Journal of Comparative Physiology A, v. 116, n. 2, p. 183-207, 1977.

46 MARTIN, S. The Volterra and Wiener theories of nonlinear systems. [S.1.]: Krieger Publishing Co., Inc., 2006.

47 COVER, T. M.; THOMAS, J. A. Elements of information theory. 2nd. ed. Hoboken, N.J.: Wiley-Interscience, 2006.

48 SHANNON, C. E.; WEAVER, W. The mathematical theory of communication. Urbana: University of Illinois Press, 1949.

49 LINHARES, A. X. The gonotrophic cycle of chrysomya megacephala (diptera: Calliphoridae) in the laboratory. Revista Brasileira de Entomologia, v. 32, n. 3, p. 383-392, 1988.

50 GOMES, G. Processos auto-organizados: efeitos de substâncias químicas que agem no sistema nervoso sobre o desenvolvimento e padrão de dispersão larval pósalimentar de dípteros (Calliphoridae e Muscidae). 2006. 202 p. Dissertação (Mestrado) - Instituto de Biociências de Rio Claro, Universidade Estadual Paulista, Rio Claro, SP, 2006.

51 LEAL, T. T. S.; PRADO, A. P.; ANTUNES, A. J. Rearing the larvae of the blow fly chrysomya chloropyga on oligidic diets. Revista Brasileira de Zoologia, v. 1, n. 1, p. 41-44, 1982.

52 GABRE, R. A.; ADHAM, F. K.; CHI, H. Life table of chrysomya megacephala (fabricius) (diptera : Calliphoridae). Acta Oecologica: International Journal of Ecology, v. 27, n. 3, p. 179-183, 2005. 
53 CASTRO, N. H. H. de. Multifractalidade no código neural da mosca. 2008. 69 p. Dissertação (Mestrado) — Instituto de Física de São Carlos, Universidade de São Paulo, São Carlos, SP, 2008.

54 ANJOS, C. A. S. dos. Registro dos neurônios H1. 2006. 52 p. Dissertação (Mestrado) - Instituto de Física de São Carlos, Universidade de São Paulo, São Carlos, SP, 2006.

55 PINTO, B. D. L. Translação e rotação: 'processamento de informação no sistema visual da mosca. 2005. 80 p. Dissertação (Mestrado) — Instituto de Física de São Carlos, Universidade de São Paulo, São Carlos, SP, 2005.

56 SPAVIERI, D. L. Codificação neural e integração dendrítica no sistema visual da mosca. 2004. 53 p. Dissertação (Mestrado) — Instituto de Física de São Carlos, Universidade de São Paulo, São Carlos, SP, 2004.

57 FRANCESCHINI, N. Retinal mosaic of the fly compound eye. In: ALI, M. A. (Ed.). Photoreception and vision in invertebrates. New York: Plenum Press, 1982. v. 74 .

58 KIRSCHFELD, K. The visual system of the fly: physiological optics and functional anatomy as related to behaviour. In: SCHMITT, F. O.; WORDEN, F. G. (Ed.). The neurosciences 4th study program. Cambridge: MIT Press, 1979.

59 LI, Y.; BAKER, N. E. The roles of cis-inactivation by notch ligands and of neuralized during eye and bristle patterning in drosophila. BMC Developmental Biology, v. 4, n. 1, p. 1-41, 2004.

60 BRISCOE, A. D.; CHITTKA, L. The evolution of color vision in insects. Annual Review of Entomology, v. 46, p. 471-510, 2001.

61 STAVENGA, D. G. Refractive-index of fly rhabdomeres. Journal of Comparative Physiology, v. 91, n. 4, p. 417-426, 1974.

62 HARDIE, R. C. Electrophysiological analysis of fly retina. comparative properties of r1-6 and r7 and r8. Journal of Comparative Physiology A: Neuroethology, Sensory, Neural and Behavioral Physiology, v. 129, p. 19-33, 1979.

63 HARDIE, R. C. Functional organisation of the fly retina. Progress in Sensory Physiology, v. 5, p. 1-79, 1985. 
64 SCHWERMER, J. Visual pigments of compound eyes structure, photochemistry, and regeneration. In: STAVENGA, D. G.; HARDIE, R. C. (Ed.). Facets of vision. Berlin, Heidelberg, New York: Springer Verlag, 1989. p. 112-133.

65 VOGT, K.; KIRSCHFELD, K. Chemical identity of the chromophores of fly visual pigment. Naturwissenschaften, v. 71, n. 4, p. 211-213, 1984.

66 VOGT, K. Is the fly visual pigment a rhodopsin. Zeitschrift Für Naturforschung C: Journal of Biosciences, v. 38, n. 3-4, p. 329-333, 1983.

67 LAUGHLIN, S. B. Principles of sensory coding and processing: general introduction. Journal of Experimental Biology, v. 146, p. R1-R8, 1989.

68 LAUGHLIN, S. B. The roles of the parallel channels in the early visual processing by the arthropod compound eye. In: ALI, M. A. (Ed.). Photoreception and vision in invertebrates. New York: Plenum Press, 1982. v. 74.

69 DOUGLASS, J. K.; STRAUSFELD, N. J. Anatomical organization of retinotopic motion-sensitive pathways in the optic lobes of flies. Microscopy Research and Technique, v. 62, n. 2, p. 132-150, 2003.

70 STRAUSFELD, N. J. Functional neuroanatomy of the blowfly's visual system. In: ALI, M. A. (Ed.). Photoreception and vision in invertebrates. New York: Plenum Press, 1982. v. 74.

71 DAYAN, P.; ABBOTT, L. F. Theoretical neuroscience: computational and mathematical modeling of neural systems. Cambridge, Mass.: Massachusetts Institute of Technology Press, 2001.

72 RIEKE, F. et al. Spikes: exploring the neural code. Cambridge, MA, USA: MIT Press, 1999.

73 TEKTRONIX. TEK Instruction manual: 608 monitor with options. Beaverton, Oregon, USA, 1987.

74 UHLENBECK, G. E.; ORNSTEIN, L. S. On the theory of the brownian motion. Physical Review, v. 36, n. 5, p. 0823-0841, 1930.

75 LEWICKI, M. S. A review of methods for spike sorting: the detection and classification of neural action potentials. Network-Computation in Neural Systems, v. 9, n. 4, p. 53-78, 1998. 
76 WARZECHA, A.-K.; EGELHAAF, M. Response latency of a motion-sensitive neuron in the fly visual system: dependence on stimulus parameters and physiological conditions. Vision Research, v. 40, n. 21, p. 2973-2983, 2000.

77 WARZECHA, A.-K.; HORSTMANN, W.; EGELHAAF, M. Temperaturedependence of neuronal performance in the motion pathway of the blowfly calliphora erythrocephala. Journal of Experimental Biology, v. 202, n. 22, p. 3161-3170, 1999.

78 LEWEN, G. D.; BIALEK, W.; STEVEnINCK, R. R. D. van. Neural coding of naturalistic motion stimuli. Network-Computation in Neural Systems, v. 12, n. 3, p. 317-329, 2001.

79 EGELHAAF, M. et al. Outdoor performance of a motion-sensitive neuron in the blowfly. Vision Research, v. 41, n. 27, p. 3627-3637, 2001.

80 LAND, M. Visual acuity in insects. Annual Review of Entomology, v. 42, p. 147-177, 1997.

81 BEYNON, J. Visual acuity and the eye. Physics Education, v. 20, n. 5, p. 234-237, 1985.

82 SNYDER, A. Acuity of compound eyes: physical limitations and design. Journal of Comparative Physiology A, v. 116, n. 2, p. 161-182, 1977.

83 FEYNMAN, R. P.; LEIGHTON, R. B.; SANDS, M. The Feynman lectures on physics. Redwood City, California: Addison-Wesley, 1963.

84 HATEREN, J. van et al. The bright zone, a specialized dorsal eye region in the male blowfly chrysomyia megacephala. Journal of Comparative Physiology A, v. 164, n. 3, p. 297-308, 1989. 


\section{APÊNDICE A - Processo de Ornstein-Uhlenbeck}

A posição ocupada pela imagem a cada $2 m s$ é determinada por um arquivo de posição gerado no computador. Este conjunto de posições é obtido ao integrarmos uma série de velocidades gerada por um processo estatístico denominado processo de OrnsteinUhlenbeck (47). Esta série temporal de velocidades $V_{t}$ é obtida da seguinte maneira,

$$
V_{t+\Delta}=c+\alpha \times V_{t}+\Phi_{t},|\alpha|<1 \text {. }
$$

Onde os valores " $\Phi_{t}$ " são obtidos de uma distribuição Gaussiana de média zero e desvio " $\sigma_{\Phi}^{2}$ ". O termo " $\alpha$ " representa quanto o próximo valor $V_{t+\Delta}$ está correlacionado com o valor anterior $V_{t}$. Veremos como a escolha de $\alpha$ determina a escala temporal de correlação entre os valores de $V_{t}$. O termo " $c$ " representa uma velocidade constante.

Para determinarmos o valor médio desta série temporal, efetuamos a média sobre ensembles da equação A.1,

$$
\left\langle V_{t+\Delta}\right\rangle=c+\alpha \times\left\langle V_{t}\right\rangle+\left\langle\Phi_{t}\right\rangle
$$

Como temos $\left\langle\Phi_{t}\right\rangle=0$

$$
\begin{array}{r}
\langle V\rangle=c+\alpha \times\langle V\rangle \\
\langle V\rangle=\frac{c}{1-\alpha} .
\end{array}
$$

Em geral teremos, $c=0$, ou seja, $\langle V\rangle=0$.

Para obtermos o desvio da distribuição $V_{t}$ de média zero, precisamos obter a média de seus valores ao quadrado. 


$$
\begin{array}{r}
V_{t+\Delta}^{2}=\left[\alpha \times V_{t}+\Phi_{t}\right]^{2} \\
\left\langle V^{2}\right\rangle=\alpha^{2}\left\langle V^{2}\right\rangle+\left\langle\Phi^{2}\right\rangle+2 \alpha\langle V \times \Phi\rangle .
\end{array}
$$

O produto de duas distribuições independentes e simétricas resulta em uma distribuição simétrica de média zero. Ou seja,

$$
\langle V \times \Phi\rangle=0
$$

Reescrevendo, $\left\langle\Phi^{2}\right\rangle \equiv \sigma_{\Phi}^{2}$ temos,

$$
\sigma_{V}^{2}=\left\langle V^{2}\right\rangle-\langle V\rangle^{2}=\frac{\sigma_{\Phi}^{2}}{1-\alpha^{2}}
$$

Vemos que para $\alpha \rightarrow 0$, reobtemos a distribuição Gaussiana inicial, $V \rightarrow \Phi$.

Podemos calcular a influência da correlação introduzida por $\alpha$ na determinação dos próximos valores desta série temporal. Escreveremos $V_{t+N} \equiv V_{N}$, ou seja, $V_{t} \equiv V_{0}$. Desta forma, iterativamente,

$$
\begin{aligned}
& V_{1}=\alpha V_{0}+\Phi_{0} \\
& V_{2}=\alpha V_{1}+\Phi_{1}=\alpha\left(\alpha V_{0}+\Phi_{0}\right)+\Phi_{1}=\alpha^{2} V_{0}+\alpha \Phi_{0}+\Phi_{1} \\
& V_{3}=\alpha V_{2}+\Phi_{2}=\alpha\left(\alpha^{2} V_{0}+\alpha \Phi_{0}+\Phi_{1}\right)+\Phi_{2}=\alpha^{3} V_{0}+\alpha^{2} \Phi_{0}+\alpha \Phi_{1}+\Phi_{2}
\end{aligned}
$$

Consequentemente,

$$
V_{N}=\alpha^{N} V_{0}+\sum_{i=0}^{N-1} \alpha^{i} \Phi_{N-1-i} .
$$

Ao multiplicarmos a expressão acima por $V_{0}$ e efetuarmos novamente a média sobre ensembles, obteremos a correlação entre a velocidade no tempo $t$ e $t+\Delta$.

$$
\left\langle V_{N} V_{0}\right\rangle=\alpha^{N}\left\langle V_{0}^{2}\right\rangle+\left\langle V_{0} \sum_{i=0}^{N-1} \alpha^{i} \Phi_{N-1-i}\right\rangle .
$$

Mais uma vez ultilizando o fato da multiplicação de duas distribuições independentes de média zero ter média zero, 


$$
\sum_{i=0}^{N-1} \alpha^{i}\left\langle V_{0} \Phi_{N-1-i}\right\rangle=0
$$

e utilizando a equação A.8,

$$
\left\langle V_{N} V_{0}\right\rangle=\alpha^{N} \sigma_{V}^{2}=\alpha^{N} \frac{\sigma_{\Phi}^{2}}{1-\alpha^{2}}
$$

Podemos reescrever esta expressão a fim de obtermos a relação entre $\alpha$ e o tempo de correlação do estímulo $\tau$,

$$
\begin{aligned}
\left\langle V_{t+N} V_{t}\right\rangle & =\frac{\sigma_{\Phi}^{2}}{1-\alpha^{2}} \times e^{-N / \tau} \\
\tau & =-\frac{1}{\ln |\alpha|}
\end{aligned}
$$

Ou seja, apartir do processo de Ornstein-Uhlenbeck (equação A.1, c =0) geramos uma série temporal Gaussiana de média zero (equação A.4), desvio $\sigma_{V}$ (equação A.8) e correlação temporal $\tau$ (equação A.17). 


\section{APÊENICE B - Medida Direta da Informação}

\section{B.1 Um neurônio H1}

Como descrito anteriormente, apresentamos um estímulo para a mosca que consiste de um conjunto $\mathcal{S}:\left\{S(t), S_{i}(t)\right\}, i=1 \ldots M$ estímulos. $S(t)$ repete-se $M$ vezes ao longo do experimento intercalado por um estímulo distinto $S_{i}(t), i=1 . . M$ com 10 segundos de duração. Como resposta a estes estímulos, obtemos um conjunto $\mathcal{R}:\left\{R_{i}(t)\right\}, i=1 \ldots M$ trens de pulsos. Estes trens de pulsos resultam da discretização do eixo temporal em unidades $\Delta \tau=2 \mathrm{~ms}=1 \mathrm{bin}$. Escrevemos esta resposta como um vetor rotulando com o símbolo 1 os tempos em que ocorreram pulsos e com 0's os que não ocorreram. A resposta neuronal torna-se,

$$
\rho(t)=\sum_{i}^{N_{s}} \delta\left(t-t_{i}\right),
$$

onde $N_{s}$ é o número total de disparos do neurônio no experimento e $t_{i}$ os instantes em que estes ocorreram (" $t$ " representa os índices do vetor " $\rho$ "). Toda informação relevante para a mosca sobre o estímulo é então codificada pelo neurônio H1 nos tempos $t_{i}$.

Separamos do conjunto $\mathcal{S}$ apenas as respostas devido ao estímulo repetido $S(t)$ para compará-las. Caso não houvessem fontes de ruído, todas estas respostas deveriam ser idênticas*. Medimos a capacidade de codificação do neurônio H1 através das diferenças presentes entre estas respostas. Quanto maior for a diversidade de respostas geradas ao estímulo $S(t)$, menor será a eficiência com que o neurônio o codifica. Esta diversidade de respostas é medida por sua entropia, equação B.2 - $p_{i}$ : probabilidade de ocorrência da resposta " $i$ ". No caso ideal só temos uma possível resposta e sua entropia é nula. No outro extremo, qualquer resposta é igualmente gerada e sua entropia é máxima, equações B.3.

\footnotetext{
* Isto ocorreria já que inibimos o efeito de adaptação introduzindo $S_{i}(t)$ entre duas repetições de $S(t)$.
} 


$$
\begin{array}{r}
H=-\sum_{i=1}^{N} p_{i} \log _{2}\left(p_{i}\right)[\text { bits }] ; \sum_{i=1}^{N} p_{i}=1 \\
N=1: p_{i}=1 \quad \longrightarrow H_{\min }=0 \\
p_{i}=1 / N \quad \longrightarrow H_{\max }=\log _{2}(N)
\end{array}
$$

Denotamos por $H(R \mid S)$ a entropia das respostas " $R$ " geradas por um dado estímulo " $S$ ". De forma geral, esta pode ser calculada da seguinte forma:

1. Contabilizamos todos os possíveis estímulos " $s_{i}$ ";

2. Calculamos a probabilidade " $p\left(s_{i}\right)$ " com que cada estímulo " $s_{i}$ " ocorre;

3. Fixamos determinado " $s_{i}$ ";

4. Contabilizamos todas as possíveis respostas " $r_{j}$ " geradas por " $s_{i}$ ";

5. Calculamos a probabilidade " $p\left(r_{j}\right)$ " com que cada resposta " $r_{j}$ " ocorre;

6. Calculamos a equação B.2 sobre o conjunto de probabilidades " $p\left(r_{j}\right)$ ", obtendo " $H\left(R \mid s_{i}\right)^{\prime \prime}$;

7. Repetimos os ítens de $3-6$ para todo " $s_{i}$ ";

8. Efetuamos a soma $H(R \mid S)=\sum_{i} p\left(s_{i}\right) H\left(R \mid s_{i}\right)$;

Sabemos que $H(R \mid S)=0$ representa a codificação perfeita, um estímulo gera sempre a mesma resposta. Entretanto, qual a qualidade da codificação feita pelo H1 ao obtermos $H(R \mid S) \neq 0$ ?

Medimos a qualidade da codificação ao compararmos $H(R \mid S)$ com $H(R)$, ou seja, comparamos a variabilidade de todas as respostas obtidas independente do estímulo apresentado com as respostas geradas ao fixarmos certo estímulo. $H(R)$ é calculado diretamente pela equação B.2 utilizando a probabilidade de todas as possíveis respostas " $r$ ". Denominamos $H(R)$ por "Entropia Total da Resposta" e $H(S \mid R)$ por "Entropia do Ruído". Caso $H(R)=H(R \mid S)$, temos que o neurônio responde a um dado estímulo com a mesma variabilidade com que responde a diferentes estímulos. Ou seja, não há informação sobre o estímulo contida nas respostas. Sendo assim, definimos,

$$
I(R ; S)=H(R)-H(R \mid S)
$$


Da mesma forma descrita anteriormente, podemos implementar um algoritmo para calcular $H(S)$ ("Entropia Total do Estímulo") e $H(S \mid R)$ ("Entropia do Estímulo dado a Resposta"). Neste caso medimos quanto diminui a incerteza sobre o estímulo ao sabermos as respostas geradas por este. Em suma,

$$
\begin{gathered}
H(R \mid S)=-\sum_{S} p(S) \sum_{R} p(R \mid S) \log _{2} p(R \mid S) \\
H(S \mid R)=-\sum_{R} p(R) \sum_{S} p(S \mid R) \log _{2} p(S \mid R) \\
I(R ; S)=I(S ; R)=H(R)-H(R \mid S)=H(S)-H(S \mid R) .
\end{gathered}
$$

A eficiência com que estes processos são realizados é definida da seguinte forma.

$$
\begin{gathered}
\epsilon_{R}=\frac{H(R)-H(R \mid S)}{H(R)}=1-\frac{H(R \mid S)}{H(R)} . \\
\epsilon_{S}=\frac{H(S)-H(S \mid R)}{H(S)}=1-\frac{H(S \mid R)}{H(S)} .
\end{gathered}
$$

Nesta seção nos restringimos ao cálculo de $\epsilon \equiv \epsilon_{R}$. Vemos a importância da definição de " $\epsilon$ " no caso em que obtemos valores elevados tanto para $H(R)$ quanto $H(R \mid S)$. Desta forma, sua diferença $I(R ; S)$ é alta e ainda assim não representa uma boa codificação realizada pela resposta neural, baixa eficiência.

Podemos eliminar os passos $\mathbf{1} \mathbf{- 3}$ do procedimento descrito anteriormente ao alinharmos os $M$ diferentes trens de pulsos obtidos como resposta ao conjunto "S $\mathcal{S}$ " e compará-los diretamente (Figura B.1). Todas as respostas contidas numa mesma coluna do raster-plot foram geradas por um mesmo estímulo. Com este procedimento, a soma presente no passo oito é substituída pela média sobre as diferentes colunas do raster, média temporal. A substituição da soma sobre a distribuição de estímulos pela média temporal é válida se o experimento for suficientemente longo e a história do estímulo for suficientemente rica (40).

Definimos uma janela de comprimento $L$ símbolos para calcular a probabilidade com que cada resposta é gerada. Devido a resposta do neurônio ser binária ${ }^{\dagger}$, teremos nesta janela de comprimento $L$ um número $N=2^{L}$ possíveis respostas do neurônio (Figura B.2). Sendo assim, tanto a Entropia Total quanto a Entropia do Ruído devem ser rotuladas com o parâmetro $L, H_{L}(R)$ e $H_{L}(R \mid S)$. Evidentemente, ao aumentarmos o parâmetro $L$, o $\dagger^{\dagger}$ : se não há disparo; 1: se há disparo de $\mathrm{H} 1$. 


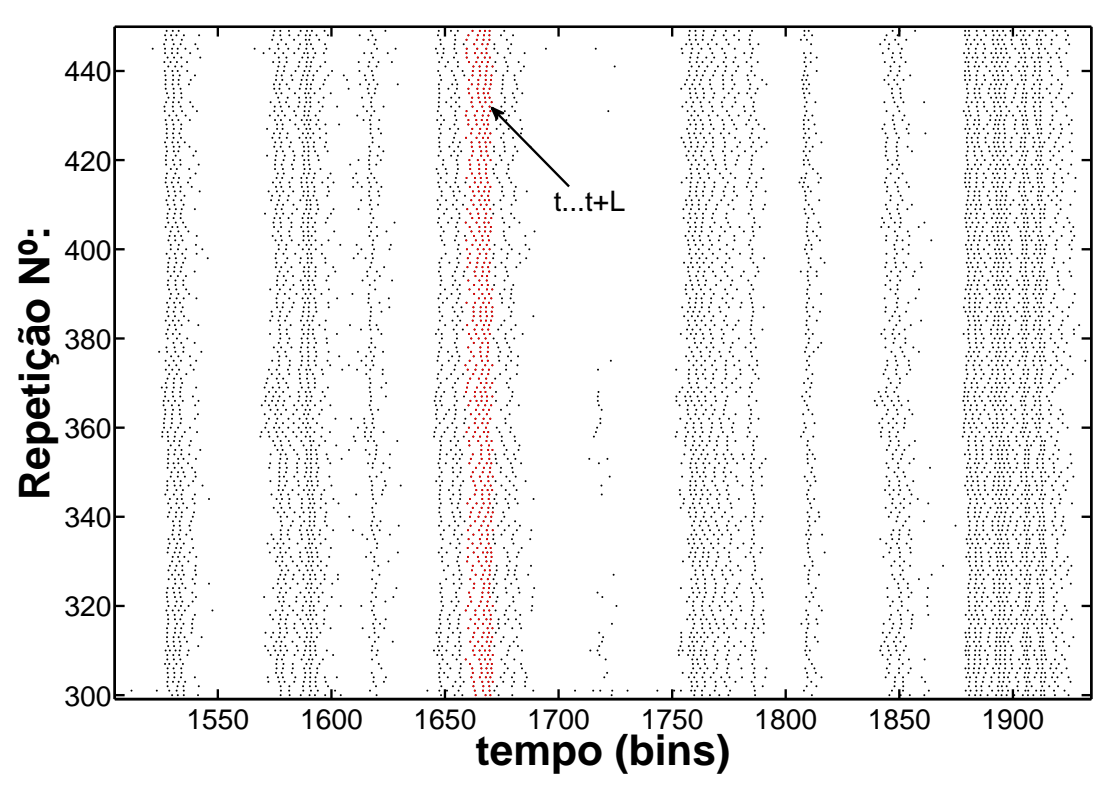

Figura B.1 - Raster-plot. Ao compararmos as $M$ respostas geradas pelo neurônio em forma de um raster-plot, percebemos a variabilidade com que este gera pulsos a um mesmo estímulo. Em vermelho, mostramos um exemplo de um subconjunto de trens de pulsos de comprimento $L=12$ bins gerados por um mesmo estímulo. A média sobre os valores da entropia de cada coluna do raster é denominada entropia do ruído, $H(R \mid S)$.

valor de ambas entropias crescem. A taxa com que este aumento ocorre é definida da seguinte forma $(47,48)$,

$$
\begin{array}{r}
h(R)=\lim _{L \rightarrow \infty} \frac{H_{L}(R)}{L}\left[\text { bits.s }^{-1}\right] \\
h(R \mid S)=\lim _{L \rightarrow \infty} \frac{H_{L}(R \mid S)}{L}\left[\text { bits.s }^{-1}\right] .
\end{array}
$$

A unidade das equações acima é obtida ao medirmos o valor de " $L$ " em segundos.

Para determinar estas taxas calculamos a razão $H_{L}(R) / L$ e $H_{L}(R \mid S) / L$ para diferentes valores de $L$. A extrapolação $L \rightarrow \infty$ é realizada seguindo o procedimento descrito em (42). Representamos este processo no gráfico visto na Figura B.3, no qual temos $1 / L$ em seu eixo " $x$ ". Desta forma $L \rightarrow \infty$ equivale a $x \rightarrow 0$. Realizamos uma extrapolação linear obtendo seus coeficientes. O ajuste linear realizado na Figura B.3 implica na seguinte expressão para $H_{L}(R)$, 


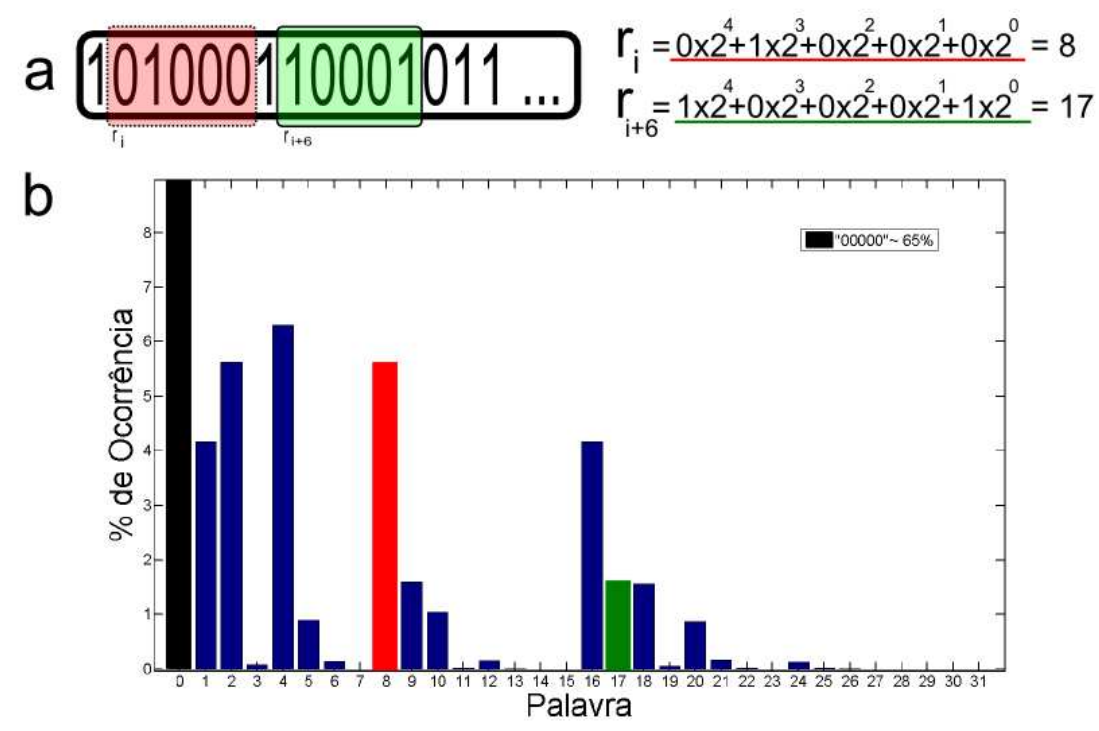

Figura B.2 - Histograma de "palavras". (a) Transformamos a resposta binária do neurônio de comprimento $L=5$ em um número decimal. Temos $N=2^{5}=32$ possíveis respostas, mas, nem todas ocorrem. Para cada instante de tempo " $t_{i}$ " temos uma resposta " $r$ ". Em (b) vemos a distribuição destas respostas. Marcamos em vermelho e verde as respostas transformadas em (a). Em preto marcamos a resposta de maior ocorrência "00000".

$$
\begin{array}{r}
f(L) \equiv H_{L}(R) / L=h(R)+\mathcal{C} / L \\
H_{L}(R)=h(R) \times L+\mathcal{C} .
\end{array}
$$

Da mesma forma para $H_{L}(R \mid S)$,

$$
\begin{array}{r}
g(L) \equiv H_{L}(R \mid S) / L=h(R \mid S)+\mathcal{C}^{\prime} / L \\
H_{L}(R \mid S)=h(R \mid S) \times L+\mathcal{C}^{\prime} .
\end{array}
$$

Ao efetuarmos $\lim _{1 / L \rightarrow 0}$ sobre $f(L)$ e $g(L)$, obtemos os parâmetros $h(R)$ e $h(R \mid S)$ através de seus coeficientes lineares. Utilizamos nesta extrapolação apenas os menores valores de $L$ uma vez que valores maiores apresentam problemas de sub-amostragem. Em um experimento de 40 minutos temos $40 \times 60 \times 500=1,2 \times 10^{6}$ aquisições de respostas do neurônio. Este número não é suficiente para obtermos boa ocupação (número de aquisições maior do que número de possíveis respostas) já para $L=20, N=2^{L}=2^{20} \sim 10^{6}$ possíveis respostas. Para cada unidade do valor de $L$ que desejamos adicionar, devemos dobrar o tempo de aquisição da resposta do H1. 


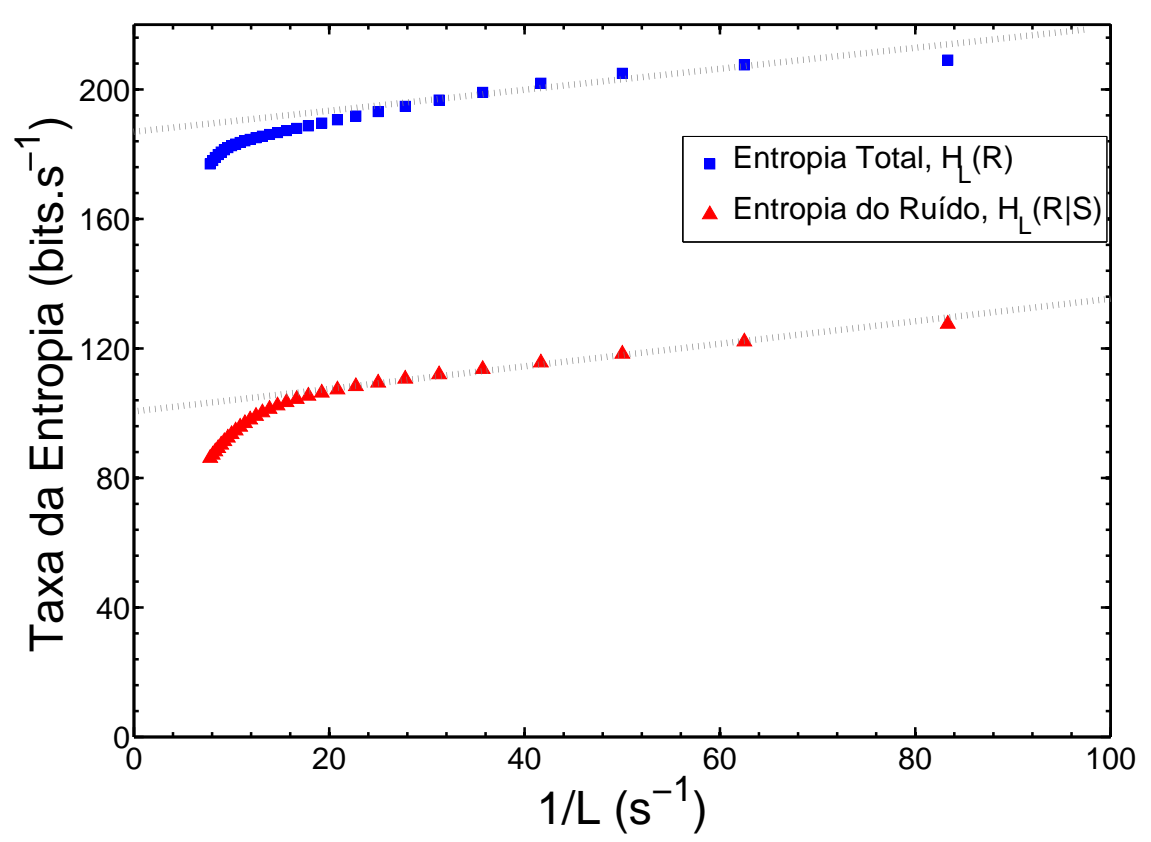

Figura B.3 - Entropia total e do ruído por unidade de tempo. Extrapolamos o tamanho $L$ da palavra para infinito (tracejado em cinza). Em azul a Entropia Total e em vermelho a Entropia do Ruído. Vemos o efeito de sub-amostragem para $(1 / L) \sim 15 s^{-1}$.

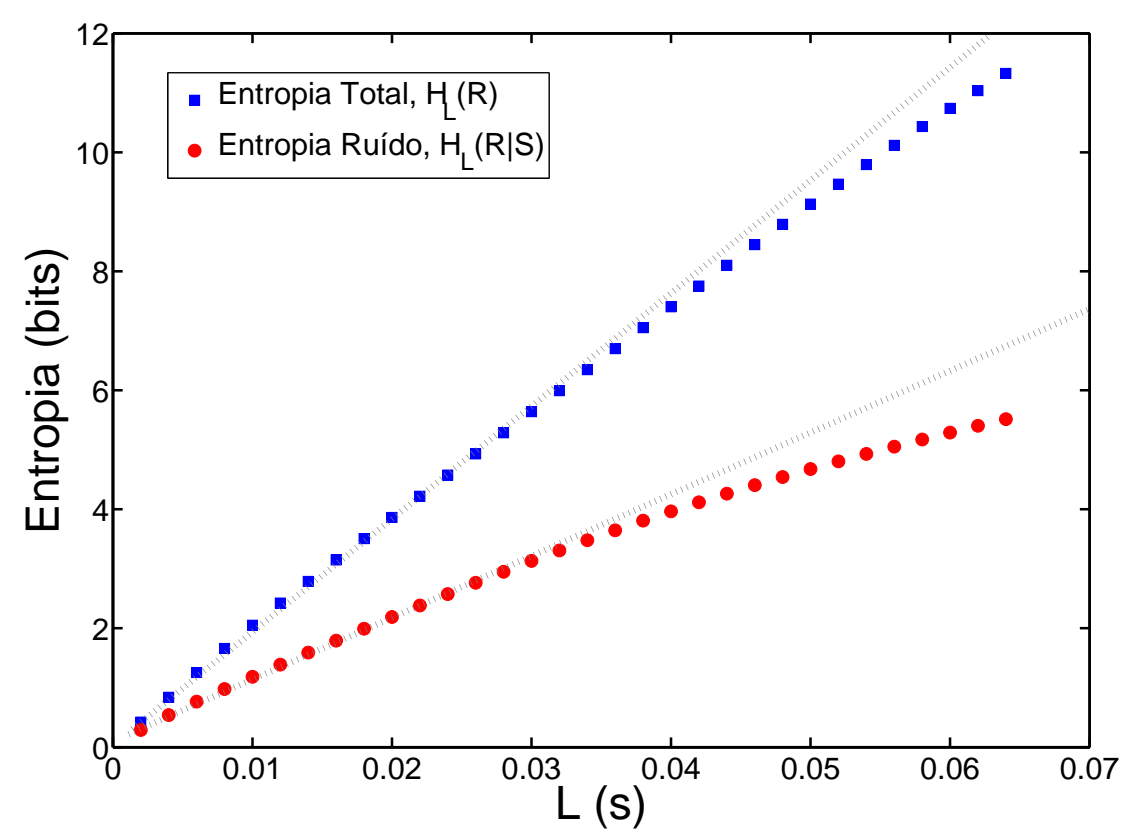

Figura B.4 - Entropia total e do ruído. Determinamos a taxa de informação transmitida pelo neurônio $\mathrm{H} 1$ através dos coeficientes angulares das curvas de $H_{L}(R)$ (azul) e $H_{L}(R \mid S)$ (vermelho). Para o ajuste linear, consideramos apenas os valores de $L=1 \ldots 8$ bins devido aos efeitos de sub-amostragem. 
De forma mais intuitiva, podemos obter as taxas de entropia $h(R)$ e $h(R \mid S)$ diretamente do coeficiente angular das expressões B.13 e B.15 (Figura B.4). Com ambos os procedimentos obtemos,

Tabela 6 - Taxa de informação transmitida pelo neurônio H1. Taxas de Entropia Total, $h(R)$, e do Ruído, $h(R \mid S)$, a partir do coeficiente "Linear" de $f(L)$ e $g(L)$ e através do coeficiente "Angular" de $H_{L}(R)$ e $H_{L}(R \mid S)$. Obtemos praticamente o mesmo valor para a taxa de informação transmitida em ambos os métodos.

\begin{tabular}{|c|c|c|}
\hline & "Linear" $\left(\right.$ bits.s $\left.^{-1}\right)$ & "Angular" (bits.s $\left.^{-1}\right)$ \\
\hline \hline $\boldsymbol{h}(\boldsymbol{R})$ & 188 & 195 \\
\hline $\boldsymbol{h}(\boldsymbol{R} \mid \boldsymbol{S})$ & 100 & 106 \\
\hline $\boldsymbol{i}(\boldsymbol{R} ; \boldsymbol{S})=\boldsymbol{h}(\boldsymbol{R})-\boldsymbol{h}(\boldsymbol{R} \mid \boldsymbol{S})$ & 88 & 89 \\
\hline
\end{tabular}

Em nosso caso teste, os resultados obtidos utilizando-se de ambos os procedimentos para calcular as taxas de entropia foram próximos. A eficiência de codificação " $\epsilon$ " em ambos os casos é de aproximadamente $45 \%$.

Como já descrito, o valor de $H_{L}(R \mid S)$ é o resultado da média sobre diferentes colunas do raster, média temporal. Antes de efetuar esta média, obtemos a entropia do ruído como função do tempo, $H_{L}\left(R \mid S\left(t_{i}\right)\right)$. Ao analisarmos a eficiência " $\epsilon\left(t_{i}\right)=H_{L}\left(R \mid S\left(t_{i}\right)\right) / H_{L}(R)$ " com que o neurônio H1 codifica o estímulo em função do tempo, deparamo-nos com uma grande variação desta quantidade. Percebemos que para regiões de baixa atividade do neurônio, estímulos negativos, a eficiência chega a 100\% enquanto que para regiões positivas do estímulo, alta atividade do neurônio, sua eficiência de codificação cai a zero, Figura B.5. Devido à média do estímulo apresentado ser zero, metade dos instantes $\epsilon \sim 100 \%$ e metade $\epsilon \sim 0 \%$, obtemos uma eficiência em torono de 50\%, Figura B.5(a). Ao apresentarmos para a mosca um estímulo de velocidade média diferente de zero, no qual temos mais regiões de atividade do neurônio, obtemos uma eficiência média muito menor, $\epsilon \sim 10 \%$, Figura B.5(b).

Observamos a variação da eficiência de codificação de acordo com a taxa de disparo do neurônio H1 na Figura B.6. Vemos que a Entropia do Ruído aumenta com o aumento da taxa de disparo e conseqüentemente, a eficiência deste processo decai. Percebemos uma saturação destes valores para uma taxa de disparo aproximadamente igual a 80 [spikes.s $\left.{ }^{-1}\right]$. Valores de eficiência próximos a 100\% só são atingidos quando não há registro de atividade do neurônio H1. Sabemos que nestes instantes de tempo devemos observar uma máxima atividade do neurônio H1 contralateral, neurônio H1 do outro hemisfério do cérebro da mosca. Vejamos o que acontece quando preenchemos estes instantes com sua atividade. 


\section{B.2 Sistema de 2 neurônios H1}

Ao considerarmos os disparos gerados pelos dois neurônios H1, ipsilateral $\left(H 1^{+}\right)$e contralateral $\left(H 1^{-}\right)$, vemos que não é suficiente rotularmos cada bin do nosso experimento apenas com zeros e uns. Rotulamos a atividade dos neurônios com zero (0) caso não haja disparo de ambos os neurônios, um (1) se tivermos um disparo proveniente de $\mathrm{H}^{+}$, com dois (2) para disparos de $H 1^{-}$e três (3) caso tivermos disparos provenientes de ambos neurônios. Desta forma, escrevemos nosso trem de pulsos como "palavras" de comprimento $L$ contendo este alfabeto de quatro "letras" , $\{0,1,2,3\}$ (Figura B.7).

Realizamos os procedimentos descritos na seção anterior utilizando a codificação da resposta neural conforme a ilustração acima e obtemos a Entropia Total e a Entropia do Ruído como função de $L$, Figura B.8. A partir da extrapolação linear obtemos $h(R) \simeq$ $488\left[\right.$ bits. $\left.s^{-1}\right]$ e $h(R) \simeq 325\left[\right.$ bits.s $\left.s^{-1}\right]$. Estes valores resultam em uma taxa de informação $i(R ; S) \simeq 163\left[\right.$ bits. $\left.s^{-1}\right]$, aproximadamente duas vezes maior do que a informação fornecida por cada H1 separadamente.

Ao analisarmos $H_{L}\left(R \mid S\left(t_{i}\right)\right)$ como função do tempo, vemos que o ruído deste sistema contém uma variação pequena em torno de sua média ao longo do experimento. Isto devese ao caráter complementar da atividade dos dois neurônios, Figura B.9. Este sistema contém um conjunto de $N=4^{L}$ possíveis palavras de comprimento $L$ resultando em valores para a Entropia Total da ordem de duas vezes as calculadas para um $H 1$. Nas regiões em que não há atividade de $H 1^{-}$registramos intensa atividade de $H 1^{+}$. Como não há atividade de $H 1^{-}$nestes instantes, entrada zero no vetor de resposta, a Entropia do Ruído de $H 1^{ \pm}$será igual a entropia calculada de $H 1^{+}$. O mesmo acontece para as regiões de atividade de $H 1^{-}$, Figura B.10. Vemos claramente a eficiência deste sistema como detector de movimento rotacional ao compararmos os resultados apresentados na Figura B.11 com a Figura B.6. 


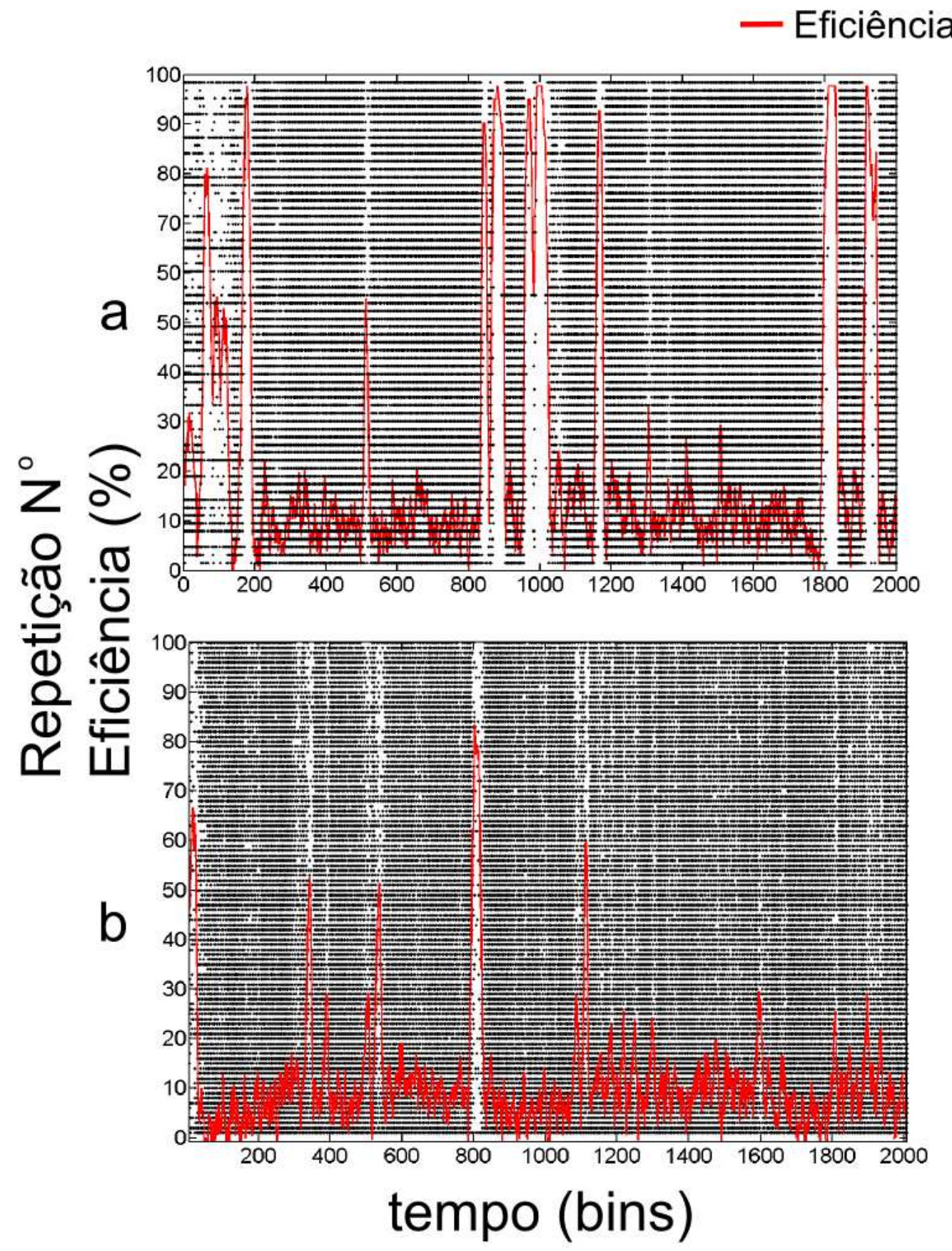

Figura B.5 - Eficiência do neurônio H1. (a) Vemos que a eficiência (curva em vermelho) com que o neurônio H1 codifica a informação em forma de pulsos varia com o estímulo apresentado. Para estímulos positivos, região de atividade do neurônio, esta eficiência cai para 0 . Já em regiões de baixa atividade, estímulos negativos, esta eficiência chega a 100\%. Isto compromete a relevância do valor médio $\epsilon \sim 45 \%$ obtido. (b) Apresentamos um estímulo com velocidade média diferente de zero. Geramos mais estímulos positivos do que negativos diminuindo a eficiência média com que o neurônio $\mathrm{H} 1$ transmite informação $(\epsilon \sim 10 \%)$. Observamos muito mais regiões em que a eficiência $\epsilon$ tende a zero do que no caso anterior devido à grande atividade do neurônio a este estímulo. 


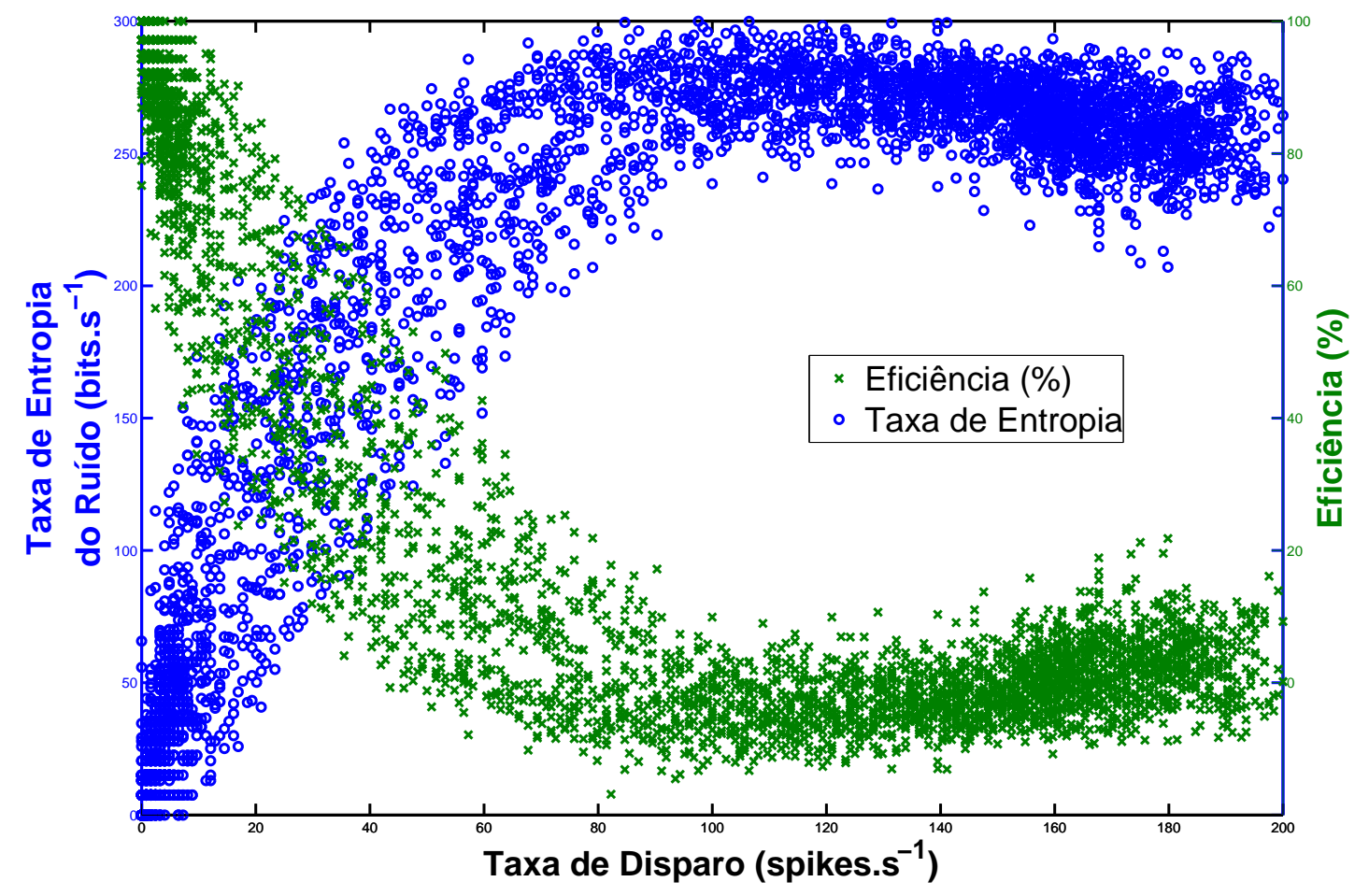

Figura B.6 - Ruído e eficiência do H1. Medimos a taxa de disparo do neurônio H1 em função do tempo em janelas de $L=12$ bins. Em cada uma dessas janelas medimos a Entropia do Ruído $H_{L=12}\left(R \mid S\left(t_{i}\right)\right.$ ) (o azuis). Com o valor da entropia total $H_{L=12}(R)$, calculamos a eficiência em função da taxa de disparos ( $\times$ verdes). Vemos uma saturação destas grandezas para taxa de disparo em torno de $80\left[\right.$ spikes.s $\left.{ }^{-1}\right]$.

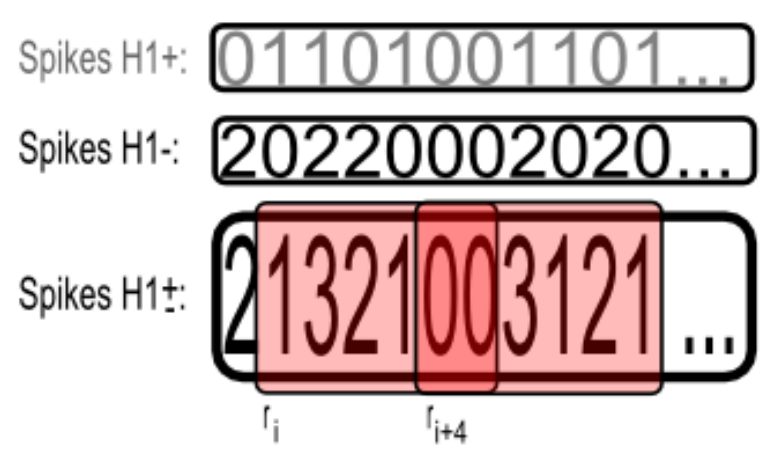

Figura B.7 - Codificação por 2 H1s. Rotulamos os tempos em que não ocorreram pulsos com "0". Rotulamos com "1" os tempos em que ocorreram apenas pulsos do neurônio $H 1^{+}$e com "2" os tempos em que ocorreram apenas disparos de $H 1^{-}$. Nos tempos em que ocorreram pulsos de ambos neurônios, rotulamos com "3". Teremos $4^{L}$ possíveis palavras contendo $L$ símbolos. 


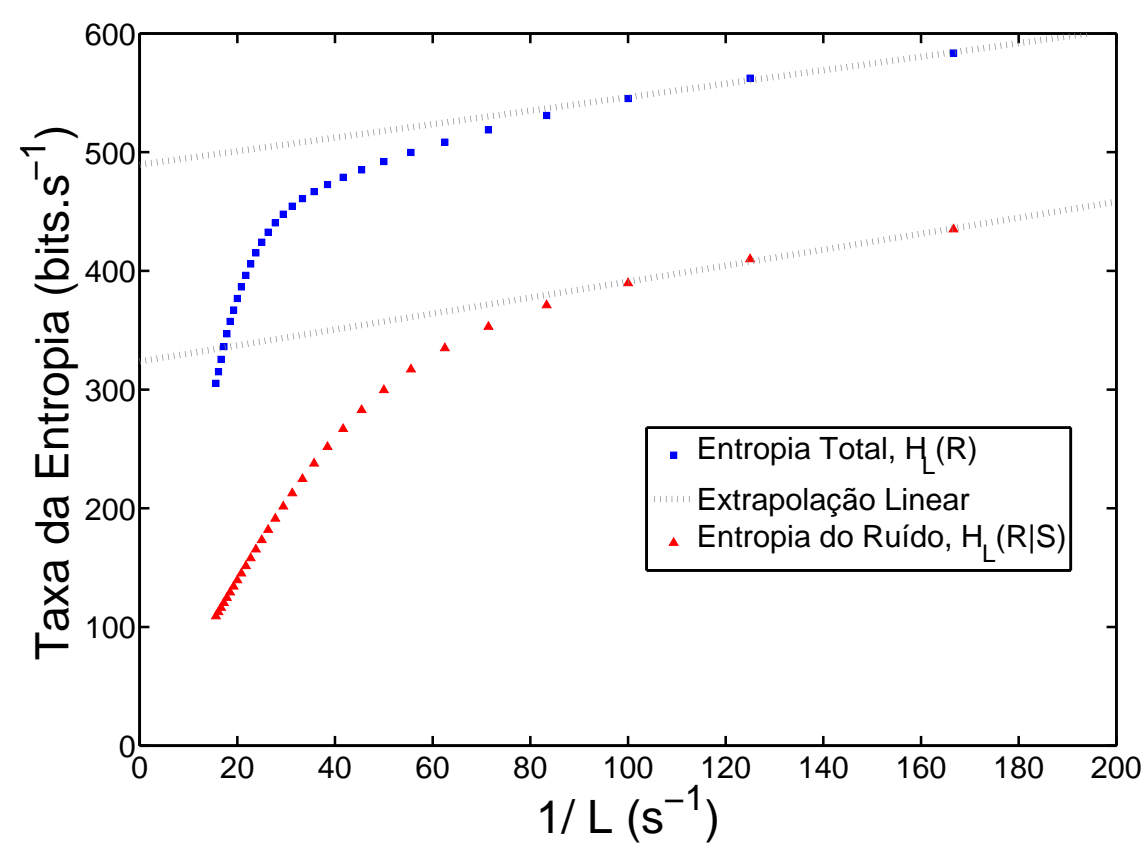

Figura B.8 - Entropia total e do ruído, $H 1^{ \pm}$. Utilizando-se do mesmo procedimento descrito para um neurônio $H 1$ e a codificação da resposta de dois neurônios, obtemos a partir da extrapolação linear os seguintes resultados: $h(R)=488\left[\right.$ bits.s $\left.^{-1}\right]$, $h(R \mid S)=325\left[\right.$ bits.s $\left.{ }^{-1}\right]$ e $i(R ; S)=163\left[\right.$ bits. s $\left.^{-1}\right]$.

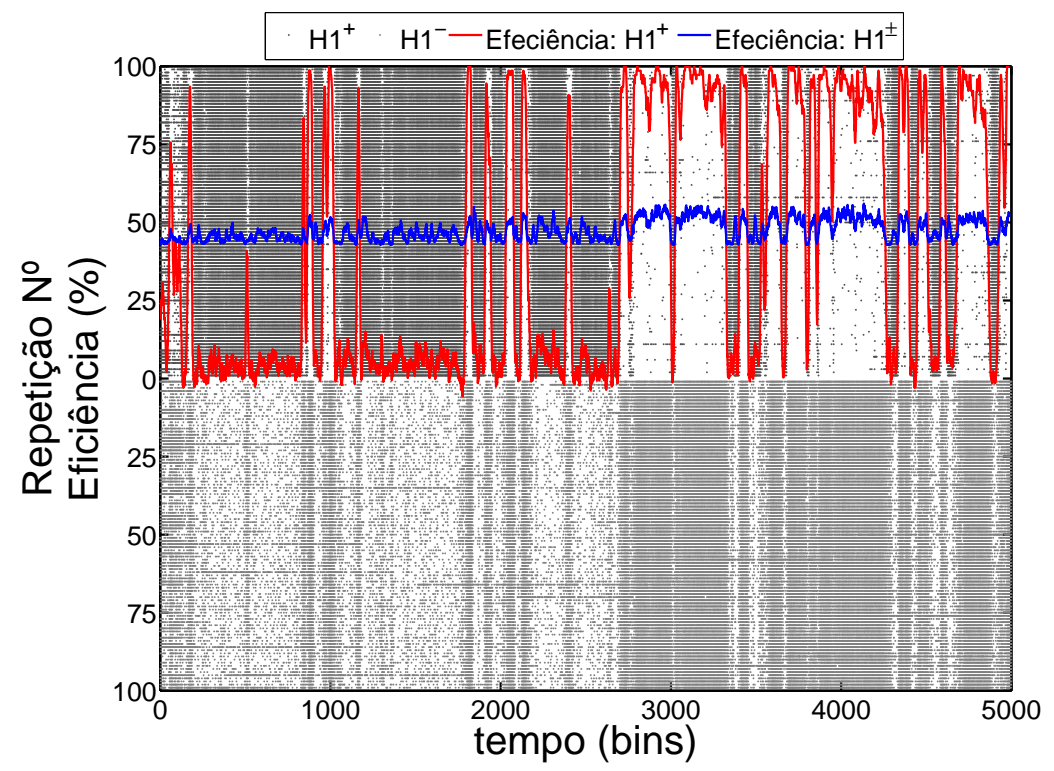

Figura B.9 - Eficiência de $\boldsymbol{H} \mathbf{1}^{ \pm}$. llustramos a resposta de ambos os neurônios a um estímulo de rotação. Vemos o caráter complementar destas respostas. Calculamos a eficiência de codificação " $\epsilon$ " como função do tempo, $L=12$ bins. Em vermelho consideramos apenas a resposta de $H 1^{+}$e em azul de $H 1^{ \pm}$. Vemos que ao utilizarmos os dois neurônios a variação da eficiência é muito menor e seu valor médio é $\epsilon \sim 42 \%$. 


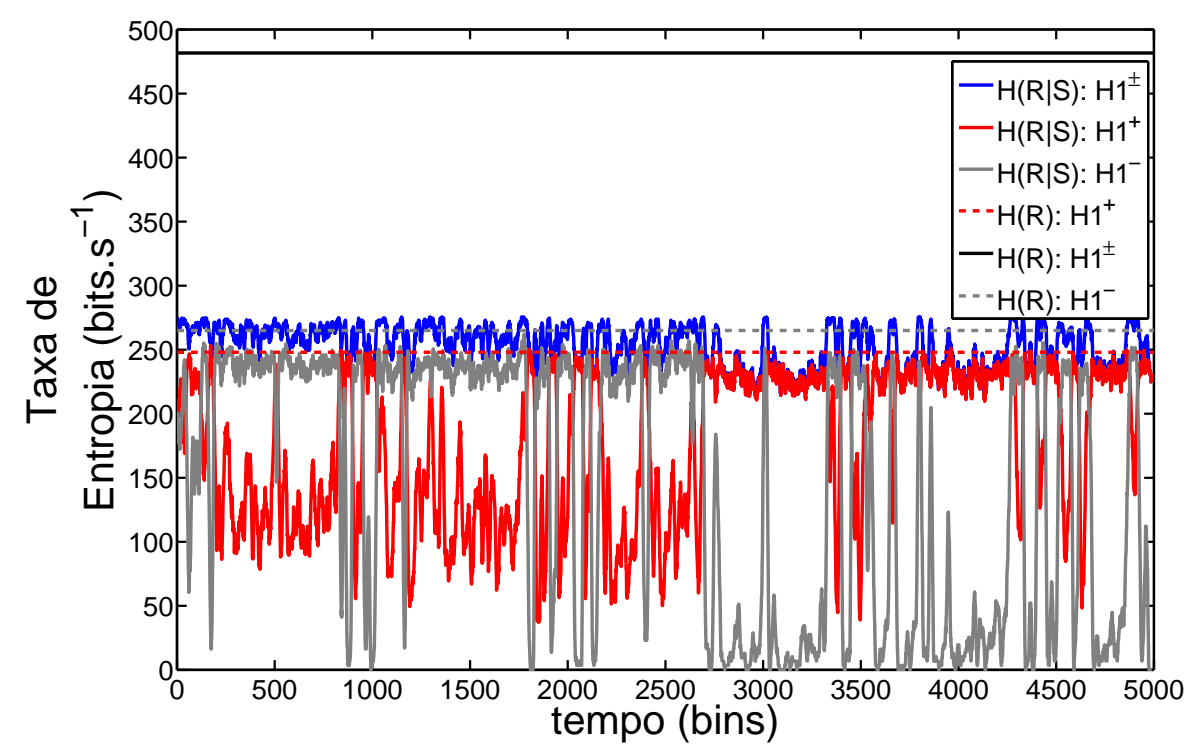

Figura B.10 - Atividade complementar de $H \mathbf{1}^{ \pm}$. Entropia Total e do Ruído para o sistema de dois e de um neurônio $H 1$. Tanto a Entropia Total quanto a do Ruído somam-se. A Entropia Total torna-se duas vezes maior do que a do Ruído devido ao caráter complementar de sua atividade.

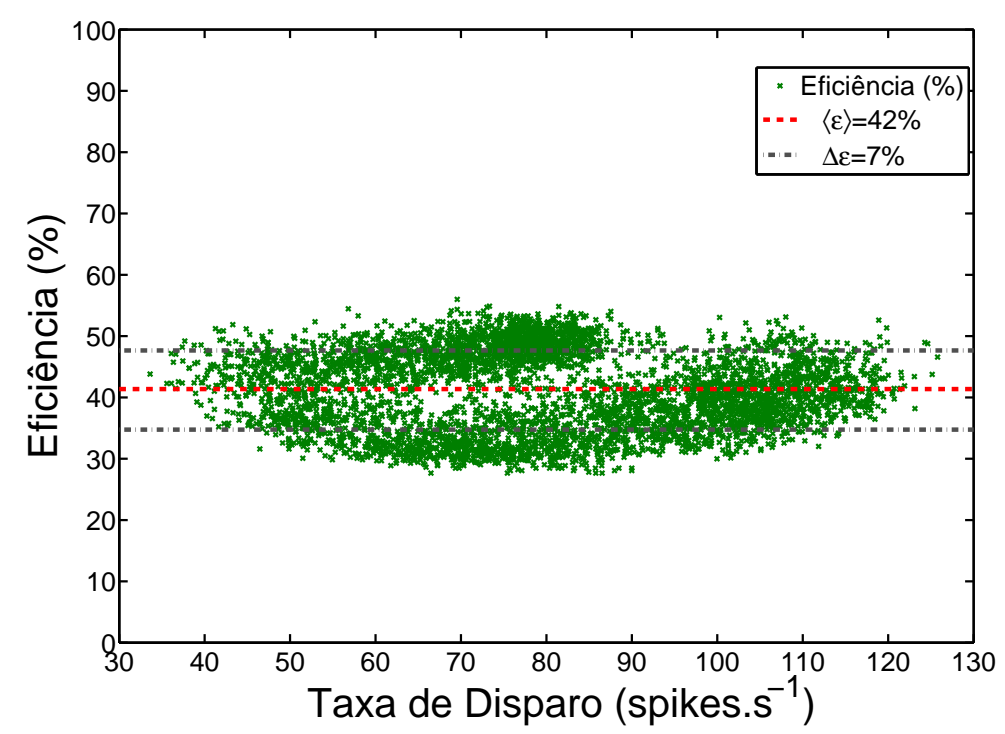

Figura B.11 - Eficiência do detector de rotação. Medimos a taxa de disparo do neurônio $H 1^{+}$e calculamos a eficiência de codificação do sistema formado pelos neurônios $H 1^{ \pm}$em função do tempo em janelas de $L=12$ bins ( $\times$ verdes). Vemos que o valor da eficiência " $\epsilon$ " é praticamente constante para qualquer valor da taxa, o que não acontece na codificação realizada por apenas um neurônio. 